\title{
A STUDY OF THE BEHAVIOR OF REINFORCED
}

CONCRETE T-BEAMS SUBJECTED TO

\section{REPEATED LOADS.}

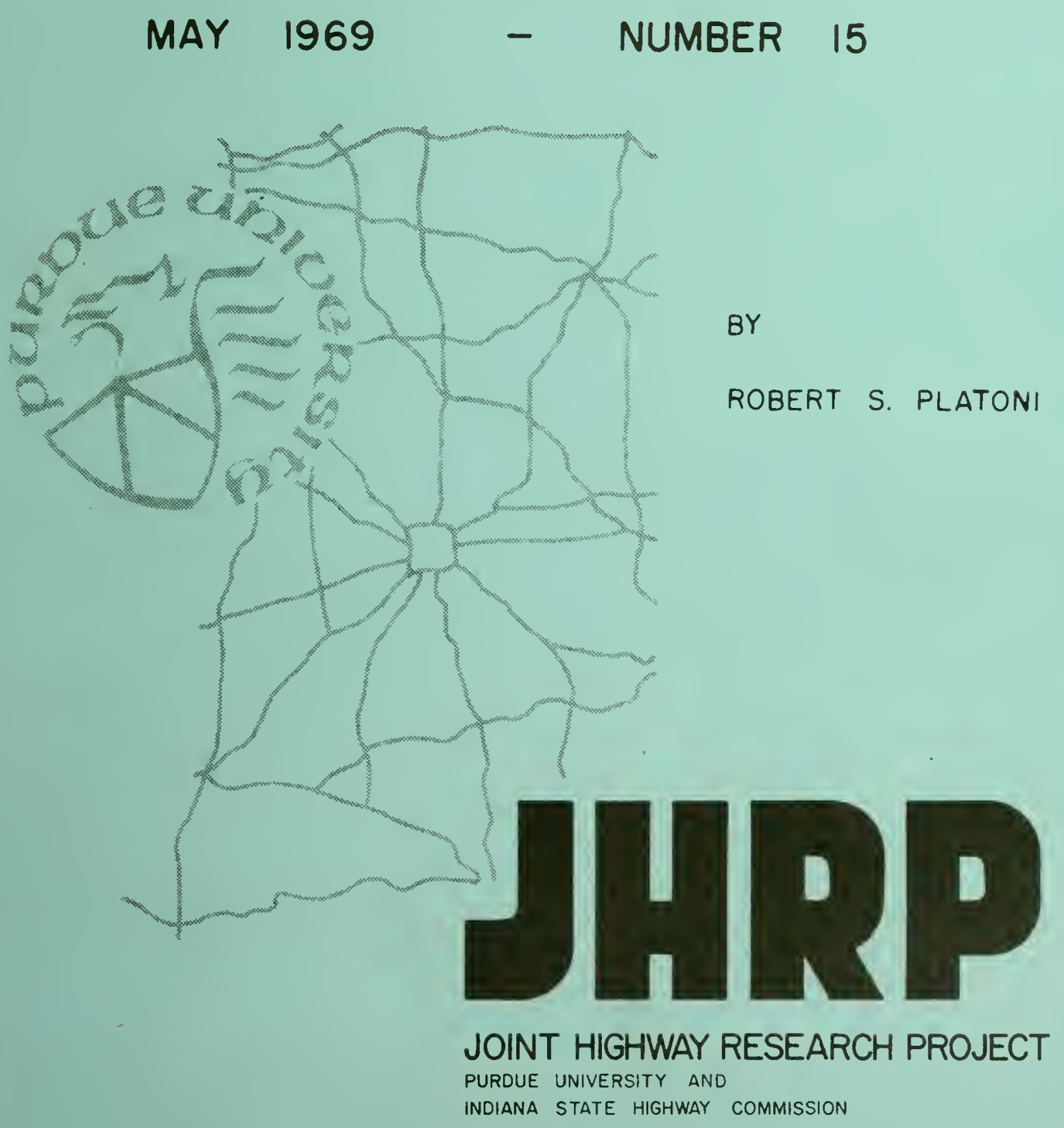





\section{A STUDY OF TME DEBAVIOE OF RETIFORCBD CORCRETE T-BEATS SUEJECAED TO REREATED LCADS}

T0:

Jo P. Mebough21: Director

Joint Mighway Regewrch Project

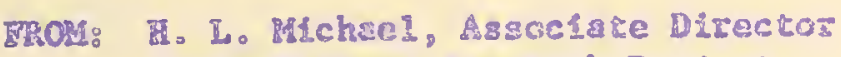
Joint Highway mesexrch Project
May 6, 1969

F11e 70 : 7-4-15

Broject

Artached is a Firal Report: "BA Study of the Rehevior of Retnforced Concrete I-Reams Subjected to Repericed Lcads." The repart har been authored by Mt. Robert S. Flatond, Graduate Aseistant in Research on our stafe, urder the difection of Brofessors $\mathrm{M}$. J. Gurruller and R. H. Lee.

This zesearch was another of a serles of research studies in the grructural ara desigued to grovicle an fingroved understanding of the mode of frilure in rectanguiar and T-Beams subjected to repeated and statl loads. The current project was concerned with repeared loads on T-Leans. The research indicated faliure by fartgue of longltudinal steel Ielaforcemen:

The report is presenced to the roszo for the record and for accoptance (3) Fulfillment of the objertives of this project.

Respectrully subaict,

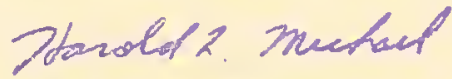

Bexold Is. Mtchael

Assochinte Direator

패내/ $/ \mathrm{g}$

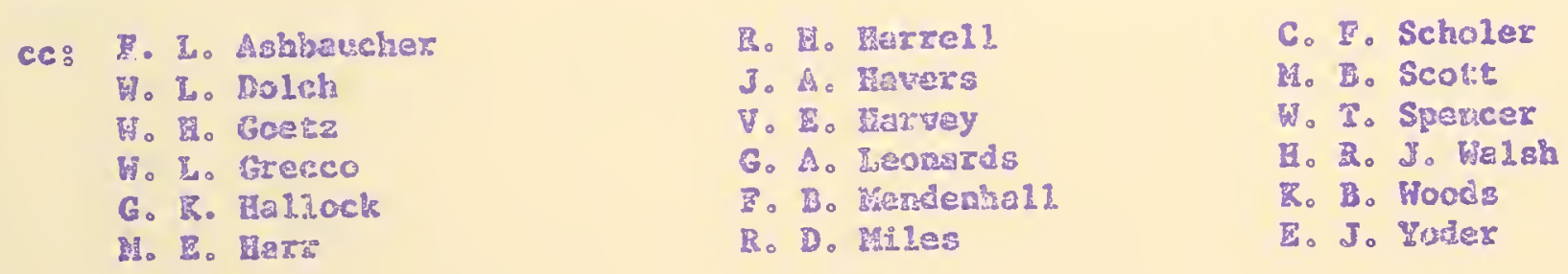


Frael Report

A STVDY OF THE BGRADIOR OI PEIAIPORCRL CORGREgE T-IEAMS

SUSUCTEU TO REREATED LOADS

by

Robert S. Platonf

Graduat Assistant in Resentch

Jolnt Jigimay Rescarch Pzoject

Rurcue DoLversity

File: 7-4a15

Project: $\quad 6-36-560$

Rurdue Uaiversity

Lafayetce, Indlans

หay 6, 1969 
ACKIOWLEDGM ENTS

Acknowledgment is first given to the members of the Joint Highway Research Board and to Professor G. A. Leonards, Directior, for providing funds for the project.

Special thanks are also given to Professors Martin J. Gutzwiller and Robert H. Lee, major professors, and to Professor $\Xi$. D. Stitz for their suggestions and advice.

The author is also grateful to Mr. William B. Telfer and Mr. G. N. Foster, laboratory tecinicians, and to the several graduate students for their generous assistance in the laboratory. 
TABLE OF CONTENTS

Page

LIST OF TABLES. . . . . . . . . . . . . . . v v ITST OF FIGURES . . . . . . . . . . . . . . . . . vii

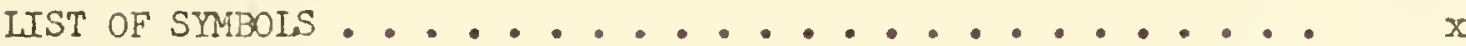

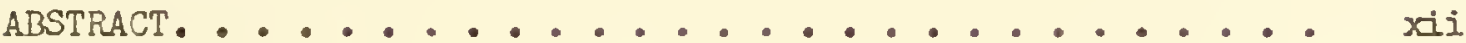
INTRODUCTION. ......................... 1

Cracking Phenomena Under Static Loading. . . . . . . . 2

Cracking Phenomena Under Repeated Loading. . . . . . 10

PURPOS OF STUDY. ............................ I8

TEST SPECTIENS AND PROCEDURAS ...................... 19

Materials...................... 21

Concrete $\mathrm{Mix}$................... 27

Aggregates ................ 2 I

Reinforcing Stcel............... 25

Fabrication and curing . . . . . . . . . . . . 26

Instrumentation and Testing rncedures . . . . . . 28

TEST RESULTS. . . . . . . . . . . . . . 33

Series I P.................... 33

Beam I P-I (6IT utimate)........... 33

Series II P. . . . . . . . . . . . . . 49

Bear II P-I (52\% Ultimate) .......... 49

Beam II P-2 (53\% UItimate) ........... 50

Beam II P-3 (64, UItimate) .......... $5 I$

Beam II P-4 (73\% U timate) ........... $5 I$

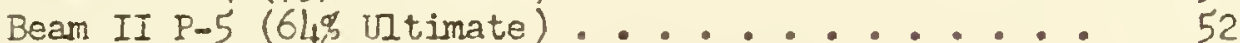

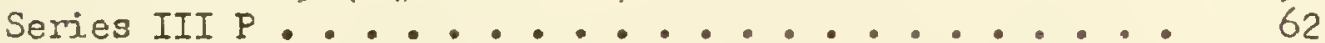

Beam III P-I (52\%. UItimate).......... 62

Beam III P-2 (60\% Ultinate).......... 63

Beam III P-3 (7I\% vitimate).......... 64

Beam III P-4 (82\% Ultimate)......... 64

Beam III P-5 (6I\% UItimate)............ 65

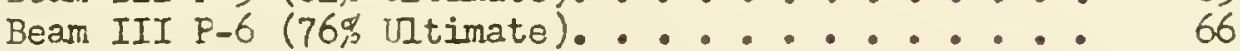

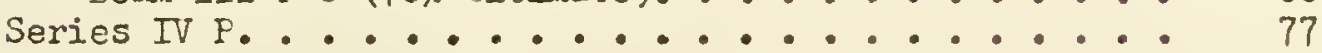

Beam IV P-I (60\% Ultimate)........... . 77 
Digitized by the Internet Archive in 2011 with funding from

LYRASIS members and Sloan Foundation; Indiana Department of Transportation 
Table of Contents (Contimued)

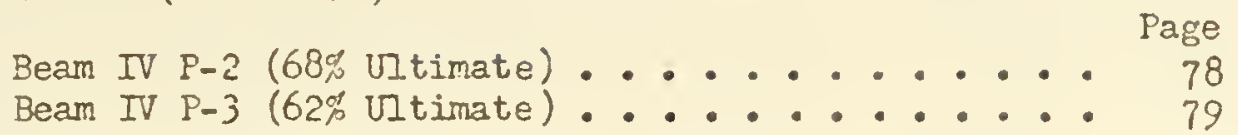

DISCUSSIOH OF TEST RESUITS. . . . . . . . . . . . 85

Temperature. . . . . . . . . . . . . 85

Modes of Failure ................. . 85

Factors Affecting Fatigue Life of Iongitudinal

Reinforcement. . . . . . . . . . 87

Resistance to Diagonal Tension and Shear-Compression

Pailures ................... 92

SUMLARY AND CONCLUSIONS . . . . . . . . . . . . 95

BIBIIOGRAPHY • . . . . . . . . . . . . . 9 96

APPENDIX A. . . . . . . . . . . . . . . . 99

APPENDIX B. . . . . . . . . . . . . . 102

APPEIDIX C........................ 105 
LIST OF TABLES

Table

Page

1. Properties of Test Specimens. . . . . . . . . . .

2. Properties of Longitudinal Reinforcing Steel. . . . .

3. Summary of Test Results .............. 34

4. Comparison of Test Strengths bith Calculated Values ...

\section{Appendix}

Table

C1. Stcel Temperature - Beem I P-I. . . . . . . . . 105

C2. Steel and Concrete Strains - Beam II P-I. . . . . . . IOT

C3. Steel and Concrete Strains - Beam II P-2......... . 109

C4. Steel and Concrete Strains - Beam II P-3......... IIO

C5. Steel and Concrete Strains - Beam II P-L. . . ..... 111

66. Steel and Concrete Strains - Beam II P-5. . . . . . 113

C7. Steel and Concrete Strains - Beam III P-I . . . . . . IIL

C8. Steel and Concrete Strains - Beam III P-2....... 115

C9. Steel and Concrete Strains - Beam III P-3........ 117

C10. Steel and Concrete Strains - Beam III P-4 . . . . . . 118

CII. SteeI and Concrete Strains - Beam III P-5 . . . . . 119

CI2. Steel Temperature - Beam III P-5. . . . . . . . . I20

C13. Steel and Concrete Strains - Beam IIX P-6........ II

CIL. Steel and Concrete Strains - Beam IV P-I. . . . . . . 122 
Appendix

Page

Table

C15. Steel and Concrete Strains - Beam IV P-2........ 123

Q16. Steel and Concrete Strains - Beam IV P-3......... 124 


\section{LIST OF FIGURES}

Figure

Page

1. Typical Flexural Failure... . . . . . . . . . 4

2. Typical Diagonal Tension Failure. . . . . . . . . 5

3. Iongitudinal Steel Peinforcement. . . . . . . . I6

4. Load, Shear and ironent Diagrams . . . . . . . . 20

5. Details of Test Specimens . . . . . . . . . . 22

6. Forms Prior to Casting. . . . . . . . . . . . 27

7. Test Setup. . . . . . . . . . . . . . . 31

8. Details of Test Setup . . . . . . . . . . . 32

9. Beams After Test - II P-I, II P-2.......... 36

10. Beam After Test - II P-3.............. 37

11. Beam After Test - II F-L............. 38

12. Beam After Test - II P-5............. 39

13. Beam After Test - III P-I . . . . . . . . . . 40

14. Beams After Test - III P-2, III P-4......... 4 I

15. Beam After Test - III F-3............. 42

16. Beam After Test - III P-5 ............ 43

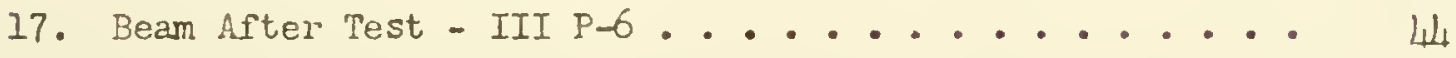

18. Bean After Test - IV P-1.............. 45

19. Beams After Test - IV P-2, IV P-3.......... 46

20. Beam I P-I. . . . . . . . . . . . . 48 
21. Pictorial Representation of Specimen on Crack Pattern Sheet............. 53

22. Load vs. Steel Strain - Series II P - First Cycle . . . 54

23. Load vs. Concrete Strain - Series II P - First Cycle. . . 56

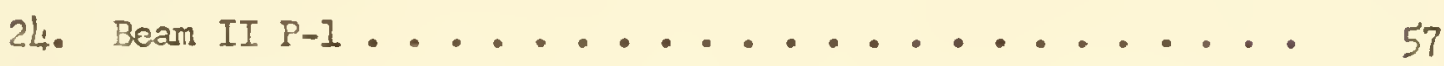

25. Beam II P-2................... 58

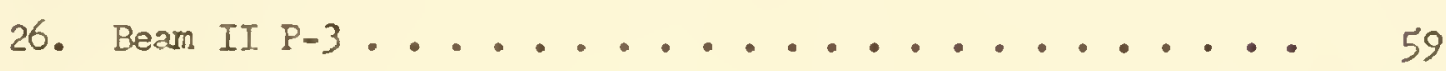

27. Beam II P-4..................................... 60

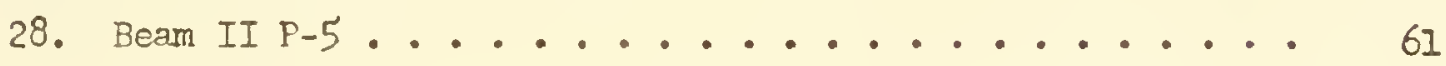

29. Ioad vs. Steel Strain - Series III P - First Cycle. : . 67

30. Load vs. Concrete Strain - Series III P - First Gycle - . 69

31. Beam III P-I. . . . . . . . . . . . . . 71

32. Bean III $\mathrm{P}-2$. . . . . . . . . . . . . 72

33. Beam III P-3.................. 73

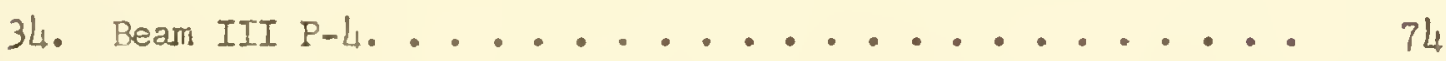

35. Beam III P-5........................ 75

36. Beam III P-6...................... 76

37. Load vs. Steel Strain - Series IV P - First Gycle . . . 80

38. Ioad vs. Concrete Strain - Series IV P - First Gycle... 81

39. Beam IV P-I.......................... 82

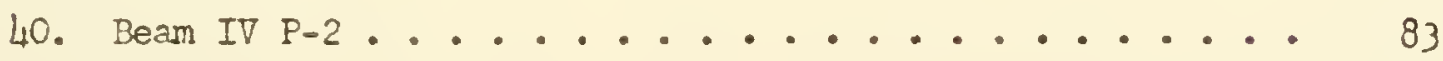

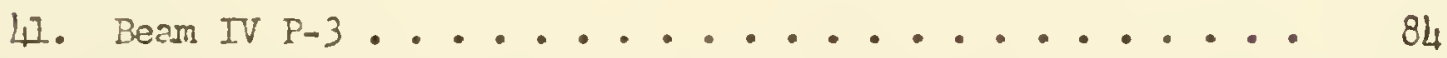

42. Stress Range vs. Number of Cycles ........... 90

43. Sumnary of Fatigue Ifves. . . . . . . . . . . 91

44. Typical Stress-Strain Properties - 16 Iongitudinal

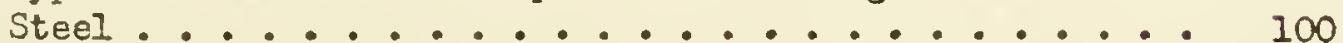


45. Typical Stress-Strain Properties - 籼 Longitudinal Steel.................. 101 
IIST OF SMIBOLS

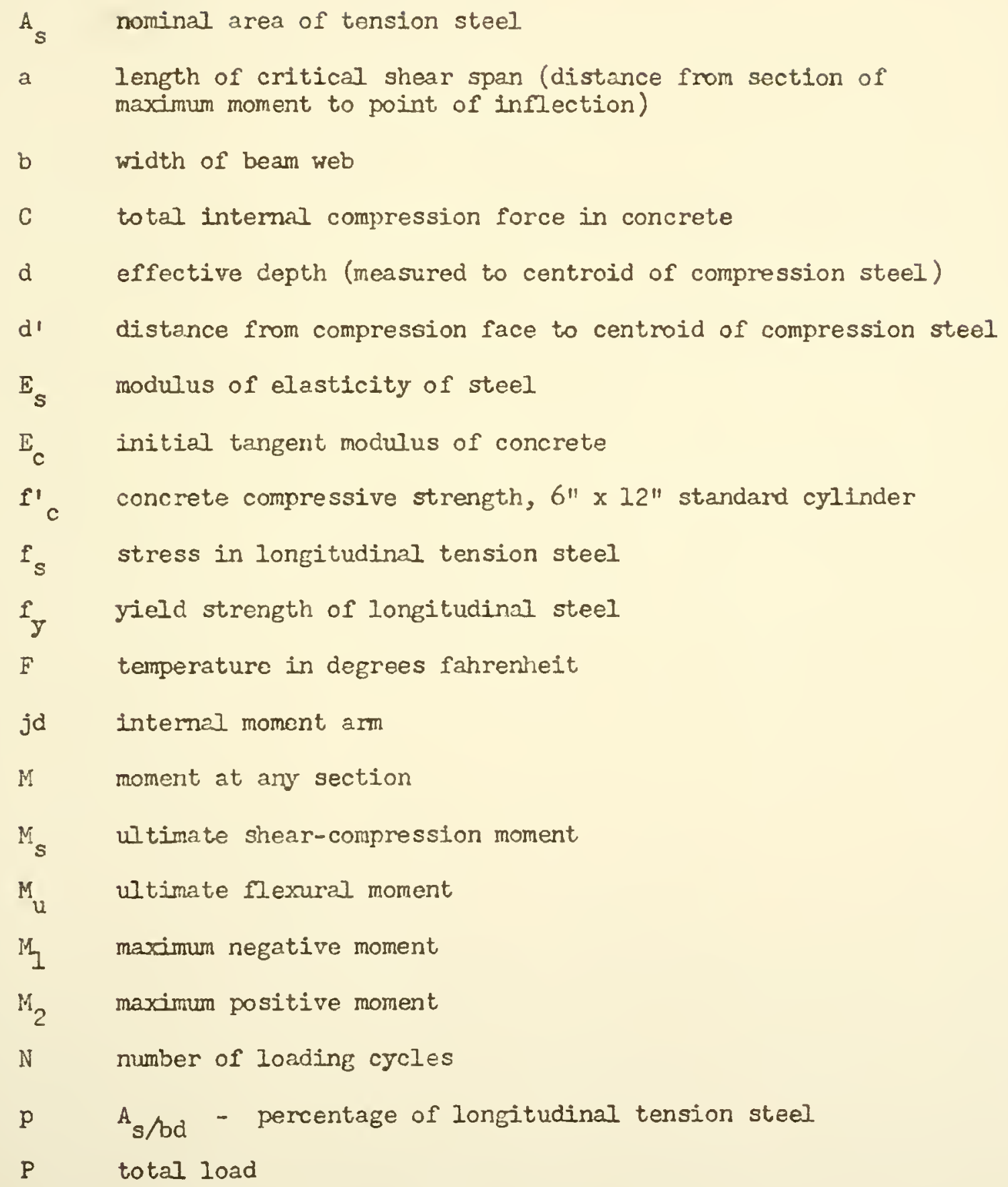




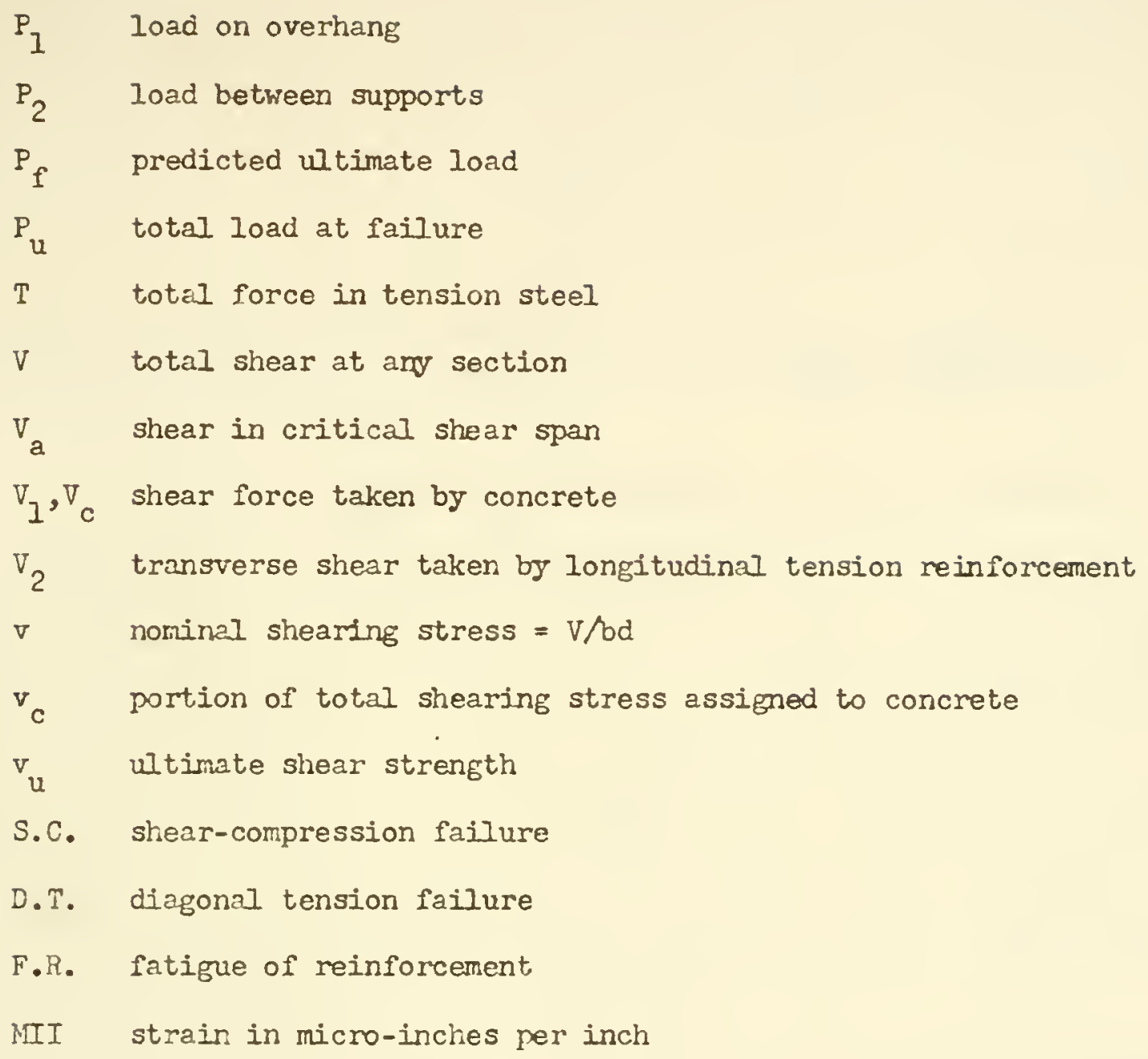




\section{ABSTRACT}

Platoni, Robert S., "SCE, Purdie University, June, 1969. "A study of the Behavior of Reinforced Concrete $T$-beams Subjected to Repeated Loads." Vajor Professors: M. J. Gutzwiller and R. H. Lee.

\section{A total of 14 reinforced concrete T-beams and one beam of} rectangular cross-section were tested to failure under repeated loadIng. The 13 inch deep beams were tested as restrained beams and were designed to be weaker in shear than Mexure, with the critical section Ior shear, or shear span, being the length from the section of zero moment to the section of maximum negative moment. The only variables were the shear span-tn-depth ratio and the magnitude of the repeated load. The shear span-to-iepth ratio ranged from 2.88 to 5.03 and the rate of loading was 250 cycles per minute.

The object of this research was to compare the mode of failure of repeatedly loaded T-beams to the failure fattern of identical T-beans subjected to static Inading. It was al so intended to make a comparison with the results of fatigue tests performed on reinforced concrete beams of rectangular cross-section. These companion bearis had been tested in two previous investigations at Purdue University.

Two of the test specimens, one $T$-beam and one rectangular, were cast with iron-constantan thermocouples attached to the reinforcing steel at, or near, the point of maximum negative moment. It was hoped to detect a significant increase of temperature due to repeated 
stressing of the steel bars.

It was found that the repeatedly loaded T-beams failed in all cases, regardless of shear span, by fatigue of the Iongitudinal steel reinforcement if subjected to a sufficient number of loading cycles. This was in direct contrast to the sheer type failures of the companion beams of both $\mathrm{T}$-shaped and rectanguler cross-section. The stress range was found to have the most influence on the fatigue Iife of the steel reinforcement while the shear span-to-ciepth ratio had almost no influence at all. The number of cycles to failure decreased with increasing stress range, and the fatigue limit was found to be approximately $40 \mathrm{ksi}$. Failure occurred at maximum repeated loads ranging, from $52 \%$ to $76 \%$ of the ultimate static load.

The amount of temperature increase detected during testing was negligible. 
INTRODUCTION

Reinforced concrete design practices in the United States have been in a continuous stage of evolution and refincment since the advent of reinforced concrete as a structural element. The resistance of reinforced concrete beams to combined shear and flexure has been both a problem and subject of intense study for almost as long, and the influence of shear has been of particular interest.

Almost a century of research has not been able to put together a thorough explanation of the shear mechanism of failure, but, instead, has continuously aroused more suspicion as to its intrinsic complexity. This is due to the fact that few investigators have included the same combination of variables, such as: size of beam, cross-section, load arrangement, concrete strength, web reinforcement, and longitudinal reinforcenent. The nonhomogenesus nature of concrete itself introduces the element of chance, disrupting any order which might be expected from a large number of tests.

In addition to the multiplicity of parameters governing beam strength, consideration must also be given to the type of loading conditions to which the beam is subjected. In particular, the use of reinforced or prestressed concrete members in bridges and other elevated structures to carry large volumes of high speed traffic raises serious questions conceming the reliability and relevance of the resilts of static load tests, and demands large scale 
investigations into the effects of dynamic loading. The recent use of new materials of higher static strength at higher working stresses may also result in a relative reduction in the resistance to repeated loads. A stage in developement may therefore be reached where consideration of repeated stresses may form a more important aspect of design than at present.

The purpose of further research in this area is to provide some arbitrary assessment of the reduction in strength that might result from fatigue loading and to show whether there could be a change in the mechanism of failure forming the accepted basis of design.

\section{Cracking Phenomena Under Static Loading}

The relative effects of flexure and shear may be exemplified by a simply supported beam loaded symmetrically at two points. The distance from the support to the load is called the shear span. See Figure 1a. If such a beam is subjected to static loading, one of four principal failure modes is noticed. They are;

1. Fracture of the tensile reinforcing steel

2. Diagonal tension failure

3. Compressive failure of the concrete

4. Loss of bond between the concrete and reinforcing steel

The major variables which seen to have the most significant influence on the mode of failure are; compressive strength of tine concrete, percentage of longitudinal reinforcement, and the ratio of moment to shear at the critical section. For simply supported beams, the last parameter mentioned may be represented as the ratio of the 
shear span to the structural depth of the member. Kany investigators have found the shear span-to-depth ratio to be a good indicator of the mode of fallure, although no exact values for the ratios which divide one mode of failure from another can be agreed on.

If the loads are applied near the center of the specimen, as in Figure la, providing a large shear span-to-depth ratio, shear has little effect and failure will be controlled by flexure. Vertical flexure cracks will form from the tension surface of the beam at intervals along the span according to the magnitude of the bending moment when the limiting tensile strain in the concrete is reached (Figure Ib). Increased loading will lead to further extension of these craciss and either crushing of the concrete or vielding of the tensile reinforcement followed by crushing of the concrete. (Figure 1c).

Hoving the loads out from the center of the member decreases the length of the shear span and increases the influence of shear on the failure mode. Figure $2 a$ shows the same sample beam with a moderate shear span-to-depth ratio. After passing through the leval of the longitudinal reinforcement, the flexural cracks in the shear span begin to incilne toward the load due to the combination of tensile and shearing stresses. As the cracks approach the neutral axis, they become more inclined because of maller flexural tensile stresses and eventually matten out after passing through the neutral axis, as can be seen in Figure $2 b$. Diagonal tension cracks may also form in the shear span between the neutral axis and the longitudinal reinforcement independently of the inclined flexural cracks.

Until the fomation of diagonal tension cracks, the behavior 

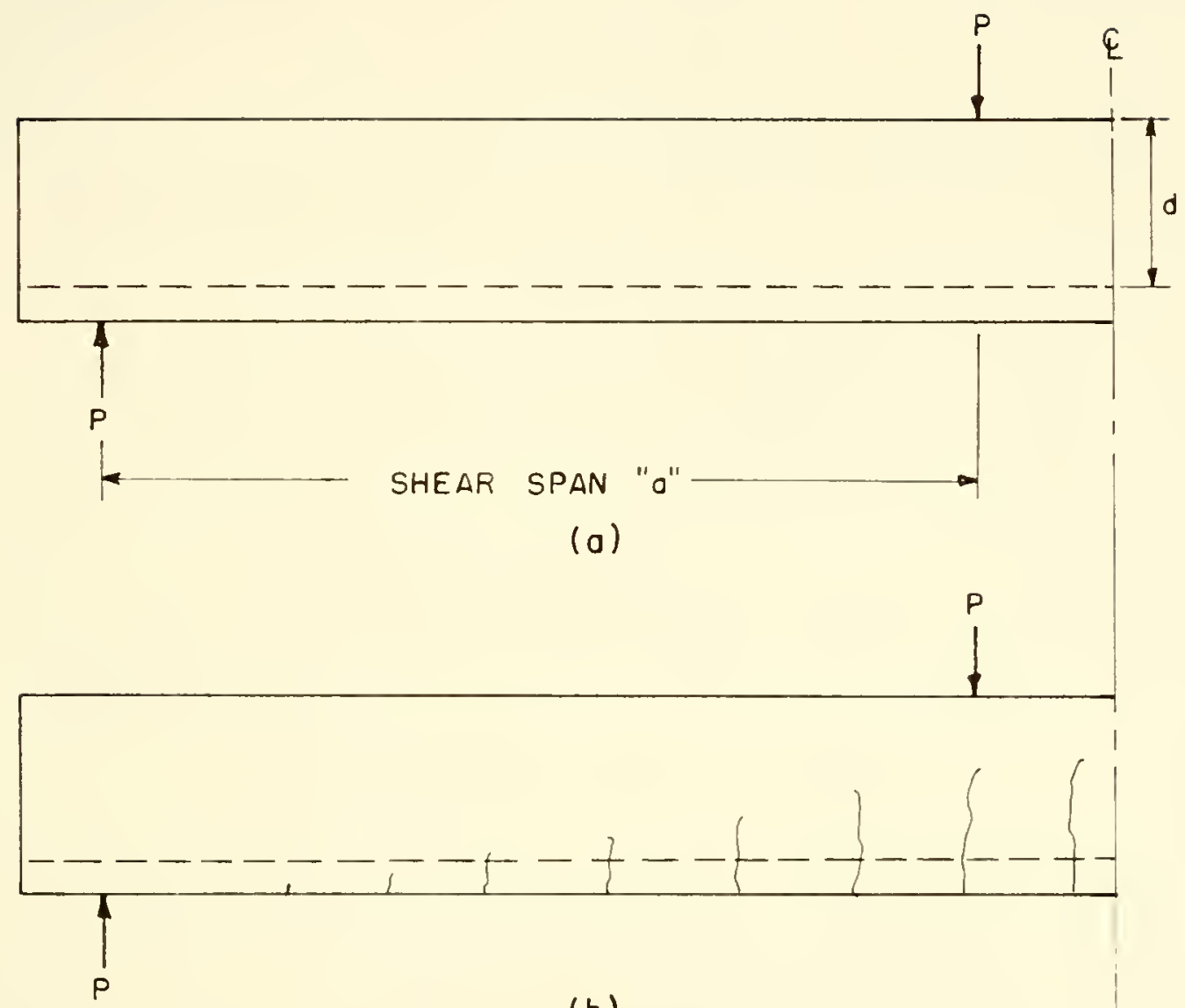

(b)

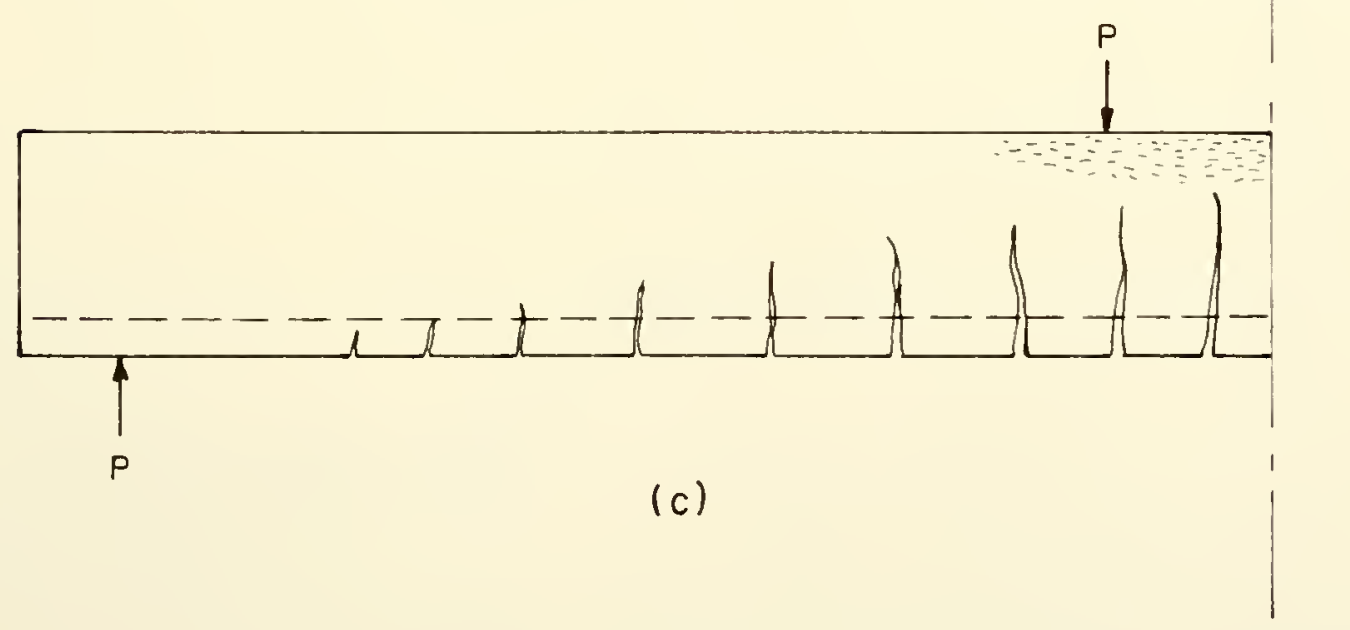

FIGURE I. TYPICAL FLEXURAL FAILURE 

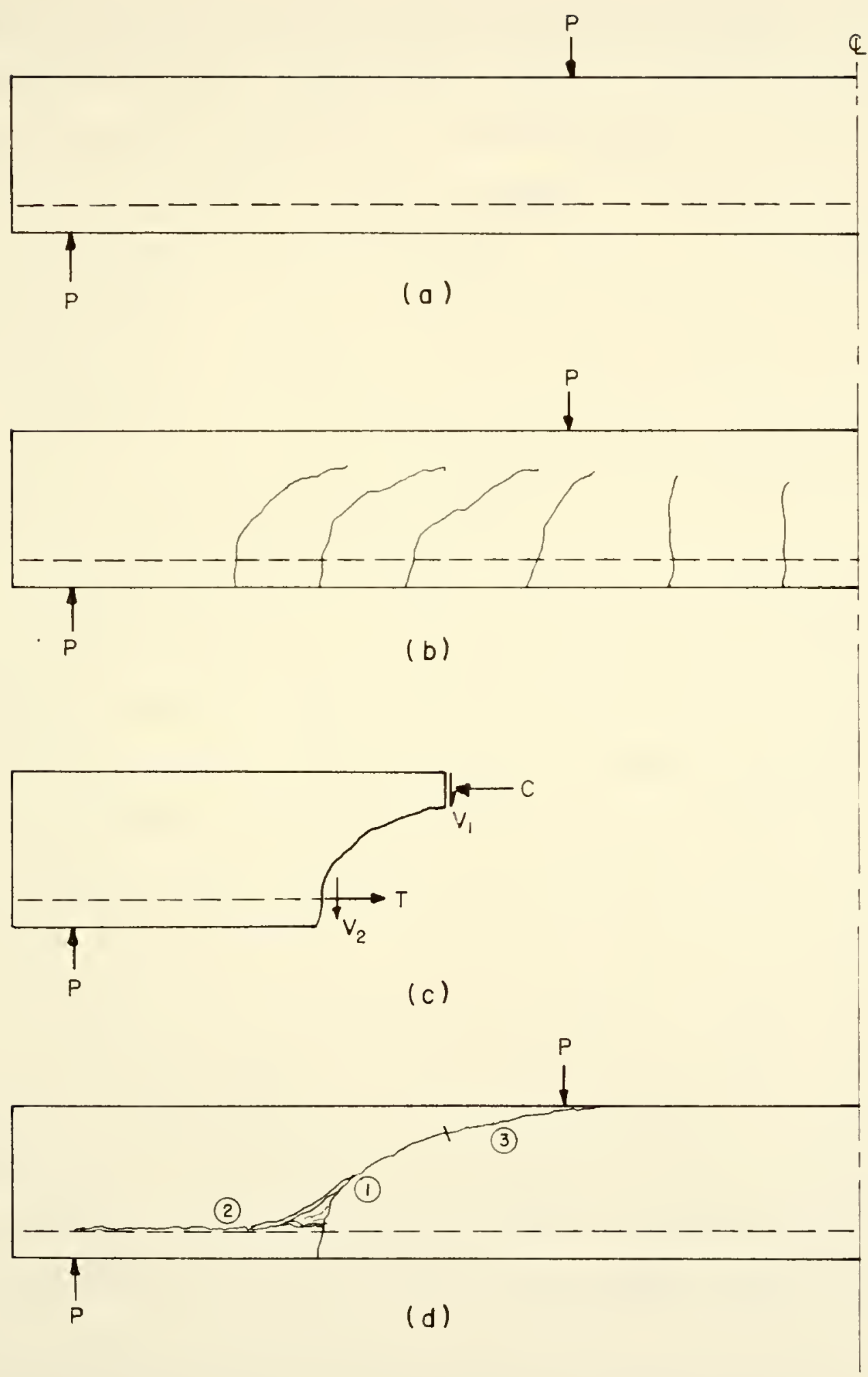

FIGURE 2. TYPICAL DIAGONAL TENSION FAILURE 
of the beam is the same as that of beams failing in flexure. The formation of diagonal cracks, however, leads to a redistribution of intermal stresses. Figure $2 c$ is a free body diagran of a typical diagonal tension crack and it will be assumed for simplicity that it is the only crack existing in the member. $C$ and $V_{I}$ are the compressive and shear forces, respectively, which act on the reduced concrete compression area. $T$ is the tensile force in the reinforcement and $V_{2}$ is the transverse shear. By suming vertical forces, it can be seen that the external shear must now be resisted by the reduced compression zone and the longitudinal reinforcement.

Knowing the true contribution of the tension rainforcement to the resistance of shear, or "dowel action", is essential in understanding the diagonal tension mechanism of failure, but, as yet, this has not been achieved. It has generally been assumed, in beams without web reinforcement, that the division of shear force between the compression face and the tension reinforcement depends on the relative stiffiness of these elements. The stiffness of the reinforcenent is small compared to the stiffness of the compression zone and, thus, the portion of shear transmitted by the tension reinforcement may be neglected. (In beams w1th web reinforcement the division is more complex but the contribution of the longitudinal reinforcement is still believed to be small). However, there are an increasing number of investigators $(3,12,14,21,25)^{*}$ who attribute greater significance to

* Superscripted numbers in parentheses refer to items in the bibliography. 
dowel action. A few of these will be discussed later. If, indeed, the dowel force is substantial, then it can easlly be seen how the redistribution of intemal forces can lead to a diagonal tension trpe failure.

After the diagonal crack has penetrated a short distance into the compression zone, (point 1 in Figure 2d), the lower portion of the crack widens and causes the two parts of the beam to rotate about the apex of the crack. At the same time, the tension reinforcement in the crack becomes deformed so that the force in that part of the bar is no longer horizontal. The vertical shearing force, $V_{2}$, aided by the skewed tension force, $T$, causes the formation of a horizontal crack along the tension steel, or backup cracking (point 2 in Figure 2d). The splitting of the concrete at the level of the steel destroys the bond progressively up to the support, changing the action from that of a beam to a two hinged tied arch. After the horizontal crack has opened, the diagonal tension crack extends at a decreased slope through the compression zone to the top surface of the beam (point 3 in Figure 2d).

In beams of mall shear span-to-depth ratio the action is similar. Diagonal tension cracks form, redistribution of internal stresses takes place, and a new equilibrium of internal and extermal forces is reached. However, horizontal cracking along the longitudinal reinforcement caused by dowel action is prevented by strong vertical compression forces in the vicinity of the nearby support. Further increase of load is possible until the reduced concrete area above the diagonal crack is crushed. The member is then said to have failed by 
shear-compression.

Thus, resistance to the dowel force and the associated phenomena of horizontal cracking seems to be the controlling factor in some diagonal tension type failures. D. N. Acharya and K. O. Kemp (3) regarded the splitting at the level of the steel due to high shear forces on the longltudinal steel as a primary cause of failure for their specimens. They added ${ }^{(4)}$ that dowel action may not have significance for all beams but neither should it be totally neglected. D. Watstein and R. G. Mathey ${ }^{(25)}$ made an evaluation of the vertical shear transferred by the reinforcement in beams with a shear span-todepth ratio of approximately two. It ranged from .38 to .74 of the total shear at loads ranging from .42 to .16 of the maximum and decreased continuously thereafter. J. Taub and A. M. Neville (2I) recognized the existence of shear forces in the steel as the cause of horizontal splitting, and William J. Krefeld and Charles W. Thurston (14) concluded that the splitting of the concrete along the tensile reinforcement from the lower end of the diagonal crack triggers the propagation of the upper end of the crack. The last two investigators mentioned also concluded that the shear resistance of the longitudinal reinforcenent, acting in conjunction with the embedding concrete, depends on the size of bars, spacing, strength of concrete, and depth of cover. (25)

This last factor was verified to some extent in an earlier investigation by A. F. Al-Alusi (5) which included a series of inverted T-beams and regular $\mathrm{T}$-beams of approximately the same shear span. A.though the inverted T-beams did not have substantially greater depth of cover than the regular $T$-beams, they did have the larger mass of 
the concrete flange surrounding the tension reinforcement and resisting horizontal cracking. The test results show that after the formation of a diagonal crack in the inverted T-beams there was a drop of load, but a favorable redistribution of internal stresses enabled the beam to carry additional load. The ultimate shearing stress of the inverted T-beams proved to be higher than that of the regular T-beams, and there was a lack of horizontal splitting along the longitudinal reinforcement, although this was not offered as an explanation at the time.

In the present investigation, the negative moment regions of the test specimens resemble inverted T-beams. The results of these tests in light of horizontal cracking will be discussed later.

Diagonal tension failures may be prevented or delayed through the use of stirrups. The addition of web reinforcement in the shear span increases the resistance to horizontal cracking by tying together the portions of concrete above and below the longitudinal bars and thereby retarding the separation of these two segments, as well as, by delaying the opening of the diagonal crack.

For design purposes, however, web reinforcement is not necessary If the shear stress does not exceed its allowable value. The 1963 ACI Building Code ${ }^{(2)}$ redefined the nominal shear stress as merely the average shear stress, $v=\nabla / b d$, which neglects the classical use of the moment APM, jd.

In an attempt to produce members for which ultimate strength tends toward being governed by flexure rather than shear so that members will have a ductile character, ACI-ASCE Comittee $426^{(I)}$ developeo the following expression for the ultimate shear stress in a 
beam without web reinforcement;

$$
v_{c}=1.9 \sqrt{T_{c}}+\frac{2500 p \nabla d}{M} \leq 3.5 \sqrt{f_{c}^{T}}
$$

For working stress design, a safety factor of approximately two is applied to this equation, and appropriate load factors are used for ultimate strength design. It can be seen that the expression contains the factors influencing the shear strength of reinforced concrete beams mentioned previously; concrete strength, percentage of longitudinal reinforcement, and moment to shear ratio.

\section{Cracking Phenomena Under Repeated Ioading}

The reduced stresses for working stress design and the load factors for ultimate strength design, such as in the previous discussion of shear stress, are based primarily on the behavior and strength characteristics for static loading conditions. It is well known, however, that under repeated loading concrete members collapse at a lower load than under static loading. Repeated stressing causes the strength of the member to be reduced substantially and the member is said to have failed by fatigue.

Present design formulas give consideration to the effects of loads other than static through the use of impact factors which merely increase the live load by some percontage based solely on the length of the nember. Experience has shown these values to be safe, but to an unknown degree. It would be wise to become more aware of their relative safety. The more efficient use of structural materials, such as higher permissible stresses or lower load factors, present an even greater need for caution. Despite a wide variety of tests conducted 
in the area of fatigue, results on the actual reduction in strength are far from adequate and considerable doubt still exists as to the inherent factors of safety and the method of their evaluation.

In 1958, Nordby ${ }^{(17)}$ reviewed more than 100 of the most important investigations performed on fatigue of concrete up to that time and presented a sumary of their findings. For the most part, repeated load tests of plain concrete in compression, flexure, and tension were inconclusive, but they did indicate typical behavior pattems. It was generally agreed that fatigue failures would not occur if the maximum value of the repeated load was less than 60 percent of the static ultimate load. Rates of laading between 70 and 440 cycles per minute had little effect on the fatigue strength, but the range of stress (maximum stress minus minimum stress) was significant; the most severe loading being one in which the mean static load is zero and the varying load causes alternate tension and corapression. This is called completely reversed loading. The fatigue limit was also found to be proportional to the concrete strength and age; a higher strength and older concrete being able to resist a higher percentage of the static ultimate load.

Fatigue investigations of reinforced concrete members were equally inconclusive, mainly because they were highly diversified. Most investigators have reported four basic fallure modes; fracture of the tensile reinforcement, diagonal tension, shear compression, and loss of bond. It should be noted that these are the same modes of failure exhibited by beams subjected to static loading conditions and, further, they are influenced by the same parameters; i.e., concrete 
strength, percentage of tensile and web reinforcement, and moment-toshear ratio. However, repeated loads introduce an additional set of varlables which have such a decisive effect on the mode of failure that identical beams may fail differently depending on whether they are subjected to static or repeated loads. The variables of most concern are: maximum value of repeated load, range, and rate of loading.

Verna and Stelson (23) found that bond is most susceptible to fatigue damage, but only if the member is also statically weak in bond. Chang and Kesler ${ }^{(7)}$ concluded that bond failures are unlikely under repeated loading with deformed bars meeting ASTM specification A305. This type of failure is not to be confused with the loss of bond associated with diagonal tension failures. Assuming a reinforced concrete member to have sufficient bond strength, then either shear or diagonal tension is most likely to be the cause of failure. Hovever, in almost every investigation, there have been reported a number of specimens whose ultimate fatigue life was controlled by the fatigue Iife of the steel reinforcement. Van ornum, (17) who was the first to extensively examine reinforced concrete beams in fatigue, noted that the beams falled through the development of a tension or diagonal tension crack, but, if the crack had penetrated far enough, then the beam failed by steel fatigue. In those beams which failed through the formation of diagonal tension cracks, it appeared that gradual progressive destruction of bond originating near the center of the specimen and moving toward the end caused failure. This may be related to the high dowel forces mentioned in the discussion of static shear 
stresses which are aggravated by repeated stressing.

Chang and Kesler $(7,8)$ ran repeated load tests of concrete beams with various ratios of static shear-to-flexure strength. When the shear and flexure strength were approximately equal, more than half of the specimens failed by fatigue of the reinforcement, with the remaining beams failing equally in diagonal tension or shear compression. They related the type of fallure to the magnitude of the repeated load; low loads resulting in flexure failure; high magnitude loads resulting in shear failure. In a later investigation, they found that, generally, a beam weak in shear will crack diagonally, with the crack progressing far enough 1nto the compression zone so that the reduced area will not be able to resist the maximum value of the repeated load. Failure then occurs by destmaction of the compression zone. Although the 39 specimens of this test were statically weaker in shear than in flexure, two failed by fatigue of the reinforcing steel.

Recent research projects at Purdue University $(11,19)$ have also involved reinforced concrete beams which were weaker in shear than in flexure. Results show a definite change of failure mode from static to dynamic loading conditions. Whereas the specimens failed by either shear compression or diagonal tension when subjected to static loads, fracture of the tensile reinforcement was found to be the cause of failure for more than half of the dymamically loaded beams, with the remainder failing by diagonal tension.

The unexpected appearance of flexure failures, and the disproportionate number of flexure failures occurring when they were expected, have led to more complete investigations of the fatigue 
strength of reinforcing bars. The Portland Cement Association (PCA) and the American Association of State Highway Officials (AASHO) have made the most significant coutributions in this area to date.

Pfister and Hognestad, (18) working for the PCA, first investigated a mumer of variables in order to determine their effect on the fatigue limit of reinforcing bars. The fatigue limit is normally expressed as the stress range which would cause failure at two million cycles of load repetition. They found it to be relatively insensitive to the magnitude of the minimum stress, bar yield strength, and beam cross section. It was also reported that the geometric details of bar deformations have strong influences on the fatigue characteristics of the bars. The stress range at the fatigue limit for one bar lot may be 35 percent less than for another lot with another deformation pattem depending on the local geometry where the transverse lugs meet the longitudinal ribs. Mis was also reported by Kokubu and Okamura (13) in Japan, who observed the incressed radius at the base of the Iug results in an increased fatigue strength. They added that sudden changes in the slope of the lug from a point $1 / 3$ up the height of the lug had little effect on the fatigue strength.

Kenneth Burton $(6)$ continued the work at the PCA and found two other variables influencing the fatigue life of reinforcing bars. The range of stress had the strongest effect, decreasing fatigue life as the stress range increased. Fisher and Viest, $(9)$ in a test of bridge materials during the AASIO noad Test, reported that the stress range was by far the most important independent variable. Burton also concluded that the orientation of the longitudinal ribs had a pronounced 
effect on fatigue Iife of the bar if the transverse lugs merged into the rib. The fatigue life of bars with the ribs placed in a vertical plane, as shown in Figure 3a, was almost 40 percent less than that of bars tested in the same stress range with the ribs in a horizontal plane (Figure 3b), indicating that the stress concentrations at the point where the transverse lug merges with the Iongttudinal rib (point $A$ in Figure 3a) may be higher than where the Iug merges with the main body (point $B$ in Figure 3b). The inverse of this was reported in $a$ later investigation at the PCA by Hanson, Burton, and Hognestad. (10) They concluded that the orientation of the Iongitudinal bar ribs in a reinforced concrete beam has little effect on fatigue strength when the lugs do not merge into the ribs, but, when the ribs are placed in a horizontal plane, the fatigue strength is not necessarily improved by teminating the transverse lugs before they reach the longitudinal ribs.

The type of deformed bars shown in the diagrams of Figure 3 were used in the AASIO Road Test. (22) (The photograph was taken of a typical fractured bar from the present investigation). Inspection of the reinforcing bars after failure in the AASHO test revealed that all cracks formed at, or passed.through, the intersection of the two diagonal lugs with a longitudinal rib (point C in Figure 3b), supporting evidence that this junction is a point of fatigue weakness.

Although definite trends in the fatigue behavior of deformed reinforcing bars have been reported, fow practical applications have boen suggested. However, Hanson, Burton, and Hognestad did conclude that the radius at the base of the transverse lugs should be 


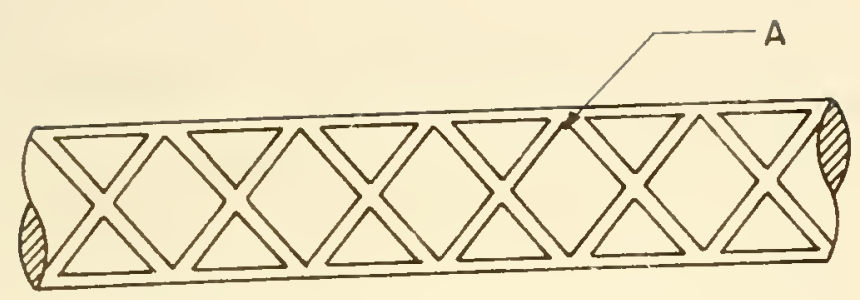

(a)
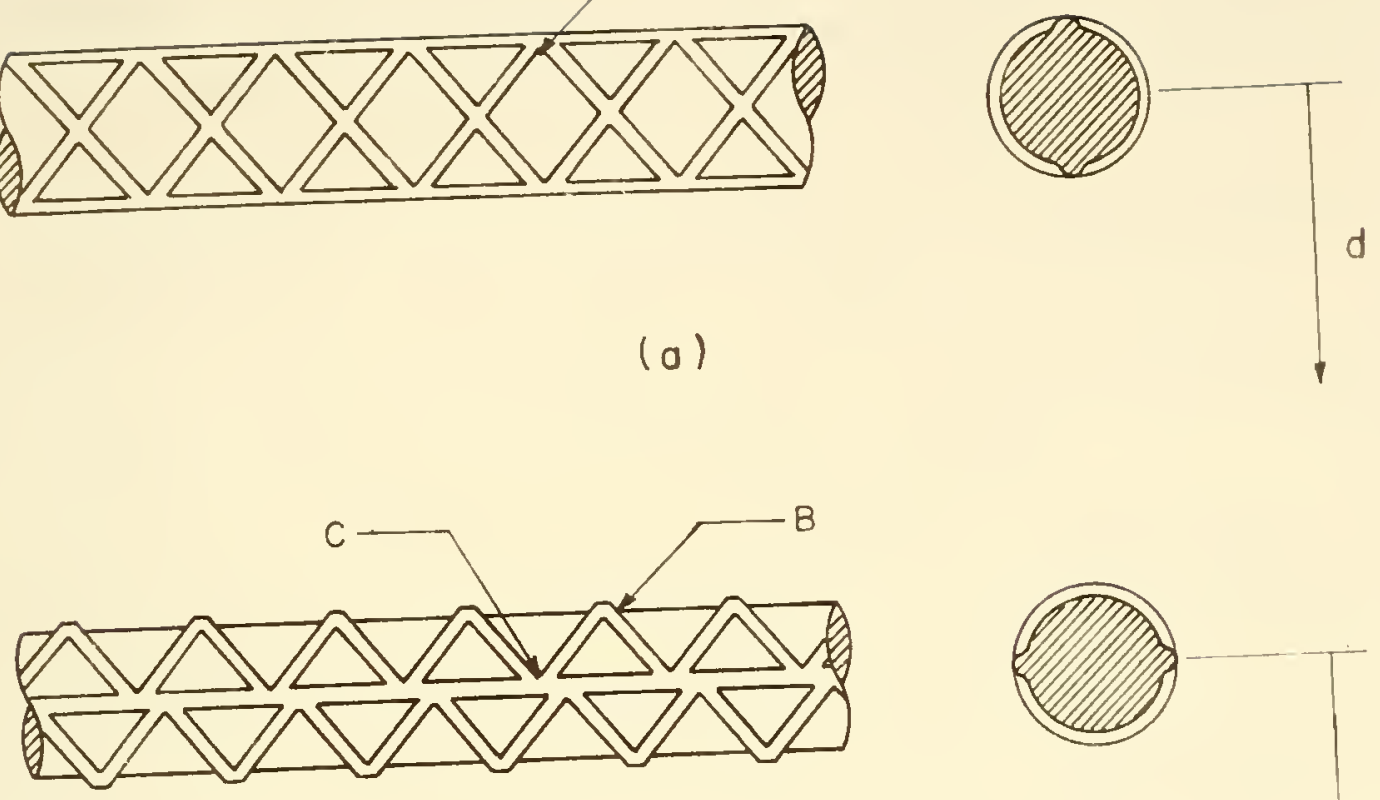

(b)
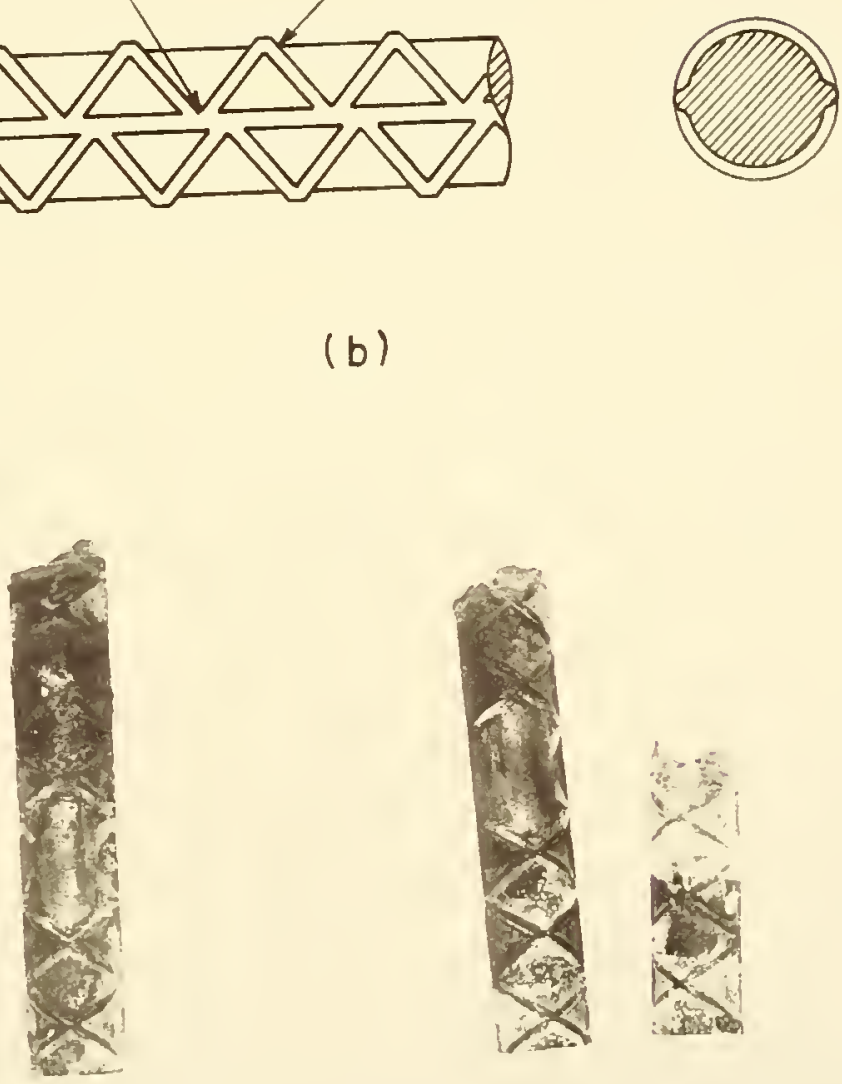

II $P-5$

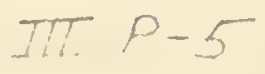

(c)

FIGURE 3. LONGITUDINAL STEEL REINFORCEMENT 
approximately equal to the height of the lug to obtain goad fatigue characteristics. All of the investigators agreed that when the stress range in the deformed reinforcing steel exceeds 20,000 psi, fatigue failure becomes possible if the member is subjected to a large number of stress repetitions. Stress ranges of this magnitude may occur in some structural members, particularly if they are reinforced with high strength steel and designed by ultimate strength methods.

In sumary, the ultimate load of a reinforced concrete member is reduced if the load is applied repeatedly, and the failure mode may be different than if the beam were subjected to static loads. The failure mode is determined mainly by the maximum value of the repeated load, the range and rate of loading. In many cases the fatigue life of a reinforced concrete beam is limited by the fatigue life of the tension reinforcement which, in turn, depends on the stress range in the steel. The stress range at the fatigue limit (two million cycles of loading), when reduced by a suitable margin of safety, can be used in design as an allowable value for stress due to repeated live load alone. The effects of all dead and live loads can then be accounted for safely by the usual nethods of working stress design or ultimate strength design. The geometric details of the deformations also have a pronounced effect on the fatigue characterlstics of reinforcing bars. The radii of curvature with which the transverse lugs merge into the main body of the bar are sigmificant, as well as the manner in which transverse lugs meet longitudinal ribs. 


\section{PURPOSE OF STUDY}

The objective of this study was to continue the research on the behavior of reinforced concrete beams subjected to repeated loads, with specific attention to T-beams. It was intended to determine the effect of shear span-to-depth ratio and magnitude of repeated load on the failure mode of the specimens. The results were then to be compared to those of static load tests of identical T-beams and repeated load tests of beams with similar rectangular cross section.

It was also proposed to evaluate any temperature gradient caused by repeated stressing of the longitudinal relnforcement. 
TEST SPECTMENS AND PROCEDURES

The cross section of all test specimens was composed of a 6 inch by 13 inch rectangular web. The T-beams had an additional 3 inch thick flange with an overall width of 30 inches. The beams were simply supported at two points with an overhang to simulate the condition of an Interior support of a continuous member. A load $\left(P_{1}\right)$ was applied at the end of the cantilever portion and a second load $\left(\mathrm{P}_{2}\right)$ was applied between the supports. The load was distributed to these two points of application in the desired ratio by means of a steel wide flange section. The position and magnitude of $P_{1}$ and $P_{2}$ produced a maximum negative moment of 2 times the maximun positive moment.

Tho high sirength No. 6 steel reinforcing bars were used to resist the negative moment and two No. 5 bars to resist the positive moment. All longitudinal reinforcement extended the full length of the test specimen to eliminate the effect of bar cutoff on diagonal. tension failure. Veb reinforcement was provided only in the cantilever portion of the beam and outside of $\mathrm{P}_{2}$, forcing any shear failure to occur within the shear span "a", which extended from the point of zero moment to the point of maximum negative moment.

The length of the shear span and the magnitude of the repeated load were the only intended variables, al though there was some variation of concrete strength.

The loads, and shear and moment diagrams are shown in Figure 4, 

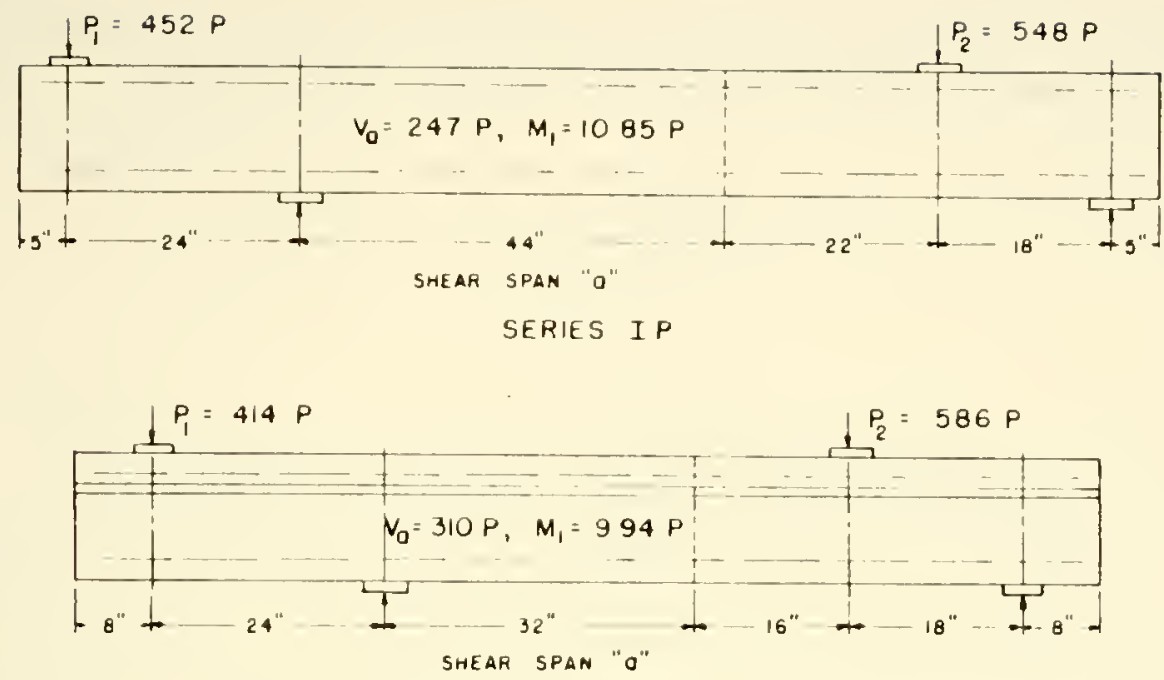
SERIES II P
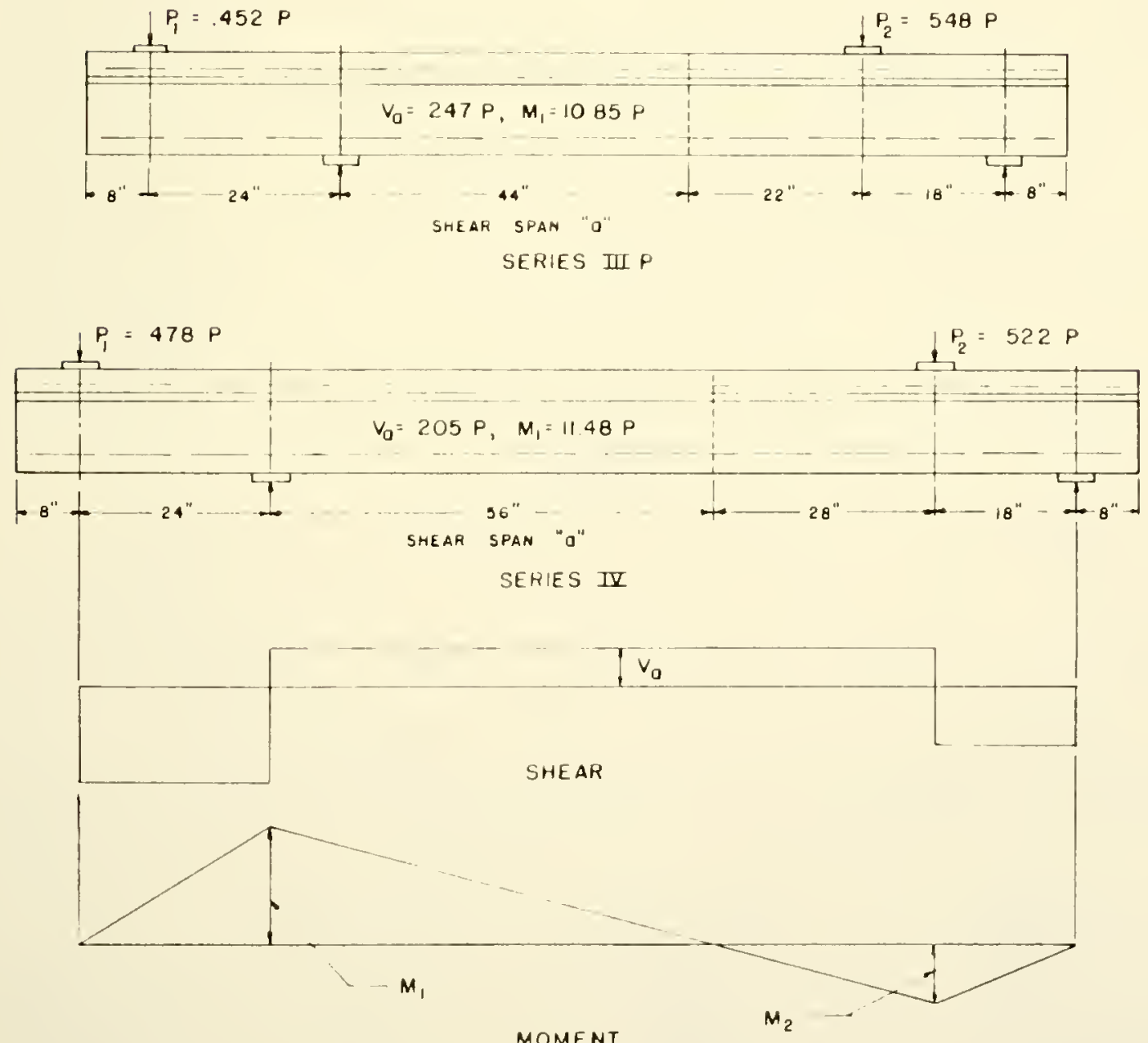

FIGURE 4. DETAILS OF SPECIMENS 
and the details and properties of the test specimens can be found in Figure 5 and Table 1 .

\section{Materials}

Concrete Mix

All concrete was made with Type I Portland cement. The concrete strength was intended to be maintained at 5000 psi, but varied from approximately 4000 to 6000 psi at 7 days. Tests were begun when the specimen had an age of at least 7 days, and failure occurred, or the test terminated, at a specimen age of approximately 14 days. Concrete strength at 14 days had an average increase of about 10 percent over 7 day strength. The proportions of the concrete mix by saturatedsurface-dry weight were $1: 2.06: 3.51$ (cement-to-fine aggregate-tocoarse aggregate), with a water-cement ratio (w/c) of .506 by weight and a cement factor of 6.12 sacks/cubic yard.

\section{Aggregates}

The aggregates were purchased from hestem Indiana Aggregates Corporation, Lafayette. The coarse aggregate was a natural gravel of I inch maximum size. After separating into two sizes, 48 percent of No. 4 to $\frac{1}{2}$ inch was combined with 52 percent $\frac{1}{2}$ inch to 1 inch by weight. Average properties of the fine and coarse aggregate are shown below.

\begin{tabular}{|c|c|c|c|}
\hline & Sp. Gr. & Absorption & $\begin{array}{l}\text { Fineness } \\
\text { Hodulus }\end{array}$ \\
\hline Fine & 2.83 & $1.26 \%$ & 2.87 \\
\hline Coarse & 2.65 & $1.37 \%$ & --- I"Max. \\
\hline
\end{tabular}

* Based on saturated surface dry welght. 


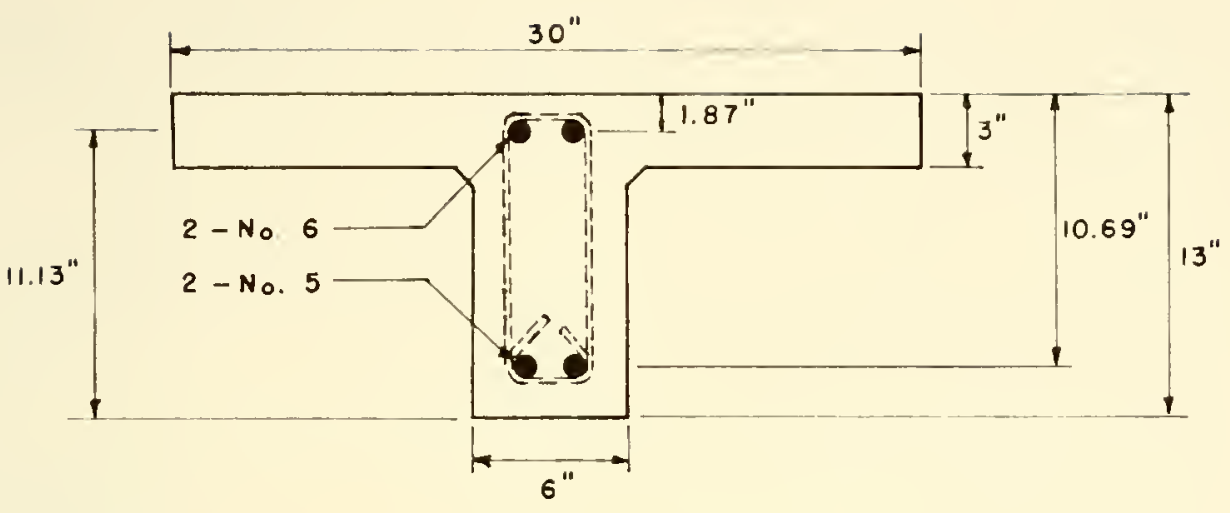

SERIES II $P$, III $P$, IV $P$

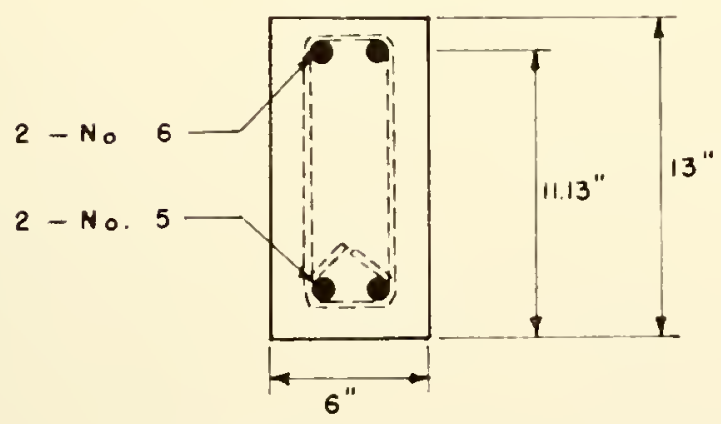

SERIES IP

FIGURE 5. DETAILS OF TEST SPECIMENS 


$$
\begin{aligned}
& \text { | }
\end{aligned}
$$

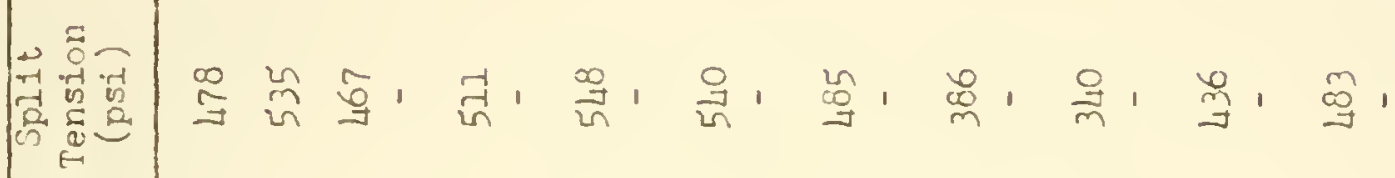

$$
\begin{aligned}
& \text { 可 } \\
& \begin{array}{l}
0.4 \\
05 \\
05
\end{array}
\end{aligned}
$$

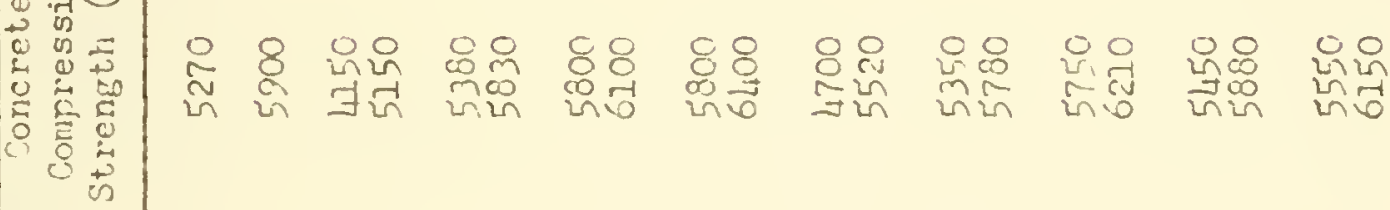

$$
\begin{aligned}
& \left(\begin{array}{lll}
3 \\
3
\end{array}\right. \\
& \text { I. }
\end{aligned}
$$

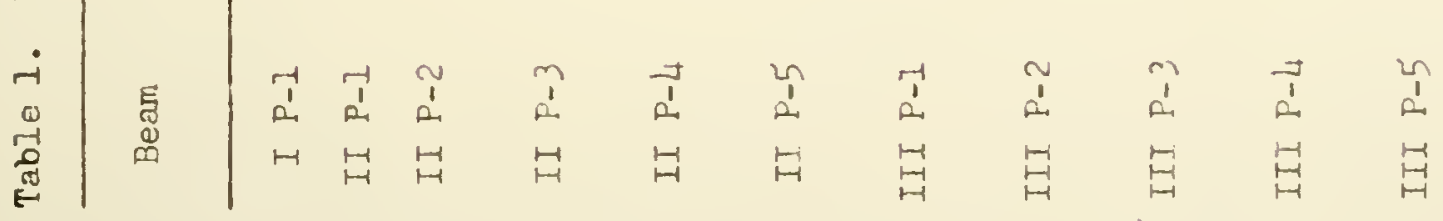




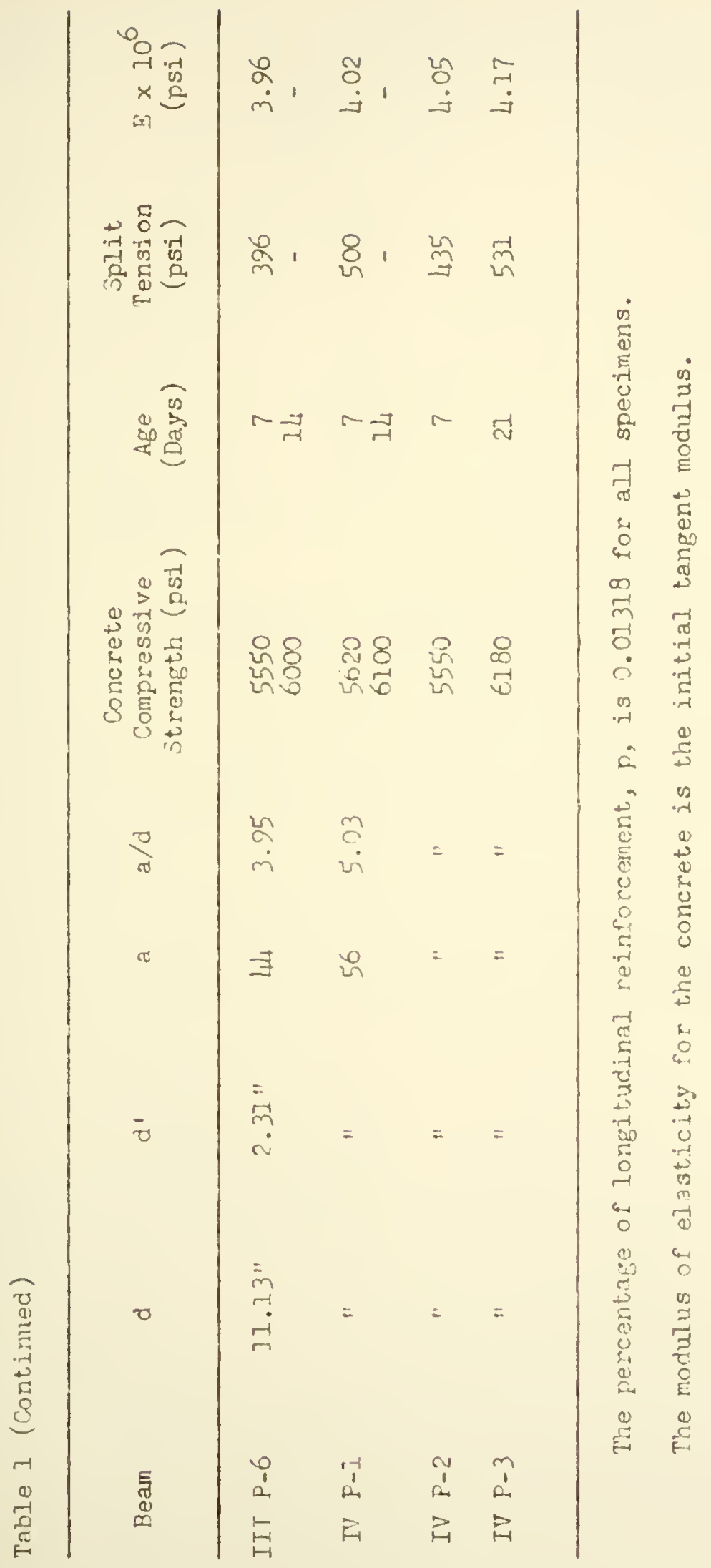




$\begin{array}{cc}\text { Gradation of Fine Aggregate } \\ \text { Sieve Size } & \frac{\text { Percent Retained }}{\text { No. } 4} \\ 8 & 16.6 \\ 16 & 36.8 \\ 30 & 48.0 \\ 50 & 87.8 \\ 100 & 96.6\end{array}$

Reinforcing steel

The longitudinal reinforcing steel was a high strength steel, A431. The No. 6 bars had a higher yield stress and ultimate strength than the No. 5 bars. Stress-strain curves for both size bars are shown in Figures 44 and 45 , and their properties can be fourd in Table 2.

Table 2. Properties of Inngituoinal Reirforcing Stecl

\begin{tabular}{lcc}
\hline & No. 5 & No.6 \\
Yield Stress & $72.1 \mathrm{ksi}$ & $96.1 \mathrm{ksi}$ \\
Utiniate Strength & $113.3 \mathrm{ksi}$ & $158.0 \mathrm{ksi}$ \\
Modulus of Masticity & $29.6 \times 10^{6} \mathrm{psi}$ & $29.1 \times 10^{6} \mathrm{psi}$ \\
Dlongation in 8" & - & $8.5 \%$ \\
\hline
\end{tabular}

The No. 2 plain bars used for stirrups in the overhang and in the 18 inch interior span were of hard grade steel with an average yield stress of 52,000 psi. 


\section{Fabrication and curing}

All specimens were cast in $3 / 4$ inch plywood forms coated with a polyester resin to prevent deterioration from repeated wetting and drying. The forms are show partially assembled in Figure 6. Tie rods were inserted through the stem of the specimen and through the base of the form to hold the form together during casting. Those tie rods which passed through the concrete were covered with rubber tubing to facilitate their removal after the concrete had hardened.

The longitudinal reinforcement was wired into a rigid cage by means of the stirrups in the overhang and outside load $\mathrm{P}_{2}$. Steel chairs were used to support the cage in the fornworls and provided the correct vertical position. This combination of stirrups and chairs allowed a concrete cover to the longitudinal reinforcement of lis inches at the top and sides, and 2 inches on the bottom, with a $1^{\frac{1}{2}}$ inch clear spacing between bars.

The concrete was mixed in a stationary rotating drum mixer with a maximum capacity of eleven cubic feet. The size of the specimens required the use of more than one batch of concrete per beam. Therefore, the quantities of materials for each batch were taken from the same stock pile and weighed prior to mixing to insure uniformity. The concrete was vibrated internally as it was placed to prevent honeycombing. Standard test cylinders were also made from the same batch.

Several hours after casting, the top of the specimen and the test cylinders were covered with moist burlap and a sheet of plastic. The forms were removed after six days in order to prepare the specimen for testing. 

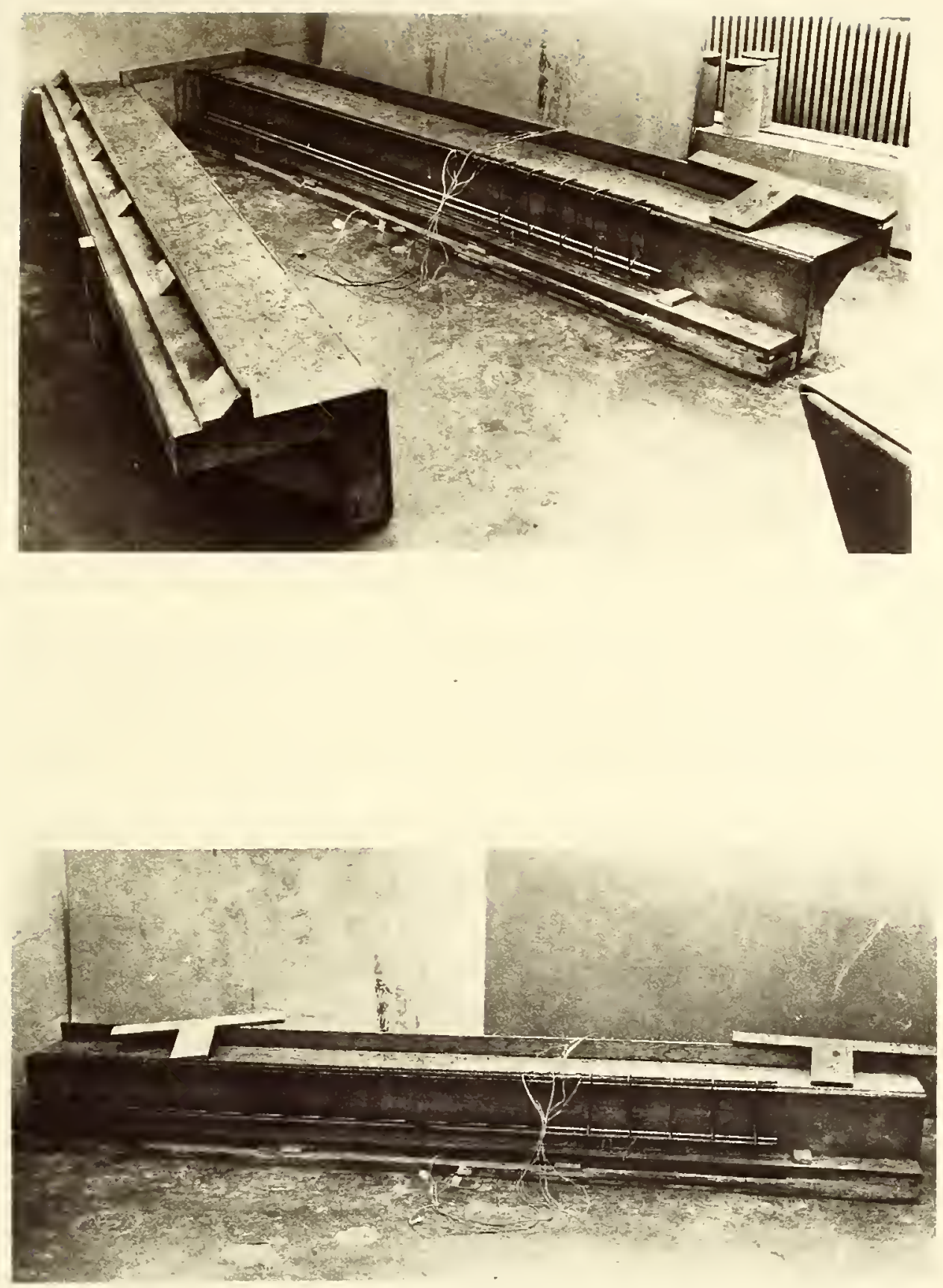

FIGURE 6. FORMS PRIOR TO CASTING 


\section{Instrumentation and Testing Procedures}

After the forms were removed, the specimen was allowed to dry for a few hours. The sides of the web and the under-sides of the flange were then painted white with a thin mixture of latex paint. A grid system was drawn over this to allow for easier reproduction of the crack patterns after failure.

An area $3^{\frac{1}{2}}$ inches from the support in the negative moment region was prepared to recelve concrete strain gages. The area was sanded, cleaned with acetone, and covered with a layer of Duco-cement. This was allowed to dry for one day before the paperback SR-4 wire gages (Baldwin-Iima-lamilton Type A-I-S6) were cemented to the surface.

Steel strain gages (Budd Metalfilm $66-1 / 1 \mathrm{~B}$ ) had previously been attached to the top reinforcing bars at the point of maximum negative moment. These gages were affixed to the bars using the procedure recommended by iillliam Bean. Dastman 910 was used as an adhesive. The gage assembly was then waterproofed with an epoxy compound (Dpoxylite 4222$)$. The reinforcement was wired into a cage with its longitudinal ribs lying in a horizontal plane. In order to make room for the strain gage, one set of criss-cross lugs was removed from the top surface of the bar with a disc grinder and the area smoothed with a hand file. For some specimens, gages were placed on both the top and bottom surfaces at the same position. In these cases, Iugs were removed from both the top and bottom of the reinforcing bar.

All steel and concrete gages were connected to a switching and balancing unit with three-wire leads. The strain signals were passed from this unit to a Budd P-350 digital read-out strain indicator, from 
which the static component of the strain was taken. The dynamic component was evaluated with a calibrated oscilloscope.

Temperature measurement on several early specimens was made with iron-constantan thermocouples, \#24 gauge wire, attached to the longitudinal reinforcement at or near the point of maximum negative moment. At first, the thermocouple wires were spot welded to the bars, but this was found not to produce a secure connection. A better connection was obtained by solcering them to a teminal strip which had been glued to the steel surface. In both cases, the wires were protected with the same waterproofing epoxy compound as was used for the steel strain gages. A Leeds and Northrup potentiometer was used in conjunction with the thermocouple wire.

Six of the nine concrete test cylinders were tested just before the beam specimen was loaded. Three were used to determine the compressive strength and the modulus of elasticity, and three others were tested in split tension. The remaining cylinders were tested in compression upon failure of the beam specimen.

The average compressive strength of the cylinders was used to predict the ultimate failure load of the test specimen. The maximum value of the repeated load was taken as some percentage of this urtimate load. In a previous investigation at Purdue University, dealing with repeatedly loaced beams of rectangular cross-section, (19) the predicted fallure load was based on an average of the expressions of Moody and Morrow, that of Moody being unconservative, and that of Morrow being conservative. However, static load tests of T-beams, (26) identical to those of the present investigation, demonstrated that 
the expression of Moody very closely approximated the ultimate failure load, while that of Morrow was highly conservative. Therefore, the maximum value of the repeated load is expressed as a percentage of the failure load using only the equation of Moody. The equations for ultimate shear-moment as derived by both Moody and Morrow, as well as sample calculations, are found in Appendix 3 . A minimum load of four kips was applied to the specimen at all times to prevent impact. The cycling of maximum and minimum load was delivered to the specimen at a rate of 250 repetitions per minute by means of an Amsler Hydraulic Pulsator. The pulsator produced a sinusoidally varying oil pressure which drove an overhead hydraulic jack. The test setup is shown in Figures 7 and 8 .

The specimen was loaded statically to the maximum value for the first cycle. The load was then reduced to the minimum value and the repeated load applied. The range of repeated load was maintained at one level throughout the test until failure occurred. A seismograph was attached to the specimen which automatically shut off the pulsator at the instant of failure. If, after approximately three million cycles, the specimen had not failed, the repeated load was terminated and the specimen loaded statically to failure. 


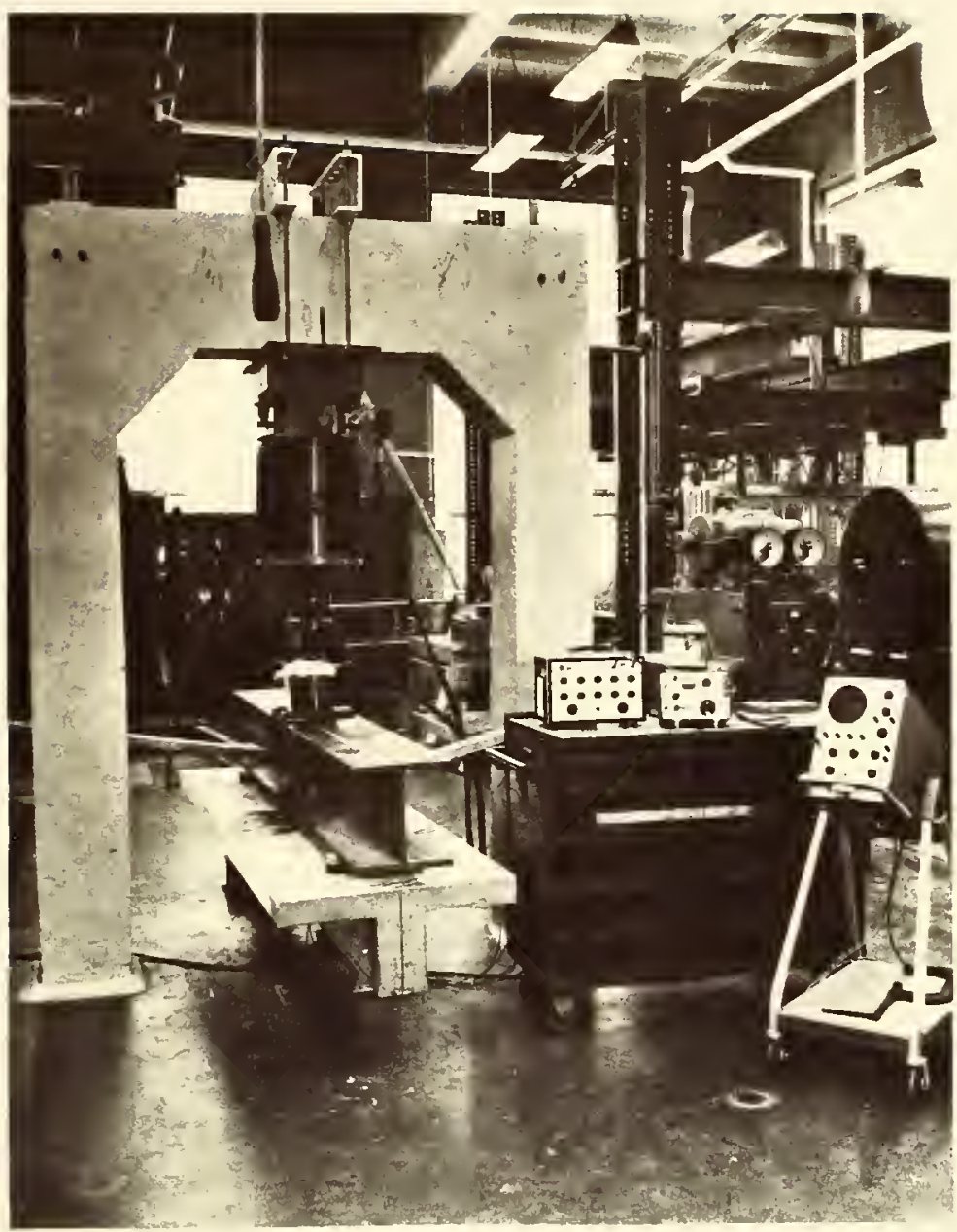

FIGURE 7. TEST SETUF 


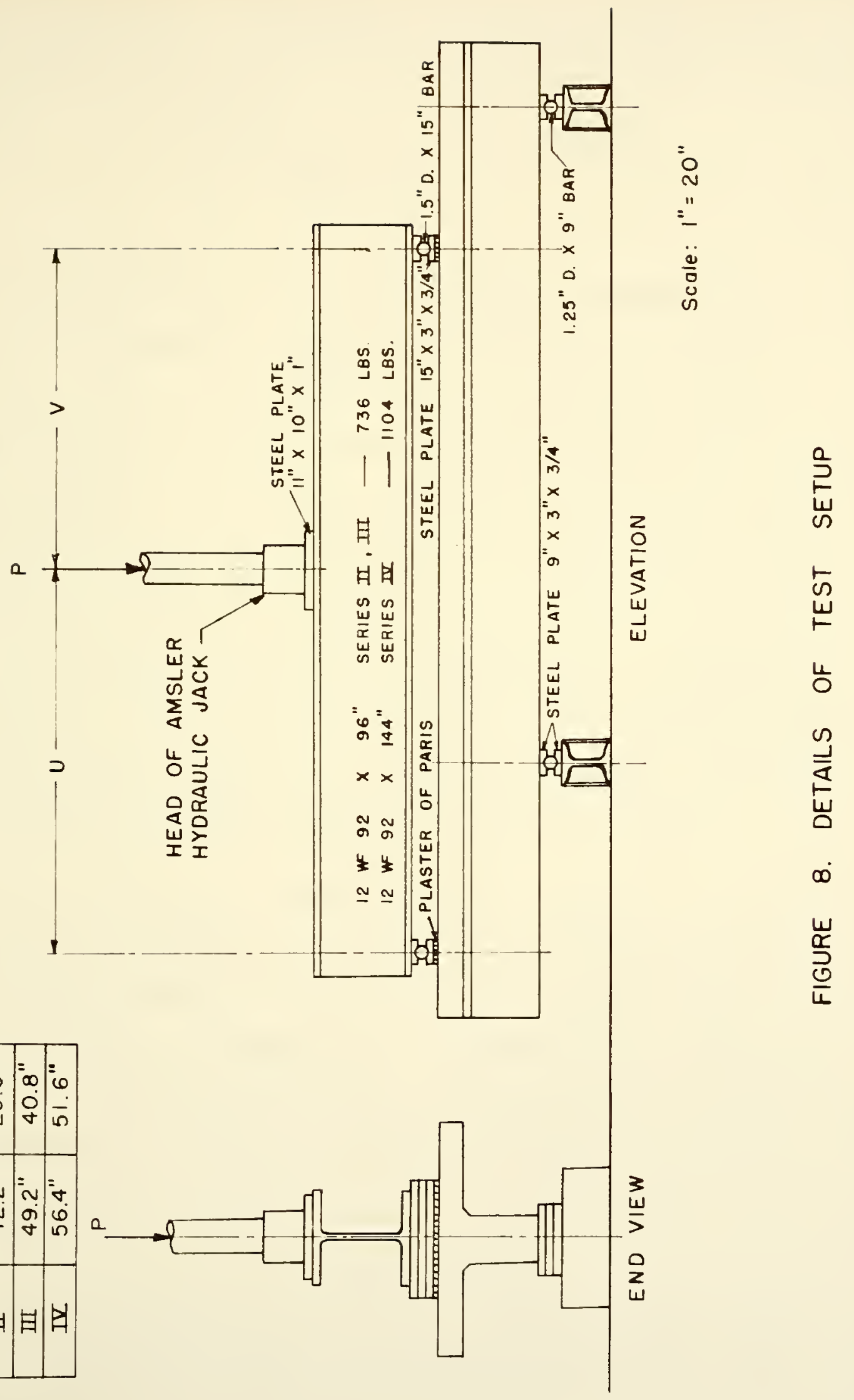




\section{TEST RESULTS}

The test results for all specimens have been sumarized in Table 3. The specimens have been grouped in the following sections according to length of shear span, or series, and shape of crosssection. Tach section includes a description of individual tests as they occurred, load versus strain curves, and crack pattern diagrams. Photographs of the specimens after failure and close-ups of the steel fractures are also found in this section.

Loads reported are total applied loads, which do not include the dead weight of the specimen nor the weight of the loading apparatus. Complete strain and temperature data may be found in Appendix C, which also includes the position of the gages and thermocouple wires.

\section{Series I P}

Seri.es I P consisted of only one beam. The primary purpose of this series was to evaluate any temperature rise in the longitudinal reinforcement during the application of the repeated load. The specimen was identical to those of series III BF in Rogers report (19) which had failed by fracture of the steel reinforcement. The shear span-to-depth ratio was 3.96 .

\section{Beam I P-I (6I, UItimate)}

The first flexural crack appeared at a load of 10 kips. After one cycle of loading six flexural cracks had formed in the negative 


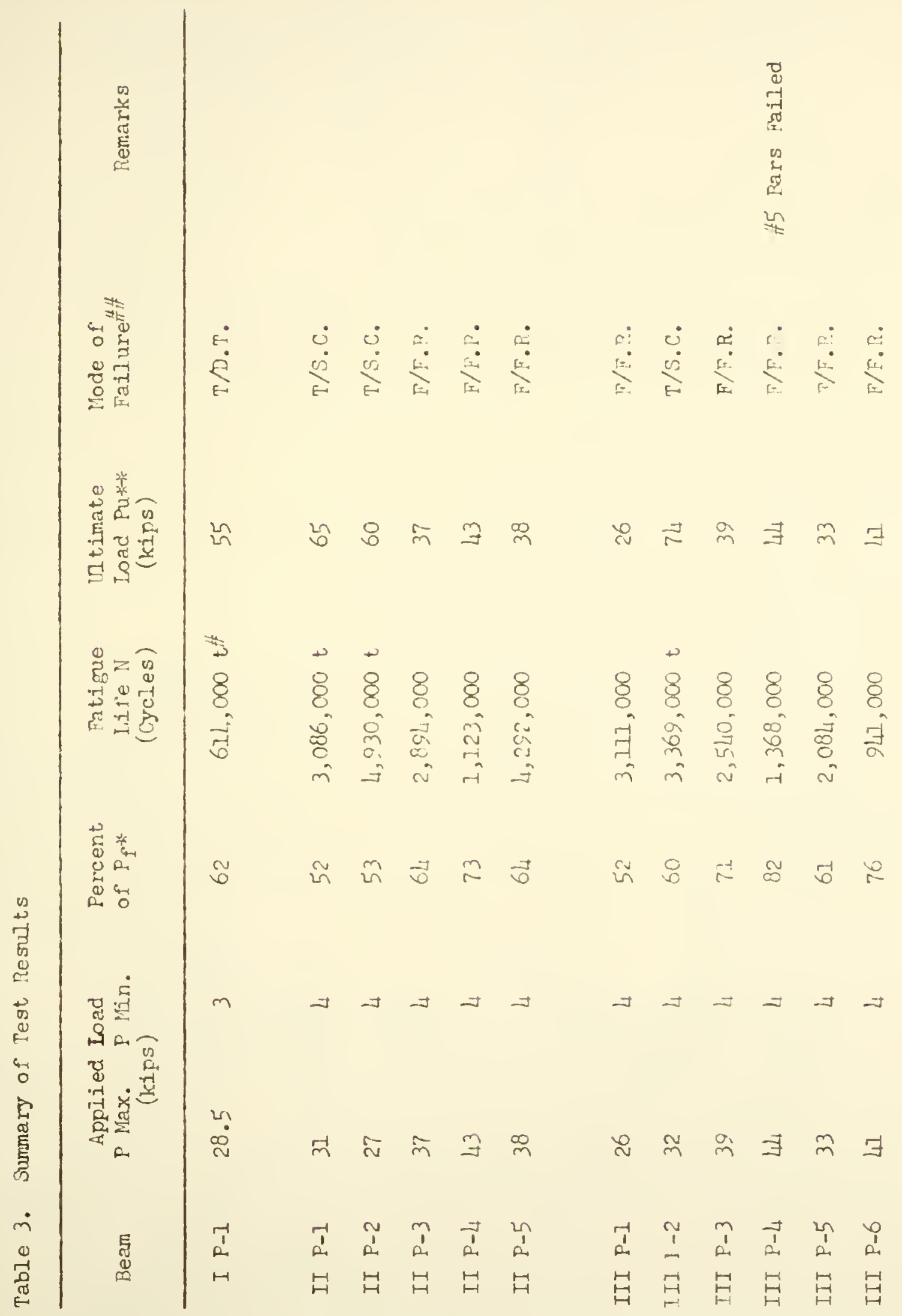




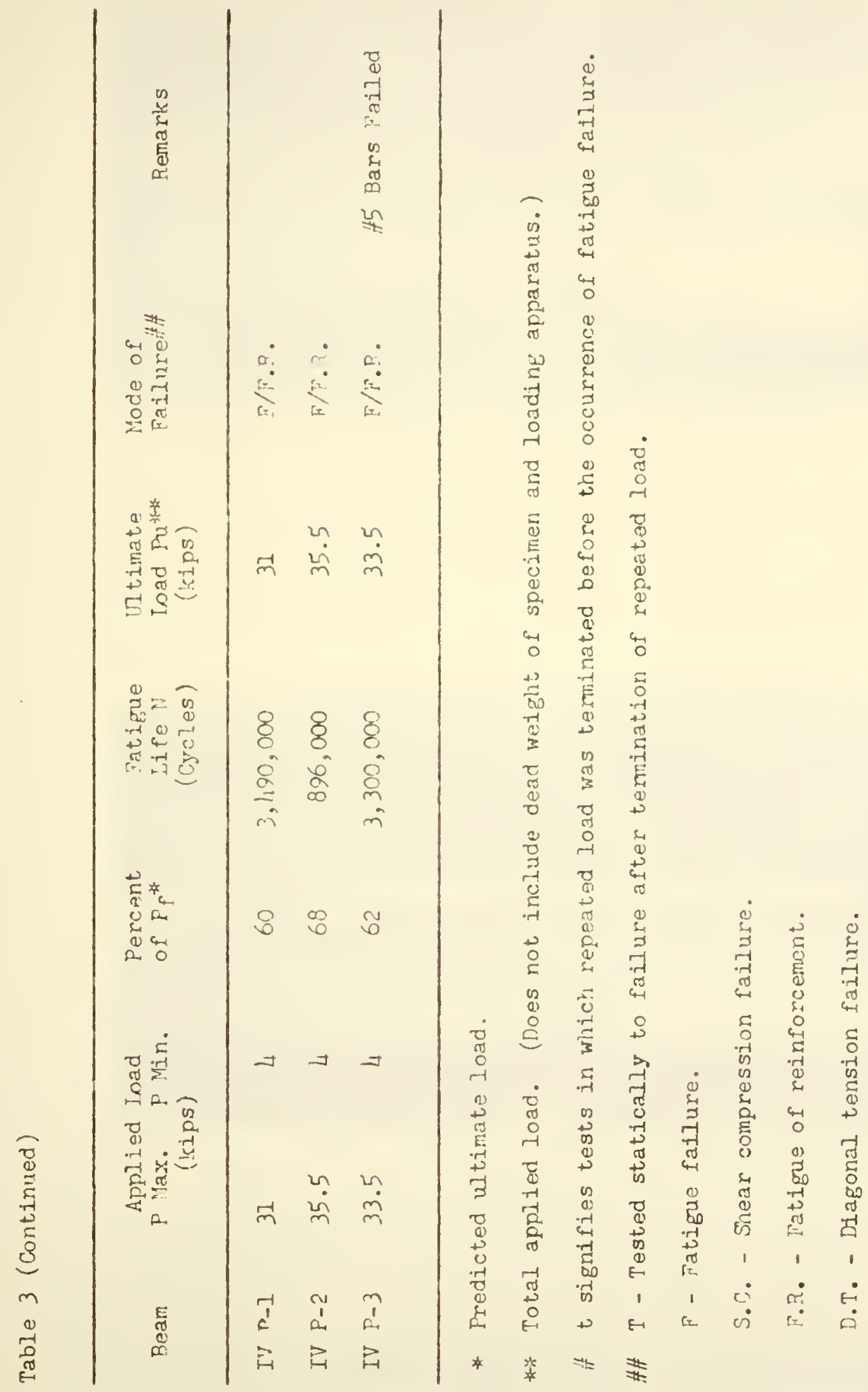




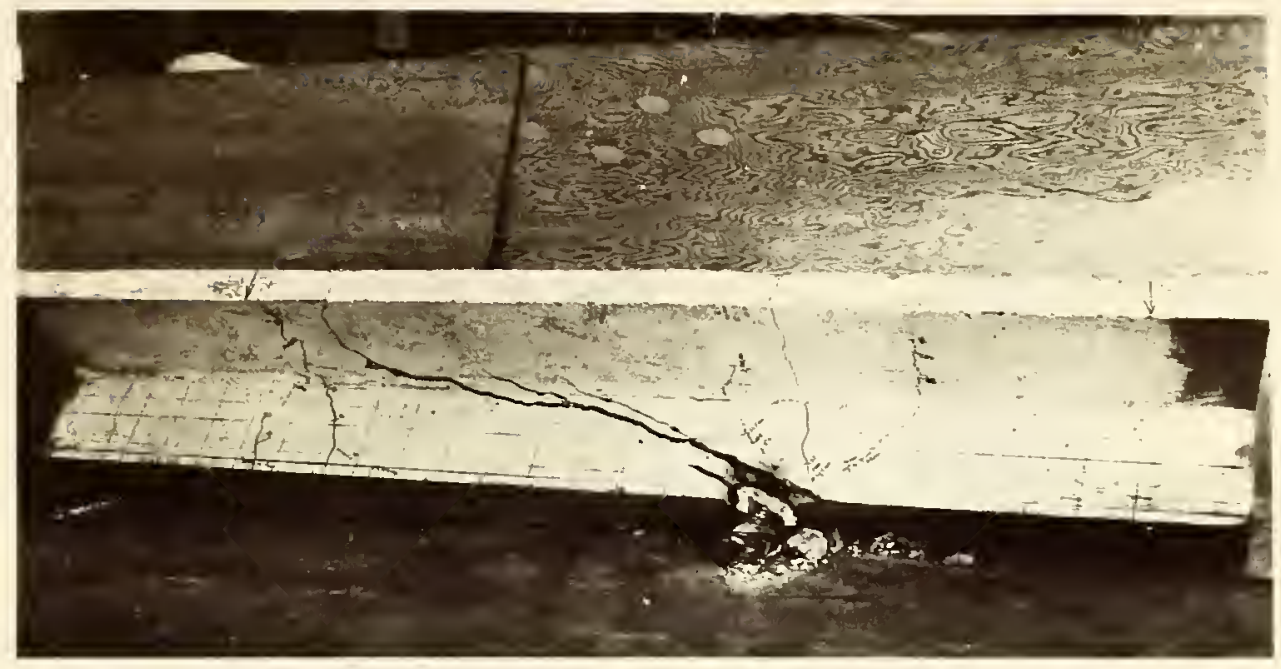

II $P-1$

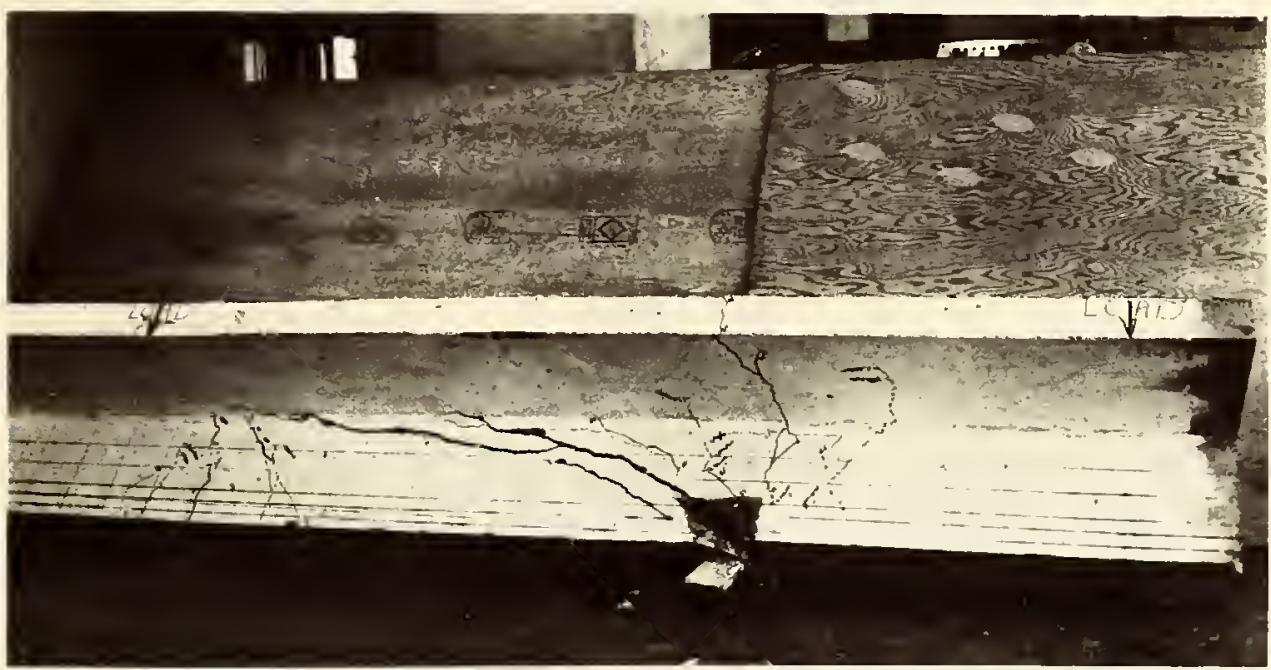

II $P-2$

FIGURE 9. BEAMS AFTER TEST - II P-1, II P-2 

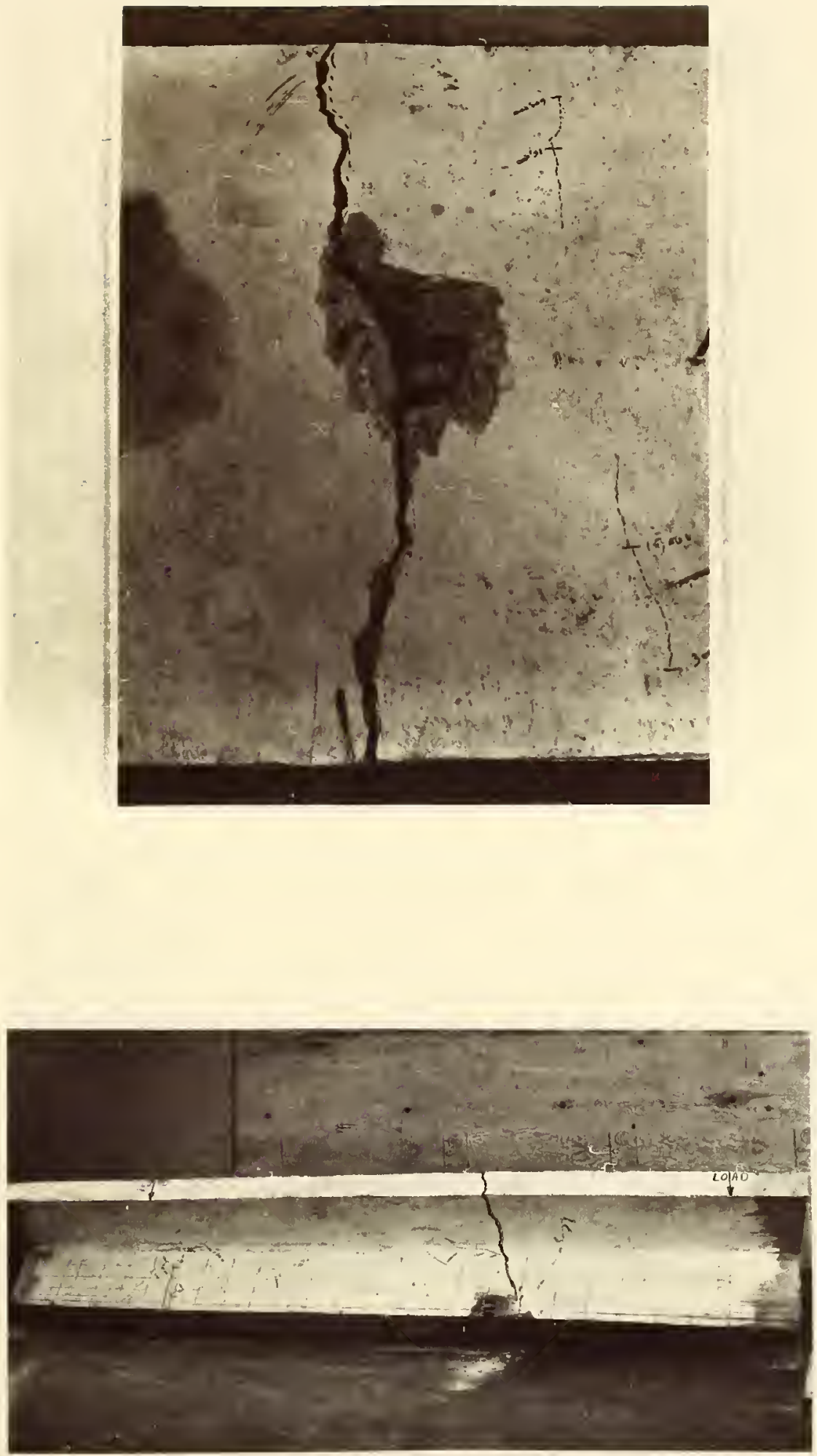

FIGURE 10. BEAM AFTER TEST - II P-3 

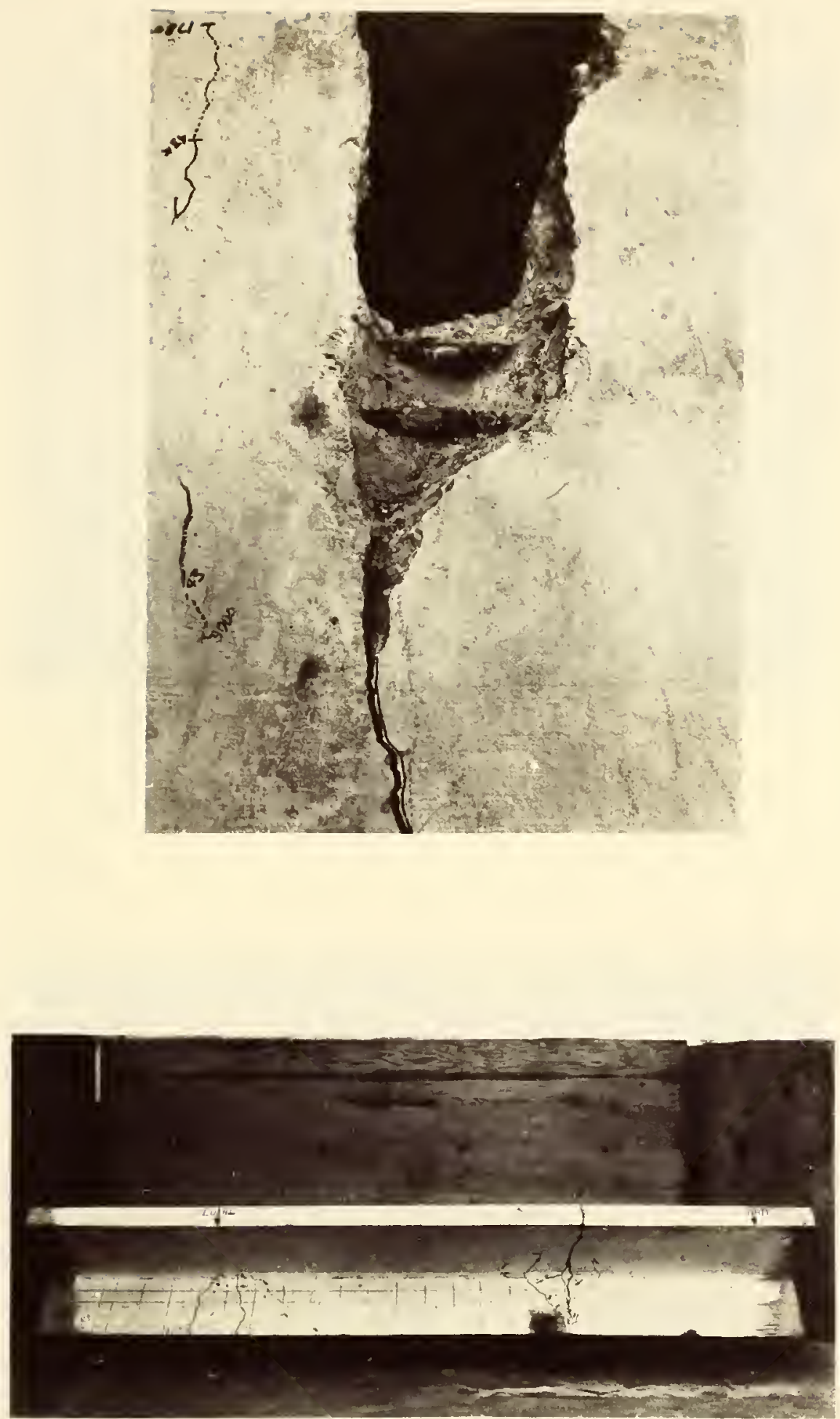

FIGURE II. BEAM AFTER TEST - II P-4 

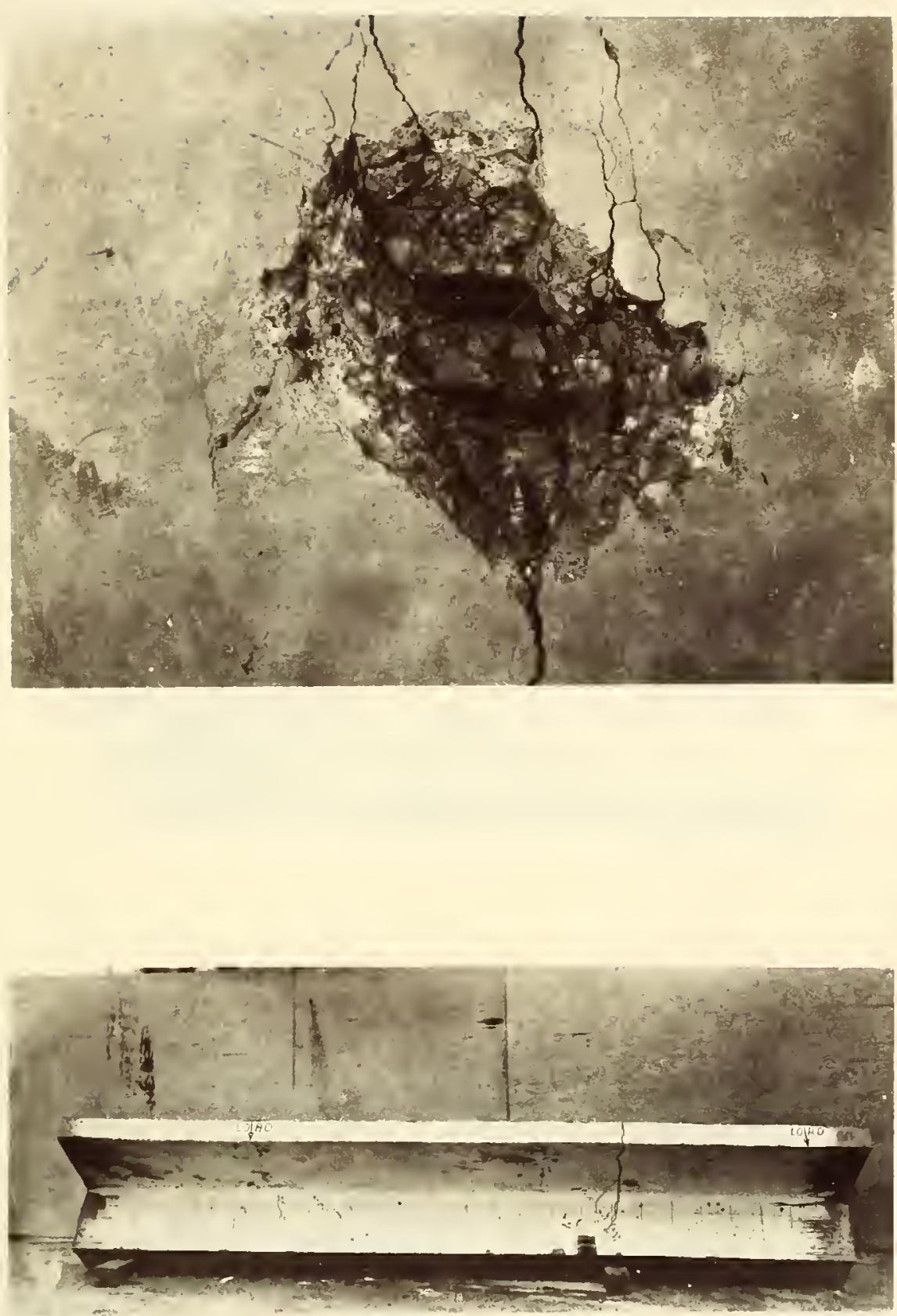

FIGURE 12. BEAM AFTER TEST - II P-5 

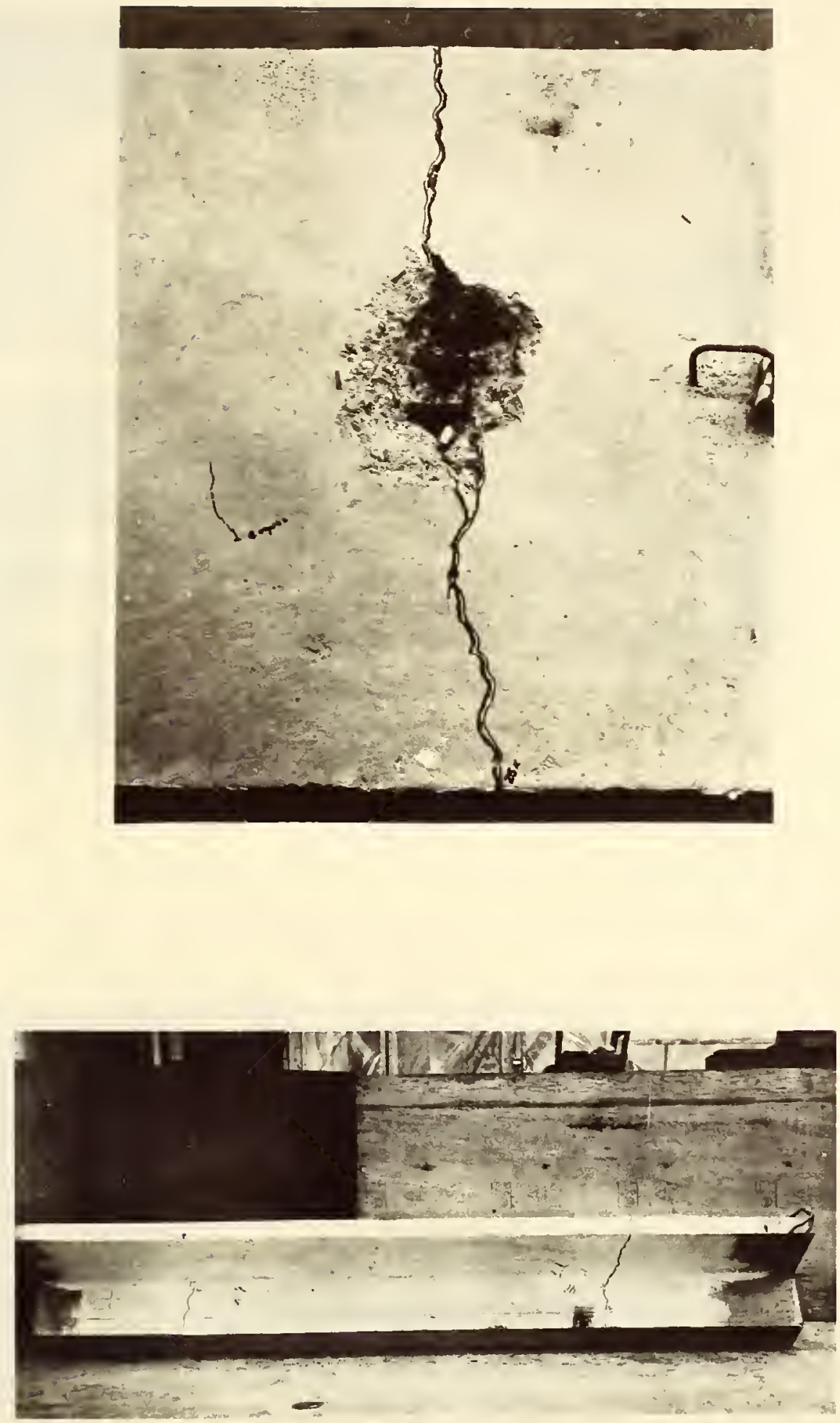

FIGURE 13. BEAM AFTER TEST - III P-I 

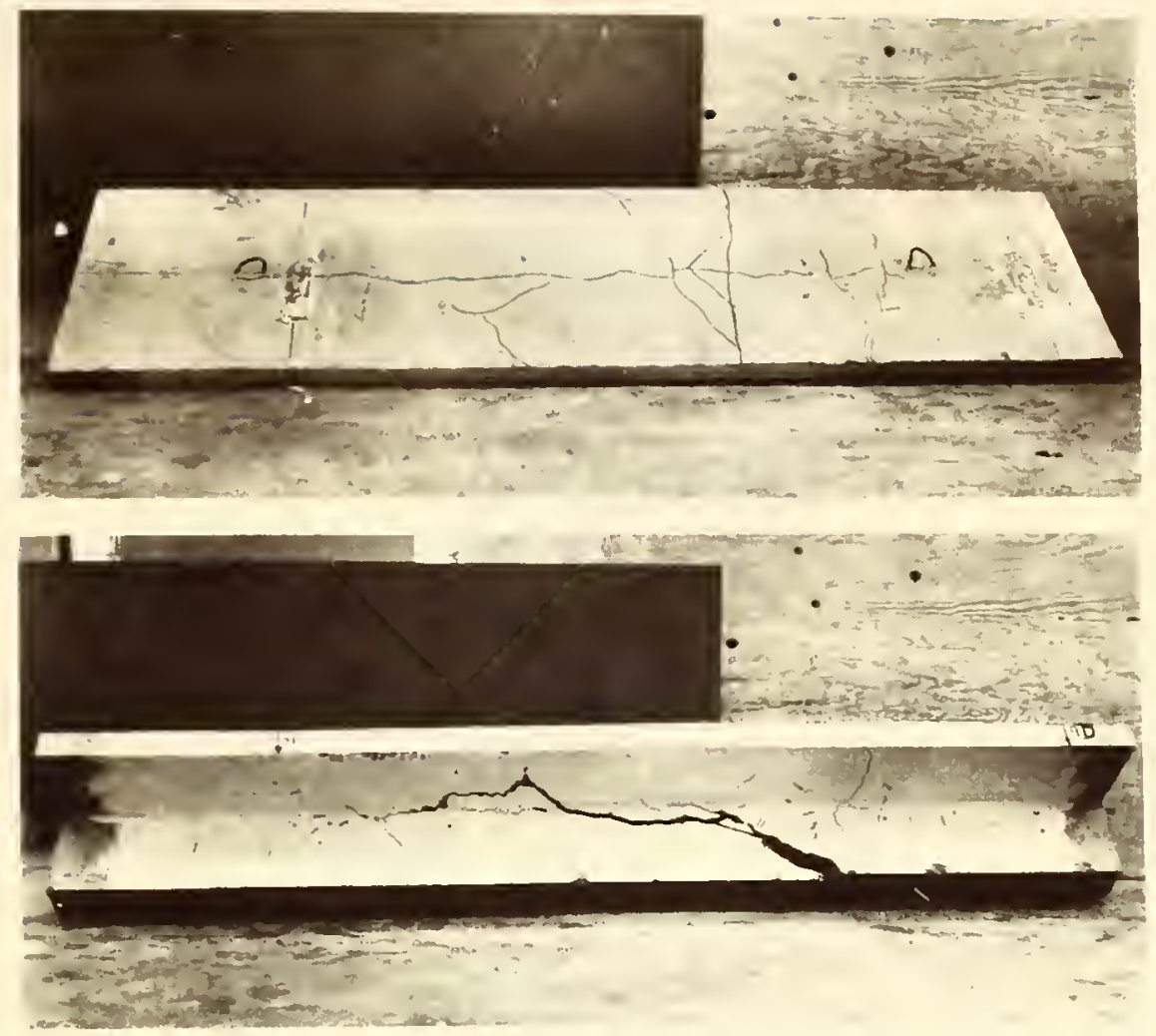

III $P-2$

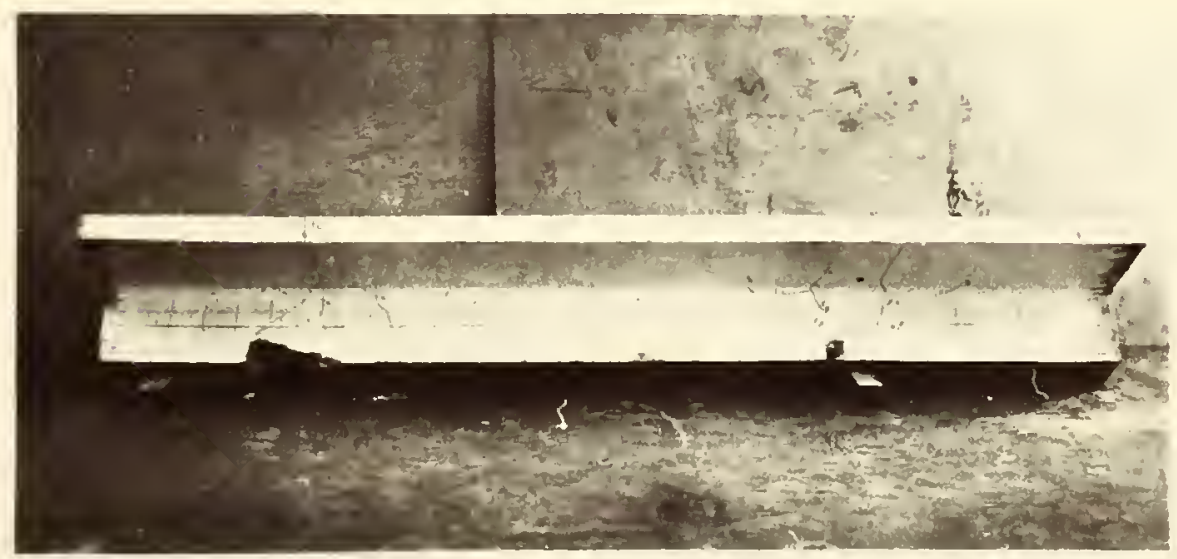

III $P-4$

FIGURE 14. BEAMS AFTER TEST - III $P-2$, III $P-4$ 

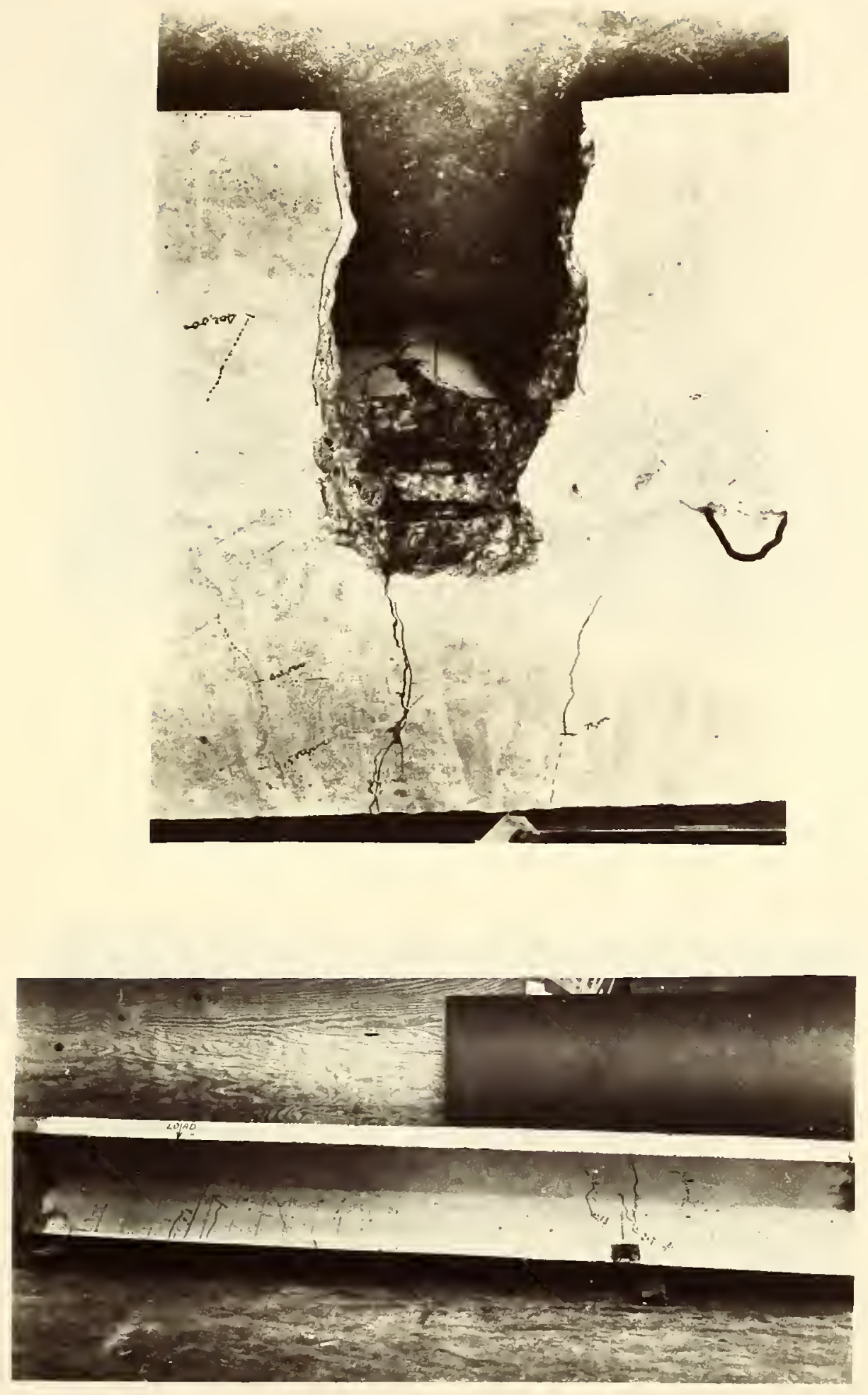

FIGURE 15. BEAM AFTER TEST - III P-3 

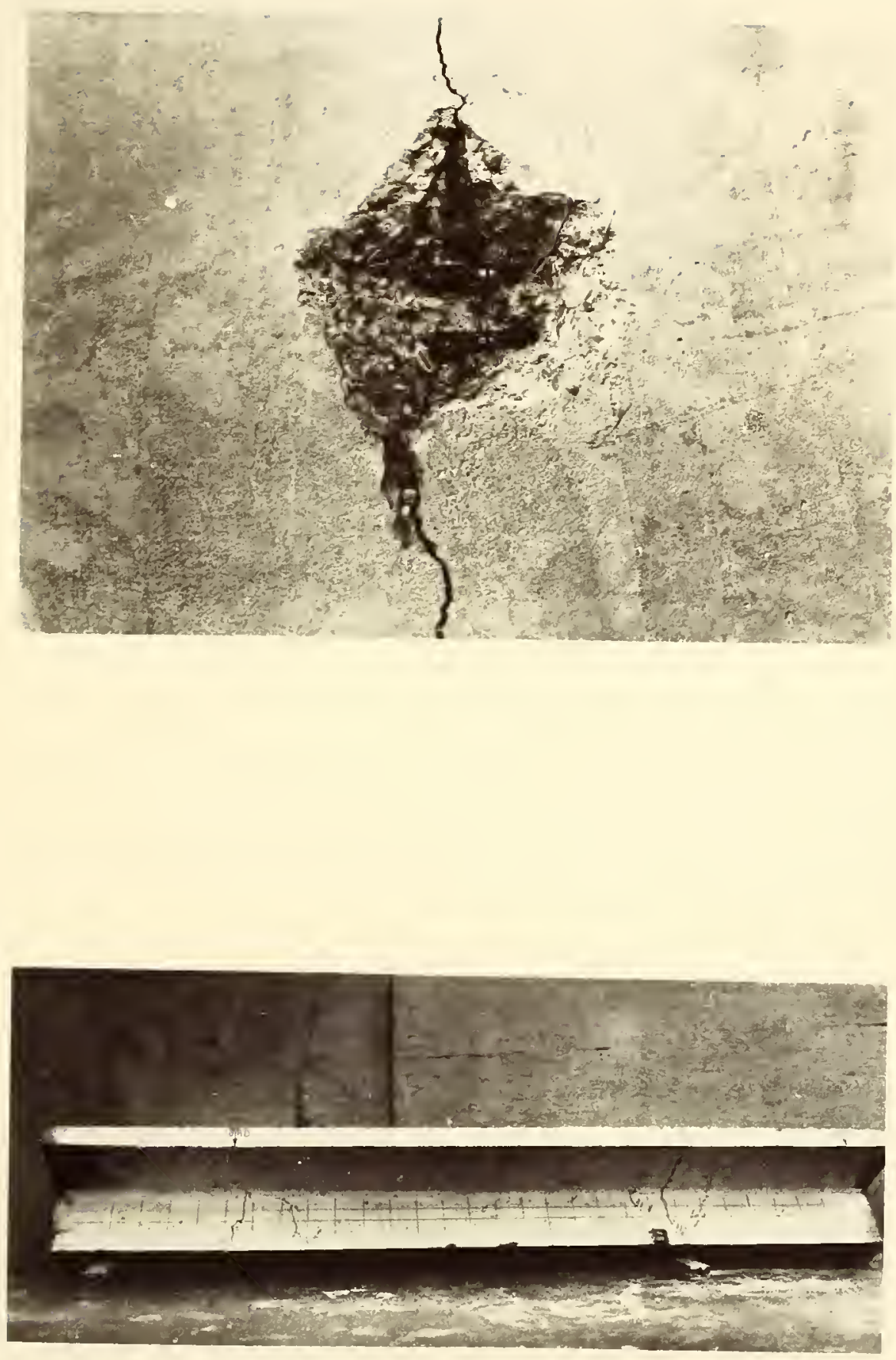

FIGURE 16. BEAM AFTER TEST - III P - 5 

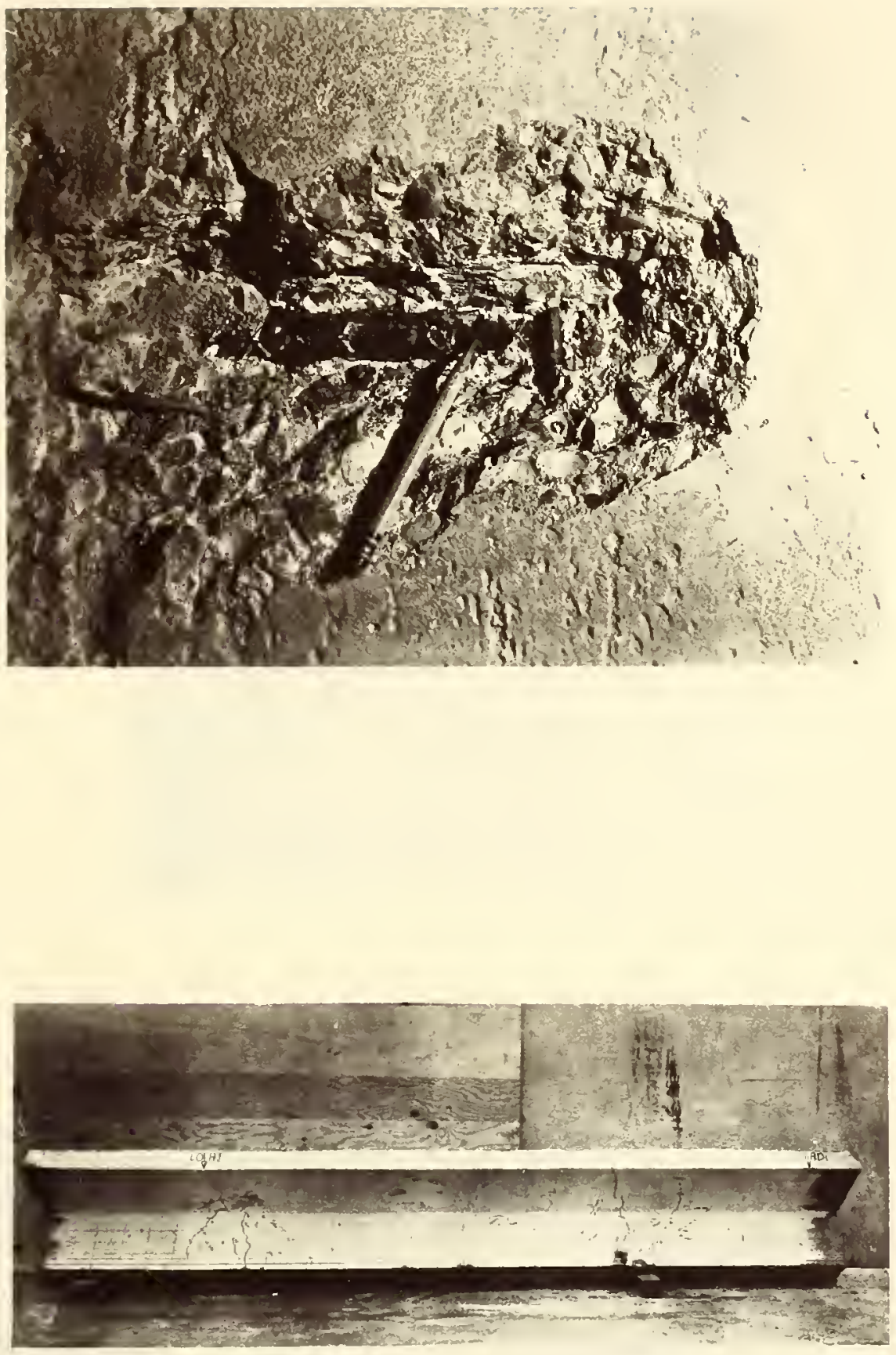

FIGURE 17. BEAM AFTER TEST - III $P-6$ 

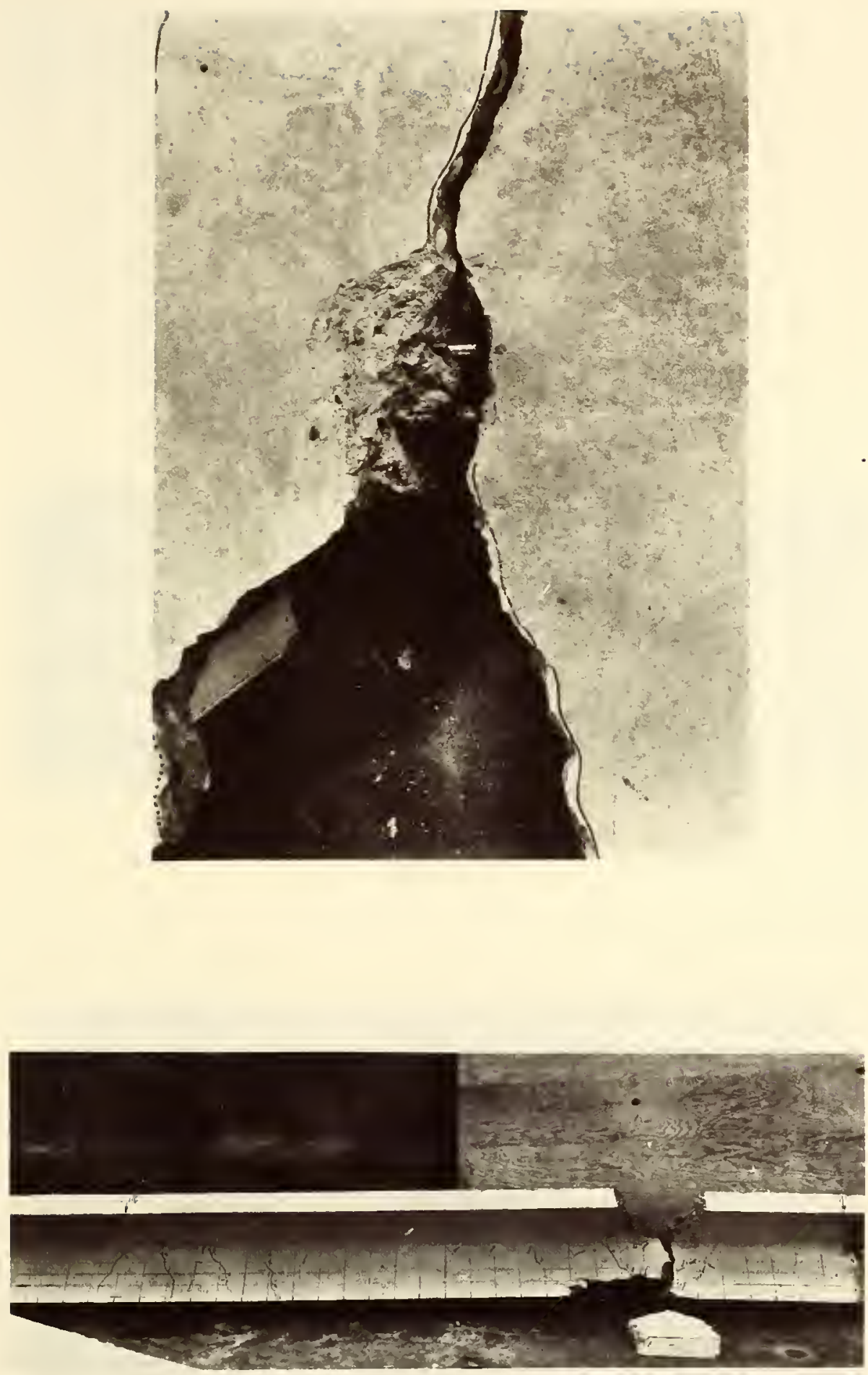

FIGURE 18. BEAM AFTER TEST - IVP-I 


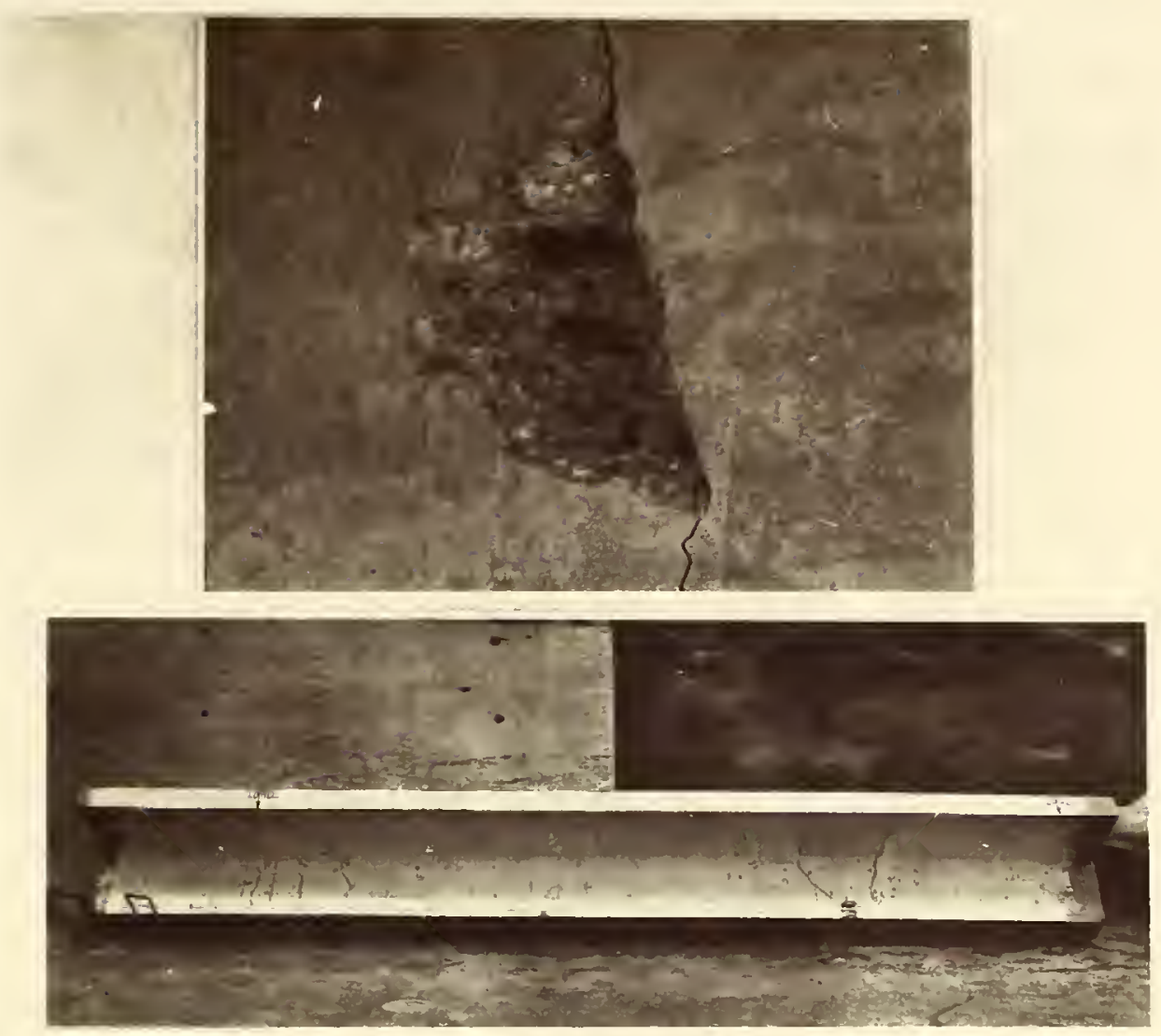

IV $P-2$

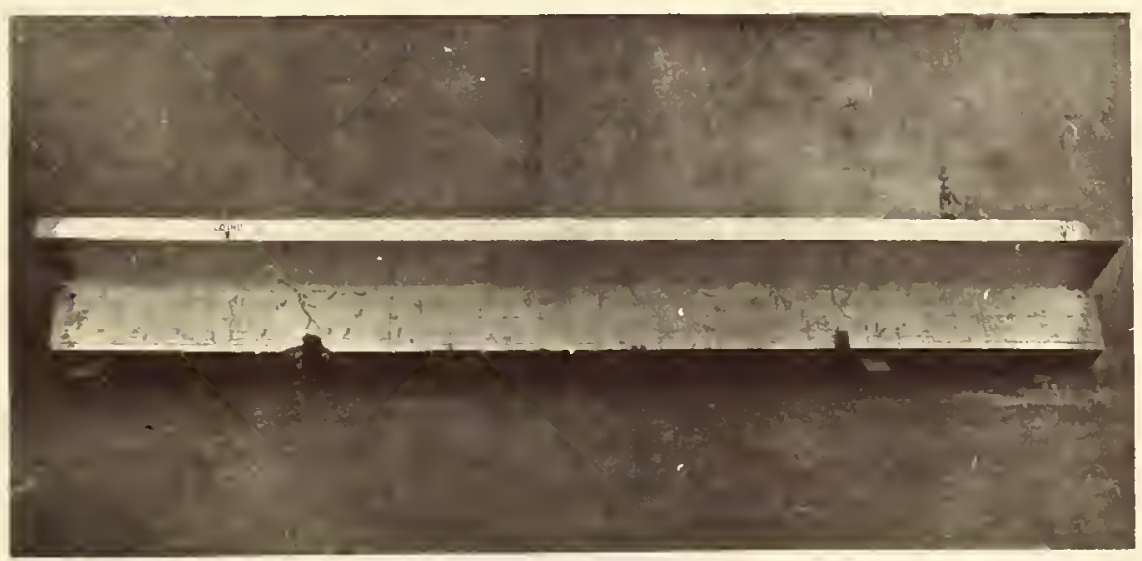

IV $P-3$

FIGURE 19 BEAMS AFTER TEST - IV $P-2$, IV $P-3$ 
moment area, the furthest from the support being 8 inches out on the overhang and 20 inches into the shear span. All of the cracks were inclined toward the support. The crack furthest out on the overhang extended to within 3 inches of the compression race. Two cracks also formed in the positive moment area" and stopped 6 inches from the compression face.

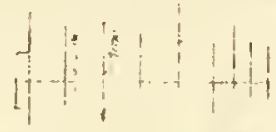

The repeated load was applied for 160,000 cycles before the pulsator shut itself off. Up to this point the temperature of the longitudinal reinforcement had remained nearly constant. The pulsator was tumed on and allowed to run until 408,000 cycles. A slight variation in temperature was detected but was found only to follow the temperature of the room. The maximun value of the repeated load was therefore raised to $70 \%$ of the ultimate laad and the specimen was stressed for an additional 200,000 cycles. Again, no temperature increase was observed and the dynamic load was removed. The load was then increased statically to produce failure. At a load of $55 \mathrm{kips}$ a diagonal tension failure occurred with the sudden opening of a diagonal crack runing from the support to a point 28 inches inside the shear span and then splitting along the longitudinal reinforcement all the

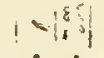

way to the interior load point.

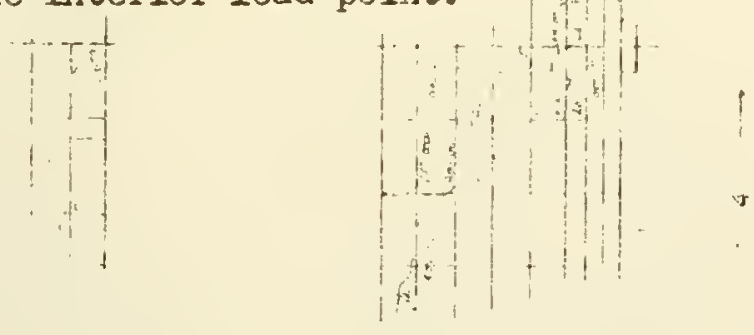



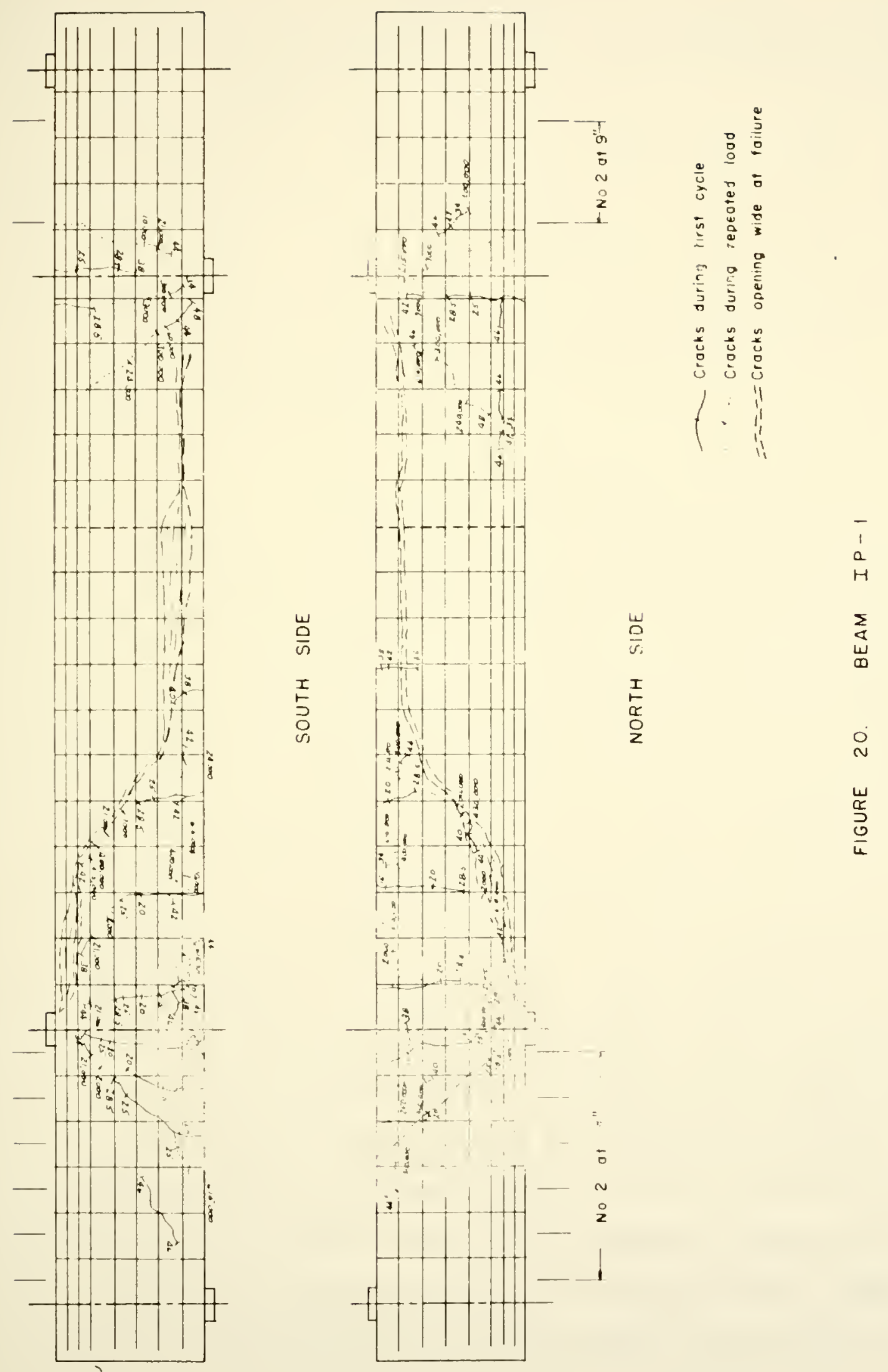


\section{Series II P}

The specimens of this series had a shear span-to-depth ratio of 2.88. They are companion to the beams of series II BF in Rogers (19) report and identical to beam II T-I in Wehr's (26) report. The \#6 reinforcing bars used in beams II P-1, II P-2 and II P-3 had a yield stress and ultimate strength of 72,000 psi and 113,000 psi respectively, while the \#6 bars used in II P-4, and II P-5 and all the beams of the other series had a yield stress and ultimate strength of 96,000 psi and 158,000 psi respectively.

\section{Beam II P-I (52\% VItimate)}

No flexural cracks appeared until a load of $30 \mathrm{kps}$. At this load a crack opened in the negative moment area approximately 3 inches in the snear span and extended from the top of the flange to within 4 inches of the compression face. At the same time, a flexural crack formed in the web at the section of maximum positive moment. The load was increased to 31 kips with no additional cracking, after which the repeated load was applied. A diagonal crack formed in the overhang portion 8 inches from the support by 96,000 cycles and anotier one 10 inches inside the shear span at 325,000 cycles. Both cracks began at the chamfer botween the web and the flange, and ran through the web toward the support in one direction and extended partially into the flange in the other. This progression was typical of all diagonal cracks to follow. Splitting along the chamfer also began at this time and connected the three cracks. The original crack had the largest opening and now extended to within 2 inches of the compression surface. There was no indication of imminent failure after $3,000,000$ cycles. Therefore, the repeated load was removed and the static load increased. At 
a load of 65 kips the diagonal crack, which had previously been formed inside the shear span, extended nearly the full length of the shear span splitting the beam from the support to the chamfer, then along the chamfer and up through the flange at the interior load point.

\section{Beam II P-2 (53\% Ultimate)}

This specimen was identical to Beam II P-I except for its concrete strength being 2000 psi less. The crack pattern was also almost identical. The first flexural crack formed at the same location at a load of $24 \mathrm{kips}$ and extended to with 4 inches of the compression face as the load was increased to $27 \mathrm{kips}$. The diagonal crack in the overhang 21 so opened at this load but did not penetrate the flange. After approximately I,000,000 cycles, a diagonal crack appeared in the shear span 8 inches from the support and extended from slightly through the flange to within 3 inches of the compression face. The other diagonal crack now also entered the flange. The test was allowed to run for nearly $5,000,000$ cycles with no appreciable change in the existing cracks. The specimen was then loaded stat1cally and failed by shearcompression at a load of $60 \mathrm{kips}$. The failure crack began 4 inches from the support, ran diagonally the full length of the shear span, along the chamfer and through the flange at the interior load point.

At the time of failure, the concrete compresslve strength had increased by $1000 \mathrm{psi}$. The ultimate load of the specimen for this concrete strength predicted by the equation of Moody was 56.5 kips, while the actual specimen failed at 60 kips. Therefore, for T-beams, it seems justifiable to express the maximum value of the repeated load as a percentage of the ultimate load predicted by Moody's equation only, as discussed previously. 


\section{Beam II P-3 (64\% intimate)}

After the first cycle of loading, a flexural crack had opened 4 inches from the support inside the shear span and extended to within 3 inches of the compression face. The repeated load produced a diagonal tension crack in the overhang at 25,000 cycles. By $1,500,000$ cycles, a small diagonal crack had formed 22 inches in the shear span on the south side and 12 inches in the span on the north side. Both cracks were only 3 or 4 inches long and terminated in the chamfer. The original flexural crack had penetrated to within 2 inches of the compression face and remained there until failure of the longitudinal reinforcement at $2,900,000$ cycles.

The concrete was stripped back to reveal the fractured bars. Both bars had failed at, or very close to, the intersection of two lugs, and one to two inches inside the shear span. It was impossible to determine which bar had fractured first.

\section{Beam II P-4 (73\% Ultimate)}

The first flexural crack opened at a load of 29 kips, 2 inches inside the shear span, and ran vertically to within 4 inches of the compression face. After the first cycle, at $43 \mathrm{kips}$, this crack had reached a point $2 \frac{1}{2}$ inches from the bottom and a diagonal crack had formed at the chamfer 6 inches inside the shear span. 50,000 cycles of loading produced a crack in the overhang 4 or 5 inches from the support. After 1,123,000 cycles, at which time failure of the longitudinal reinforcement occurred, this crack opened wide in the flange on the south side of the specimen. The original flexural crack also opened wide at failure. The reinforcing bars failed at a section 2 or 
3 inches into the overhang. The crack in the north side bar began at the intersection of two lugs at the top surface, while in the south side bar it began at the intersection of the lugs and the Iongitudinal rib. Strain readings indicate that the north side bar had failed some: where between 870,000 and $1,068,000$ cycles, after which the entire load was taken by the south side bar until its failure.

\section{Beam II P-5 (64: UItimate)}

A flexural crack formed at a load of 30 kips directly over the support and extended to within 4 inches of the compression face. At the end of the first cycle, (maximu load 38 kips), it was three inches from the compression face. The repeated load was then applied and 8,000 cycles caused two diagonal cracks to open in the shear span on the north side of the beam. The shorter one was 4 inches from the support and the longer one, which stopped 4 inches above the bottom of the specimen, was 10 inches from the support. The latter crack also opened on the south side of the specimen at the same time, along with an extension of the original flexural crack 2 inches from the support into the overhang.

After $4,000,000$ cycles of loading, there was very little change in the crack pattem. Steel and concrete strains also remained constant and low. At 4,105,000 cycles the north side 16 reinforcing bar failed very close to the section of maximum moment. Inspection of the bar after failure revealed that the crack had originated at a point where the defomation lugs merged with the longitudinal rib. The south side bar later failed at 4,292,000 cycles. 


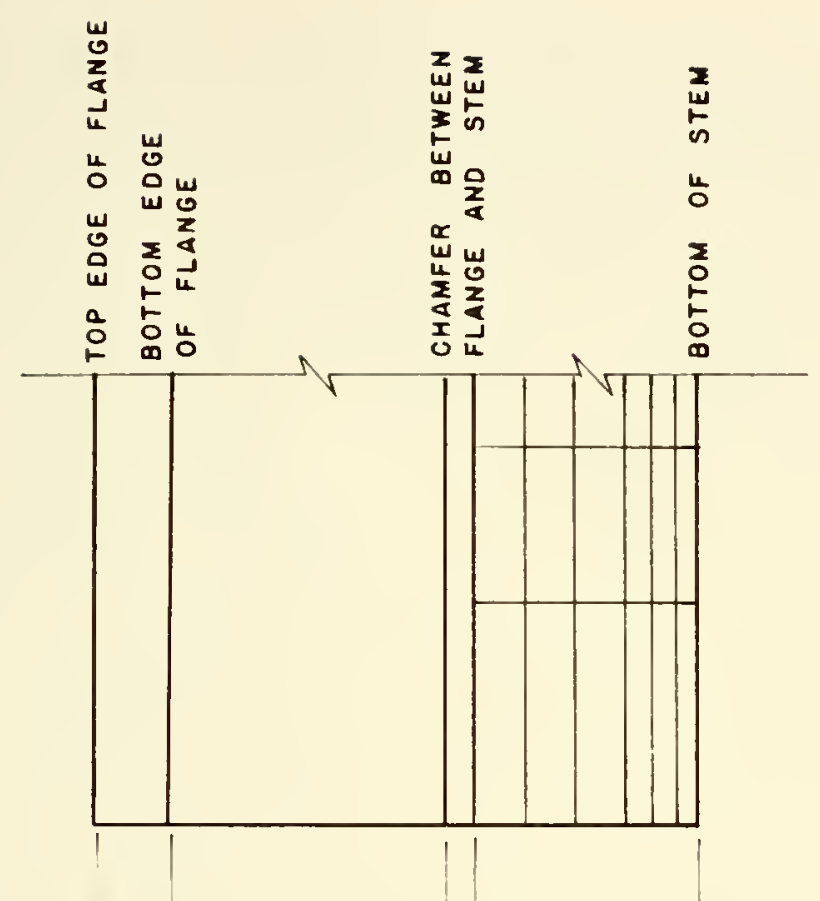

芘

荘

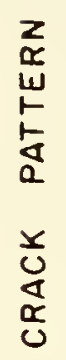

蛋

U⿺⿻一⿰冫⿰亅⿱丿丶丶⿱⿰㇒一乂

z

$\frac{\sum^{u}}{0}$

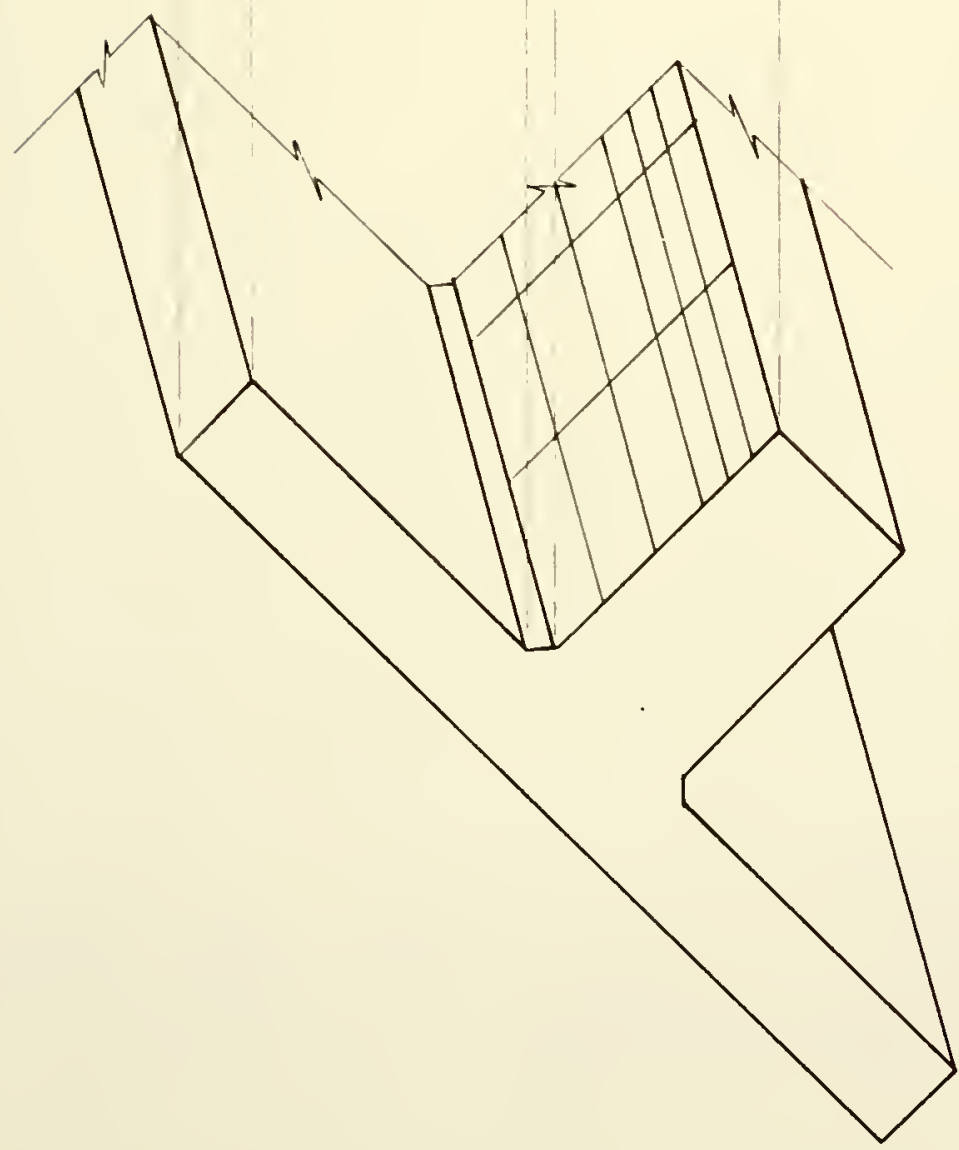

능

z

$z$
$\frac{w}{2}$
$u$
$a$
$a$

$\frac{1}{5}$
$\frac{1}{0}$
$\frac{1}{2}$
$\frac{0}{2}$

$\dot{N}$

$w$
$\frac{\pi}{\partial}$
$\frac{0}{4}$ 


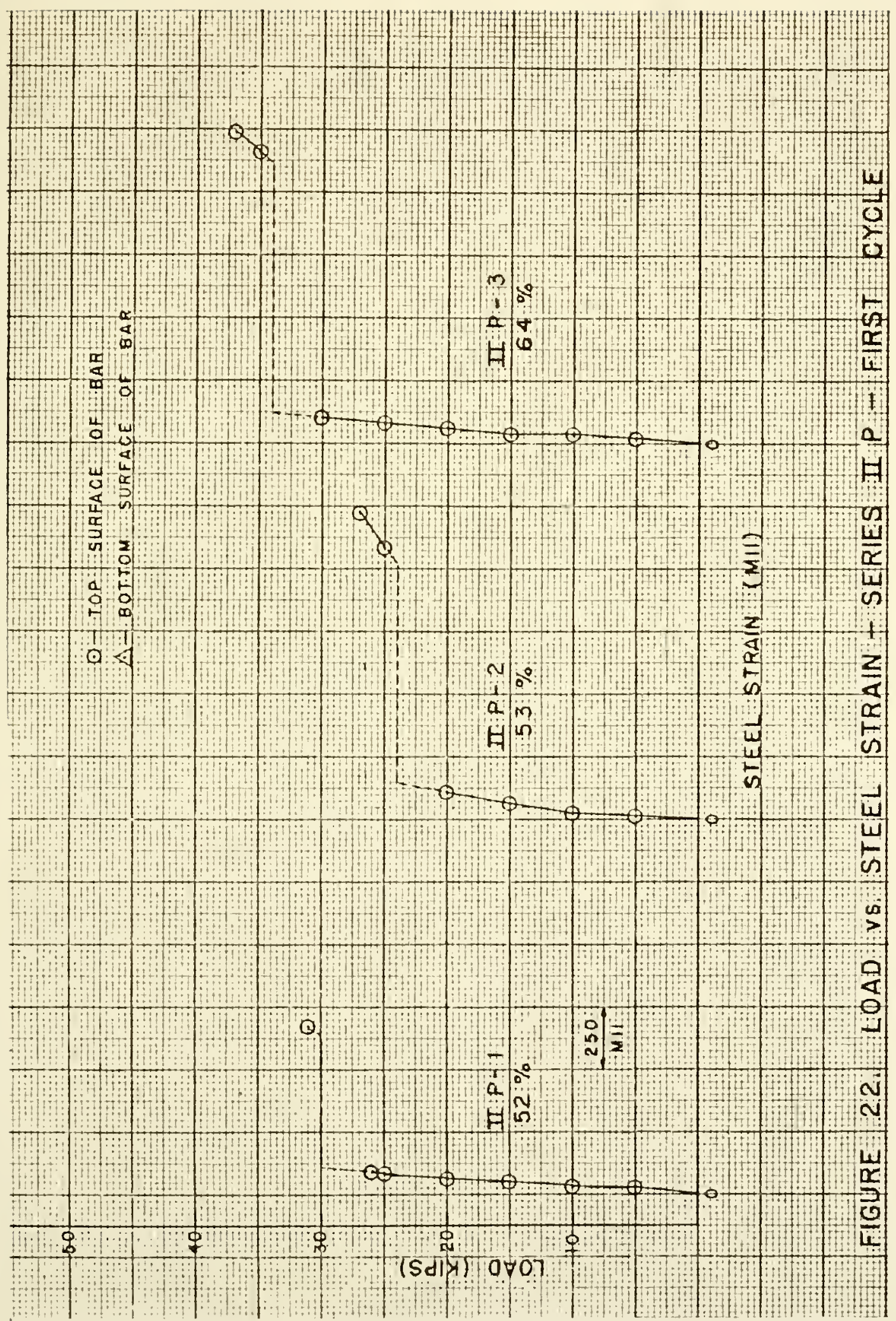




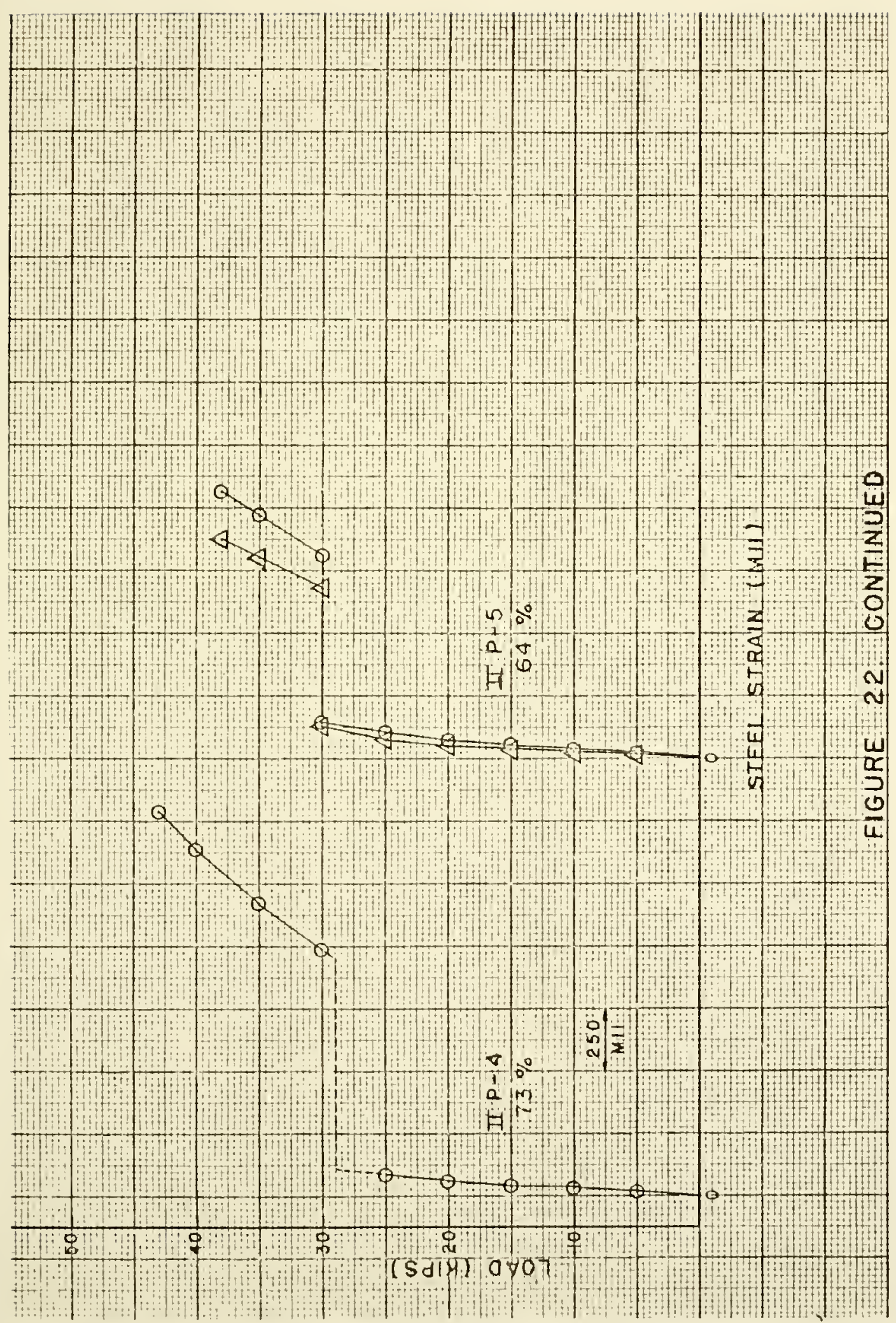




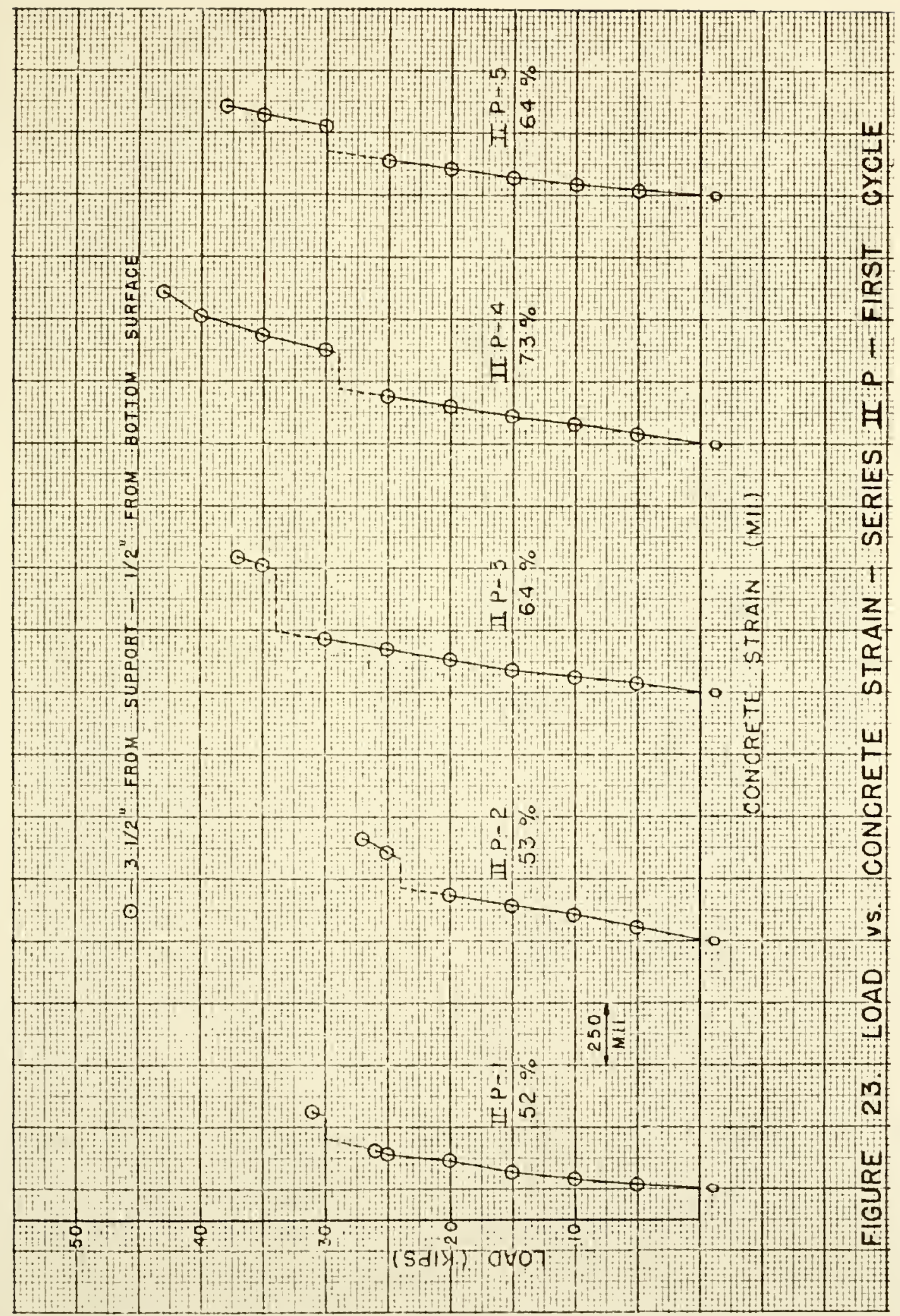



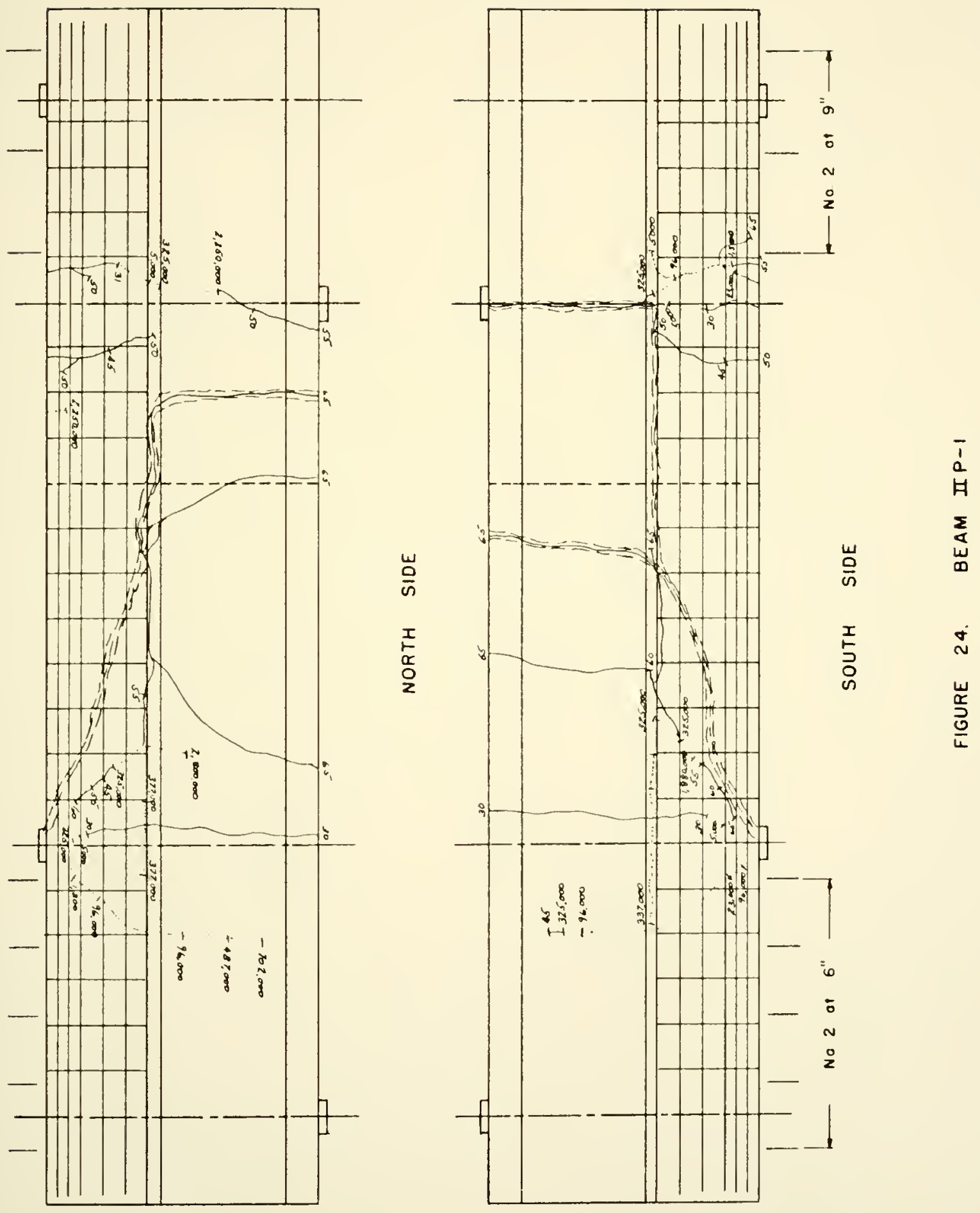

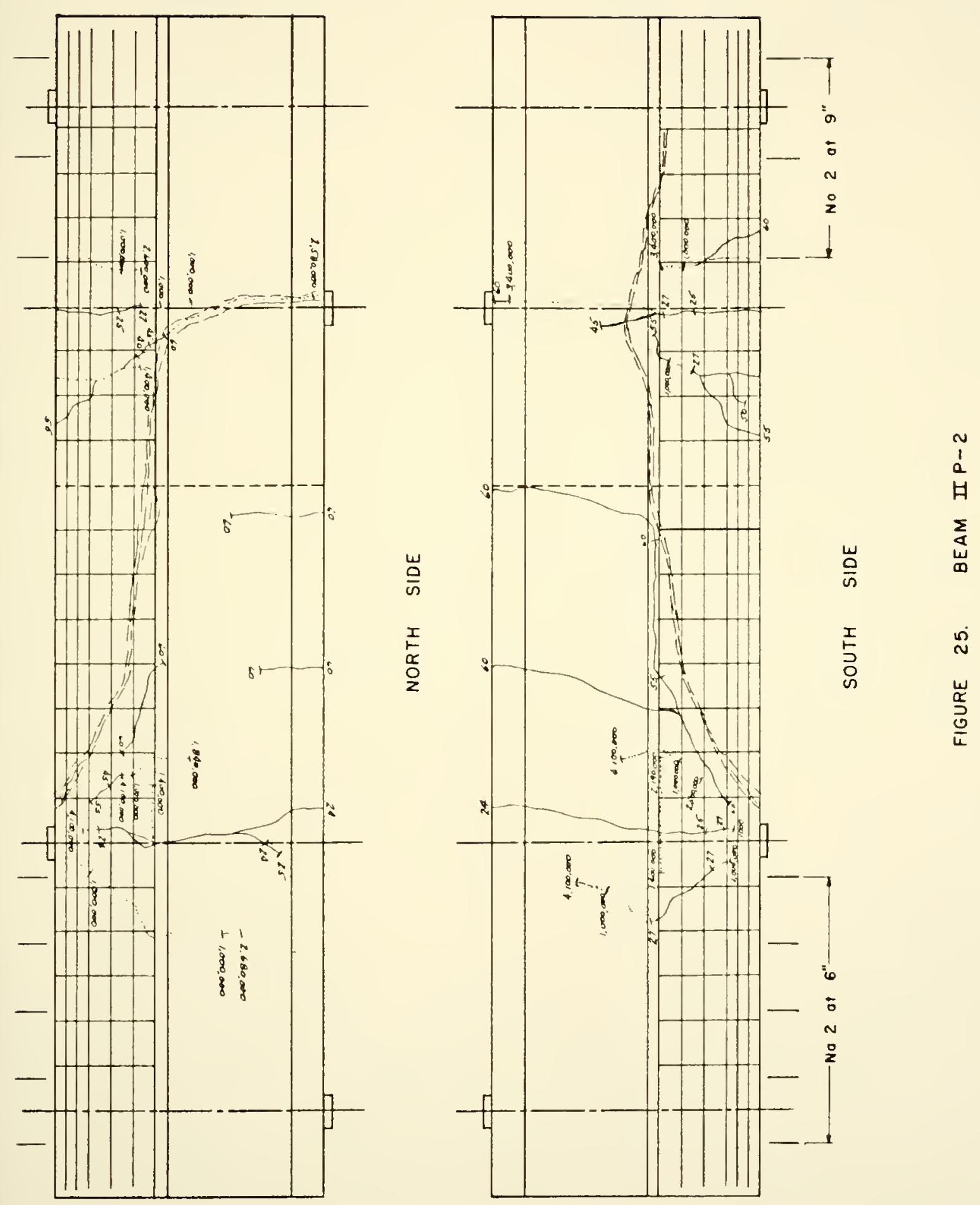

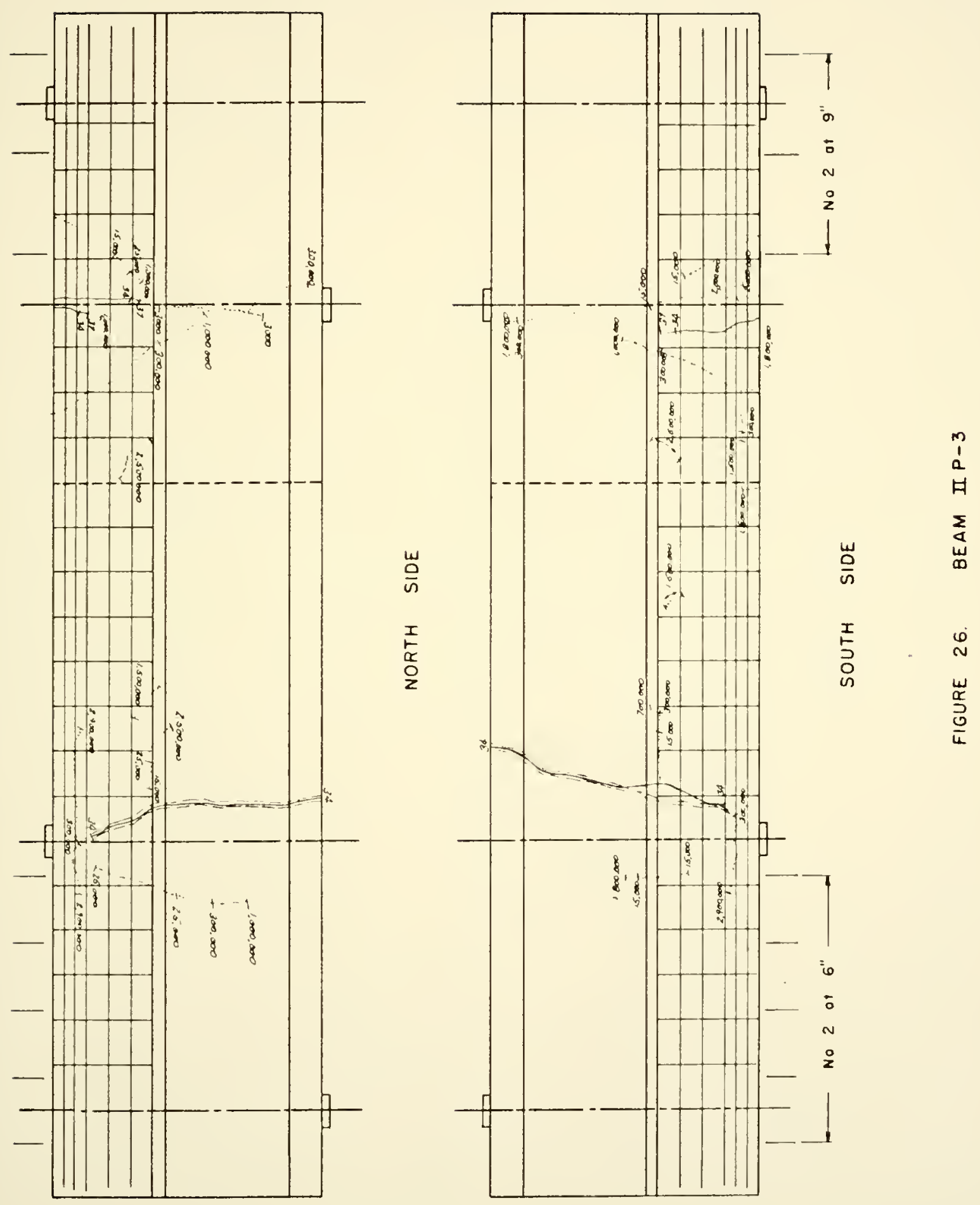

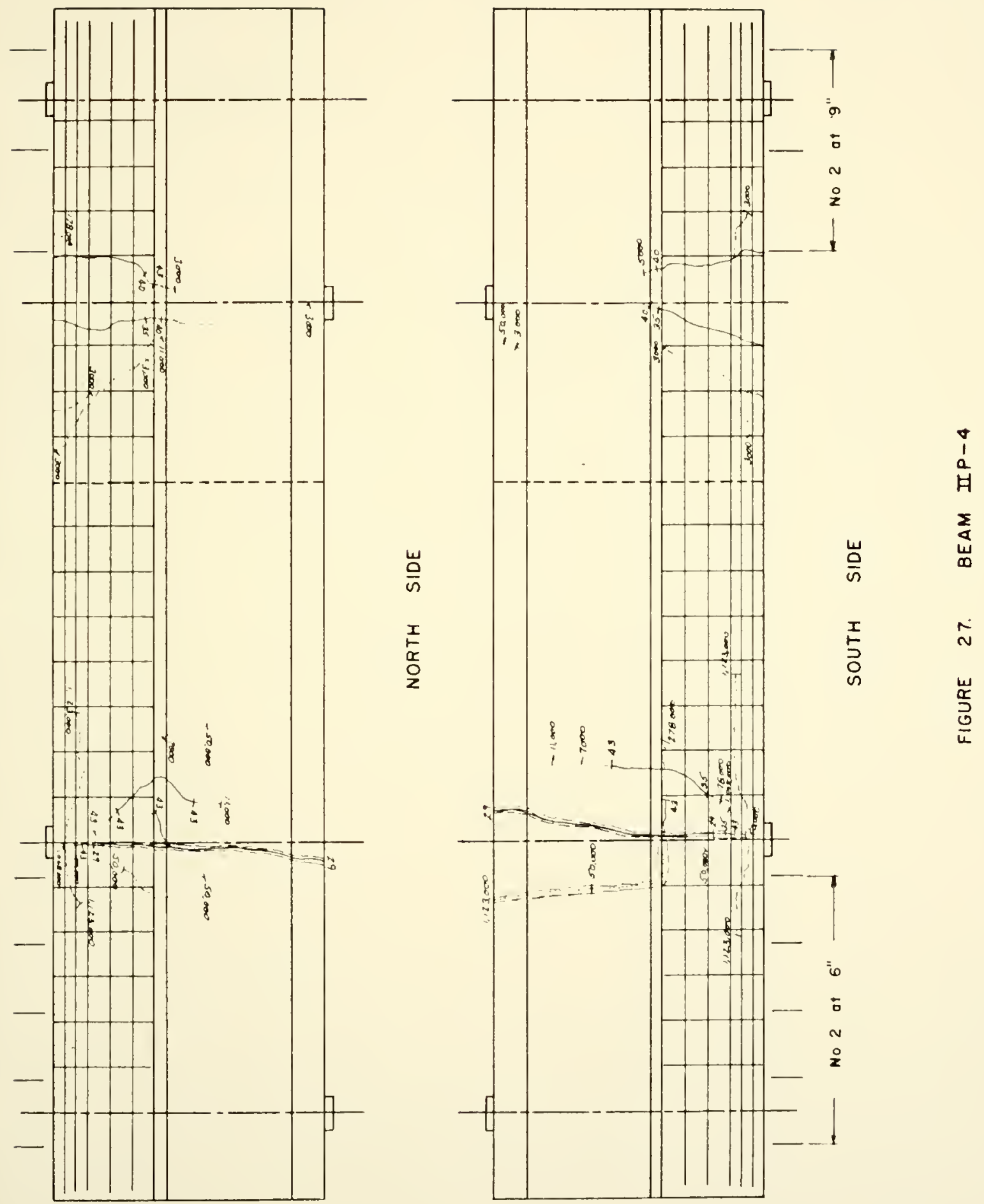

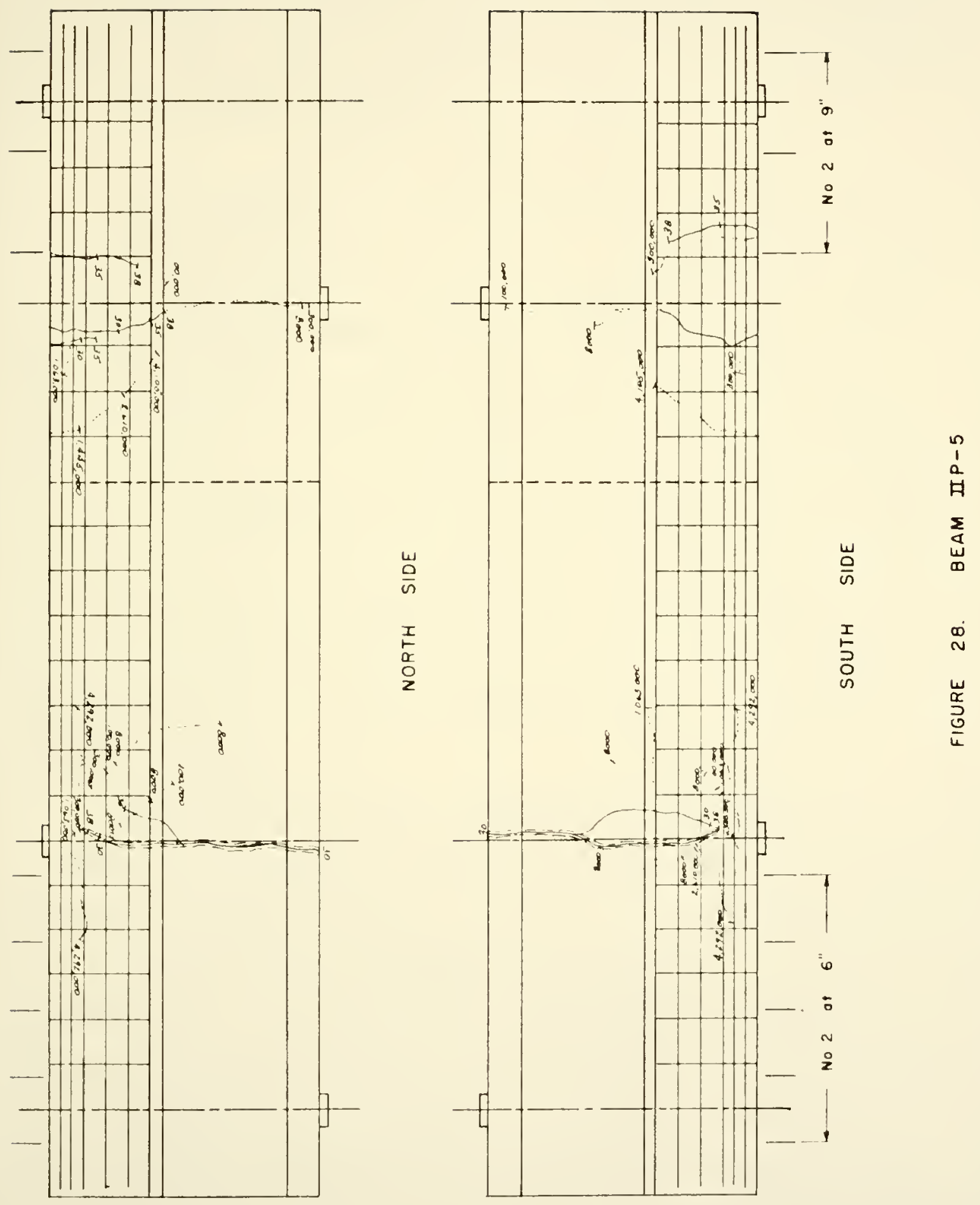


\section{Series III P}

The specimens of this series had a shear span-to-depth ratio of 3.95. They are similar to the beams of series III BF in Rogers' (19) report and to beam III T-I in Whar's ${ }^{(26)}$ report.

\section{Beam III P-I (52\% UItimate)}

A Ioad of 25 kips produced a flexural crack directly over the support extending to within 4 inches of the compression face. A similar crack opened under the interfor load and terminated in the chamfer. Neither crack lengthened during the remainder of the first cycle. By 300,000 cycles the crack in the negative moment region had penetrated to within 2 inches of the compression face. A small diagonal tension crack opened on both sides of the beam at 400,000 cycles. It appeared in the shear span 8 inches from the support on the south side and 6 inches from the support on the north. The north side crack lengthened slightly after 3,000,000 cycles while the crack on the south side remained unchanged.

During the early stages of repeated loading, strain gages attached to the longitudinal reinforcement showed both bars to have nearly equal static components of strain, but the south side bar to have a much higher dynamic component. Both gages were lost after 771,000 cycles. At $3,005,000$ cycles, concrete strains slightly decreased on the south side of the specimen and sharply increased on the north side indicating that the south side bar had fractured. At 3,117,,00 cycles, the north side bar also failed. Both bars failed at sections in the overhang; the north side bar I inch from the support and the south side bar 2 inches from the support. 
Beam III P-2 (60\% Untimate)

As in the previous specimen, the flexural crack formed directly over the support. Mis occurred at 28 kips and after the first cycle had beem completed, total load 32 kips, the crack was 4 inches from the bottom surface. After 10,000 cycles, diagonal tension cracks had opened at points 6 inches on either side of the support and the chamfer had split between them. Another diagonal crack formed 12 inches inside the shear span at 346,000 cycles and penetrated the flange by 681,000 cycles. At 1, 465,000 cycles, the other two diagonal cracks were halfway through the flange and the flexural crack had extended to within 2 inches of the compression face. 3,369,000 cycles of loading produced no additional cracking. Therefore, the repeated load was ramoved in order to fail the specimen statically. The static load was increased to 55 hips before further cracking was observed in the negative moment area. At a load of 60 kips, concrete strain gages indicated a cormressive stress of approximately 4000 psi at positions 部 inch and $I$ inch above the bottom surface and increasing rapidly. Concrete gages at all locations were lost simulaneously after that reading. A shear-compression failure occurred at a load of 74 kips. The crack pattern at failure was almost identical to that of beam III T-I in Harvey's report. Prior to failure, the diagonal cracks inside the shear span had not penetrated the neutral axis and gage readings indicated high compressive stresses at least as far as 2 inches above the bottom surface. At failure, the web spalled badly along a diagonal line from the support to a point 12 inches inside the shear span. The chamfer then split open from that point to the 
interior load, with the flange cracling at three other points in between.

\section{Beam III P-3 (71\% tntimate)}

At a load of 30 kips, the flange cracked 4 inches inside the shear span. After passing through the flange, the crack inclined toward the support and stopped $2^{2}$ inches from the compression face on the south side and 6 inches from the face on the north side. After the first cycle, with a total load of 39 kips, the south side crack remained unchanged while the north side crack extended to within $3 \frac{2}{2}$ inches of the support. A diagonal tension crack also formed 9 inches from the support in the shear span at the chamfer and extended 3 inches into botil the flange and the web. 5,000 repetitions of load caused a diagonal crack to form 6 inches out on the overhang. The length of all cracks increased slightly with additional loading. At 2,449,000 cycles, the diagonal crack in the overhang had split the flange completeIy and opened wide on the south side due to failure of the longitudinal reinforcenent on that side. The bar was later found to have cracked at a section 2 inches from the support in the overhang. The crack originated at a point on the bar where the lugs merged with the longitudinal rib.

Beam III P-4 (82\% UItinate)

As in the previous specimen, the first flexural crack formed at a load of 30 kips. It was located 4 inches in the overhang, inclined toward the support aficr rassing through the chamer and stopped 3 inches from the compression face. A diagonal tension crack opened at a load of 35 kips at a point 6 inches from the support in 
the shear span. By 45,000 cycles of loading this crack had split the flange completely and extended to within 2 inches of the bottom surface. A parallel crack formed 10 inches into the shear span, at the same time, as well as a diagonal crack 10 inches out on the overhang on the north side. This last crack opened on the south side at the same position with 659,000 cycles.

Steel strain gages indicated high stress, increasing in both \#6 reinforcing bars until the gages were lost sometime after 659,000 cycles. However, at 1,368,000 cycles, there was a fatigue failure of the $\# 5$ reinforcing bars placed at the bottom of the web to resist the positive moment. Repeated loading had caused the flexural crack in the positive moment area to penetrate deeply into the compression flange. At 200,000 cycles it was less than ${ }^{2}$ inch from the extreme fiber on the south side. This excessive penetration may have been the cause of failure even though the positive moment was only half of the negative monent.

\section{Beam III F-5 (6I\% UItimate)}

At a load of $26 \mathrm{kips}$, the tension flange cracked 2 inches from the support in the shear span. The crack extended to within 4 inches of the compression face and did not penetrate and deeper with additional static loading. At the end of the first cycle, 33 kips, a short diagonal crack had opened 8 inches in the shear span at the chamfer. Ey 5,000 cycles this crack had lengthened in both directions and a diagonal crack formed 6 inches from the support in the overhang. After $1,000,000$ cycles, the cracks remained nearly the same except for the original flexural crack which was now only 2 inches from the bottom 
surface. The north side 16 reinforcing bar failed at 2,070,000 cycles and the south side bar followed at 2,084,000 cycles. The section of failure was 2 inches inside the shear span which was the location of the flexural crack. Thermocouples attached to the bars very close to the point of fracture gave no indication of temperature increase.

\section{Beam III P-6 (76\% U1timate)}

A flesural crack formed at a load of 25 kips. The crack appeared in the flange directly over the support on the south side and 6 inches from the support in the shear span on the north side. When the crack reached the chanfer it was 2 inches in the shear span on both sides. Wibth a load of $40 \mathrm{kips}$ it had extended to within 3 inches of the compression face and two diagonal tension cracks had formed. One was in the shear span 10 inches from the support and the other was 5 inches out on the overhang. By 5000 repetitions of loading all cracks had lengthened slightiy and an additional diagonal crack opened in the shear span 15 inches from the support. After 100,000 cycles, extensive splitting along the chamfer was noticed and a small diagonal crack opened 10 inches in the overhang. The flexural crack on the southside and a diagonal tension crack on the north side had penetrated to within $1^{\frac{1}{2}}$ inches of the compression face by this time.

Sometime after 300,000 cycles, the indicated strain on the top surface of the south side 10 reinforcing bar at the location of the strain gage began to decrease in both its static and dynamic components. The strain on the bottom surface, and the strains on both surfaces of the north side bar increased slowly but contimously. A fatigue failure of the south side bar occurred at 947,000 cycles. 


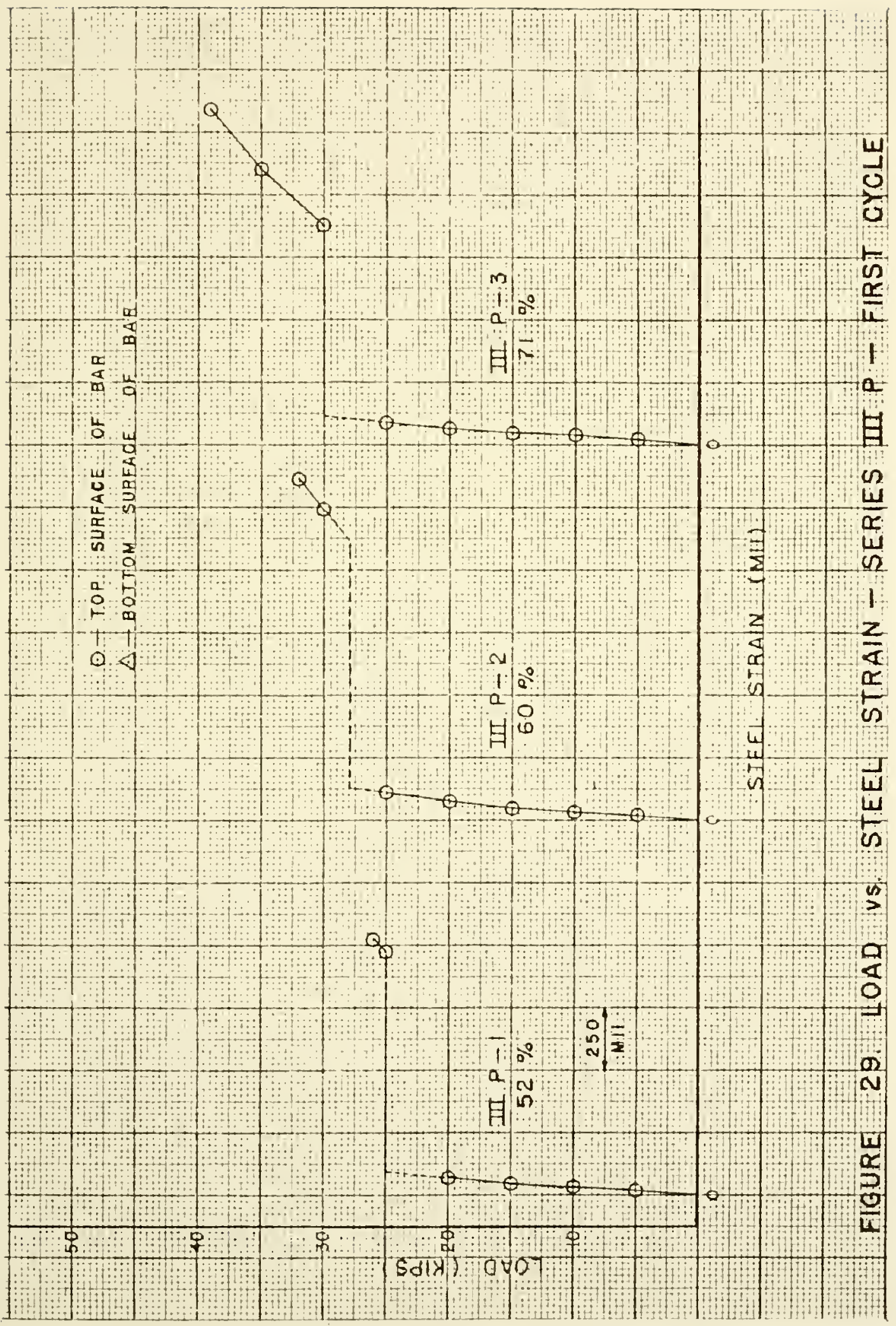




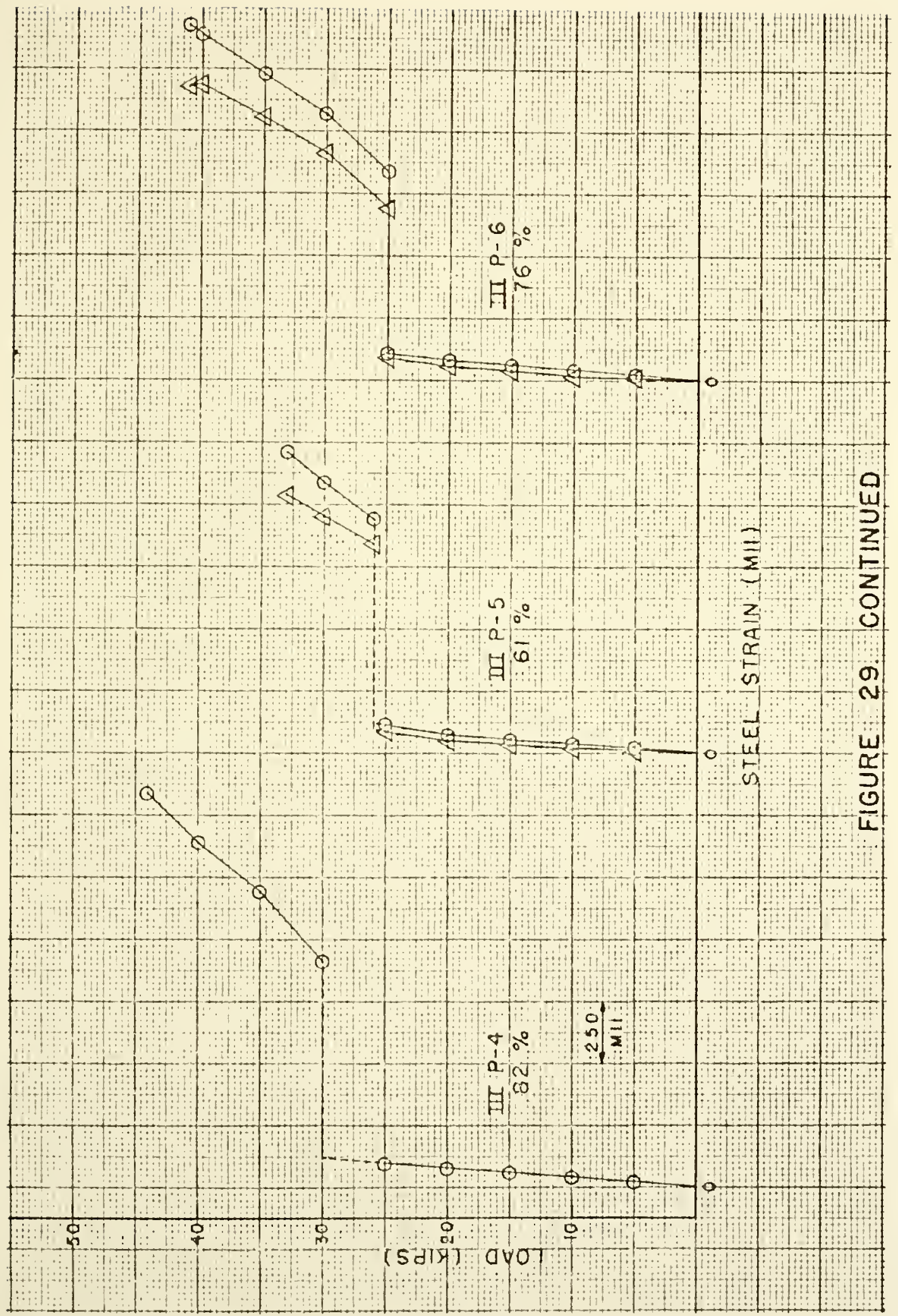




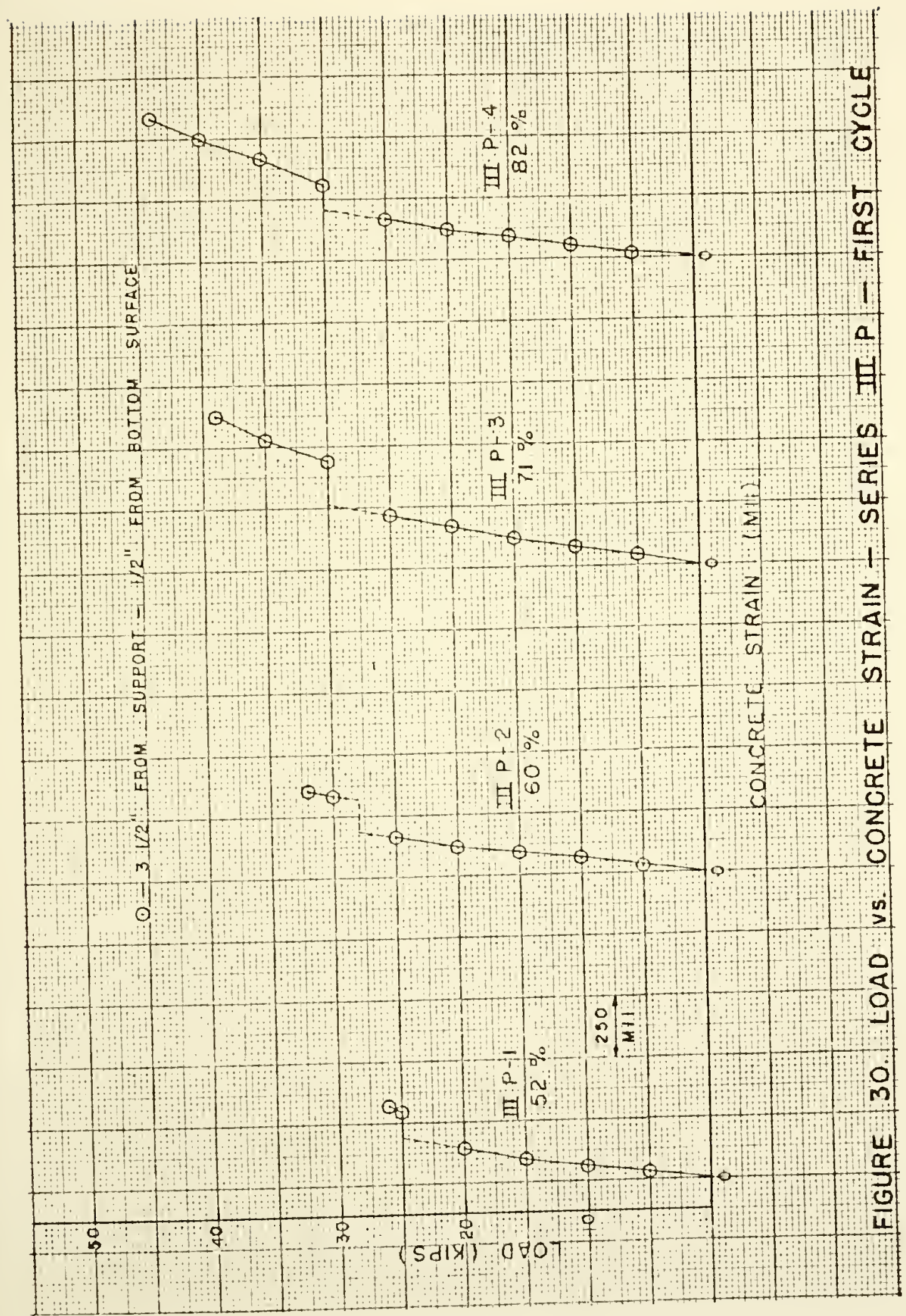




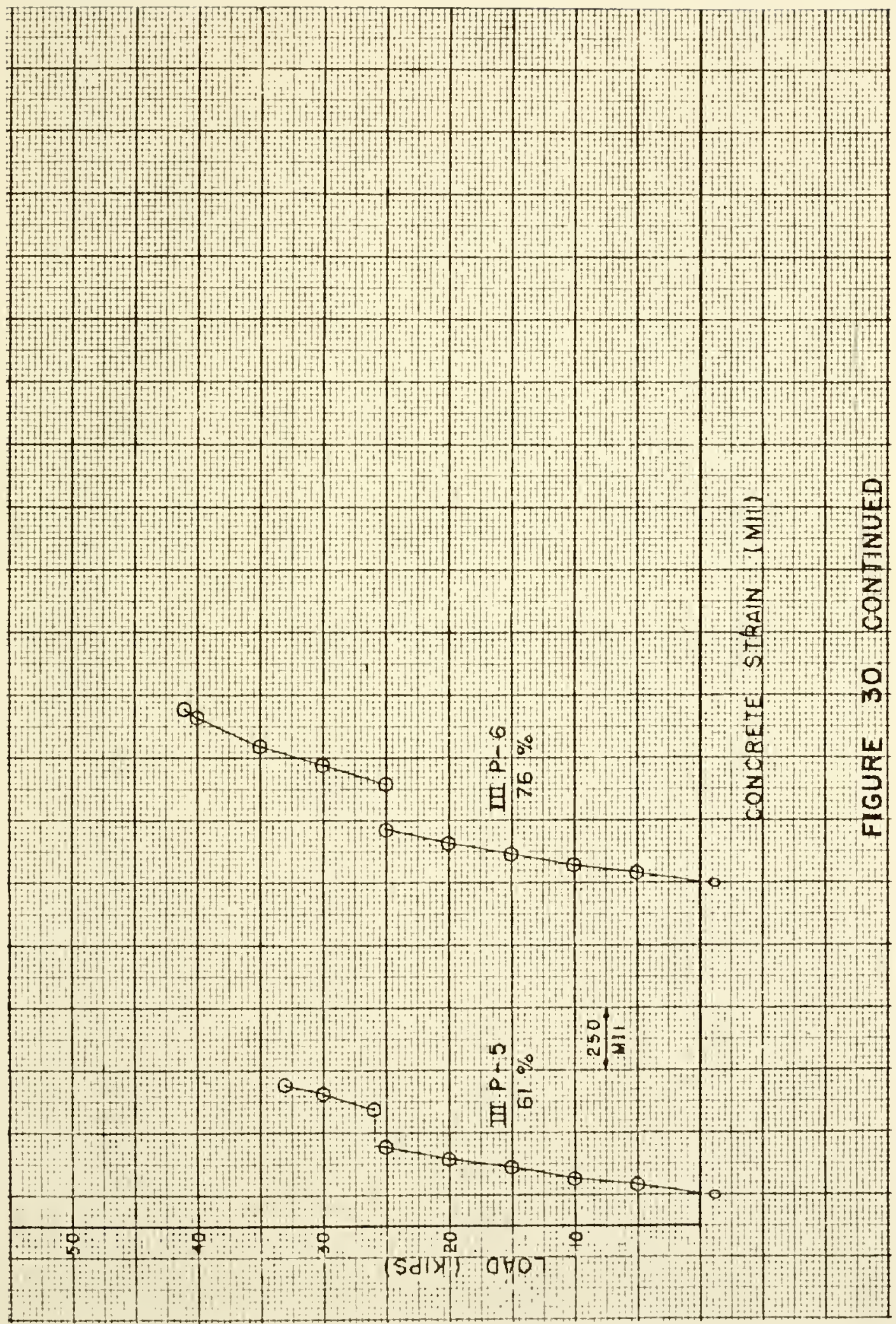



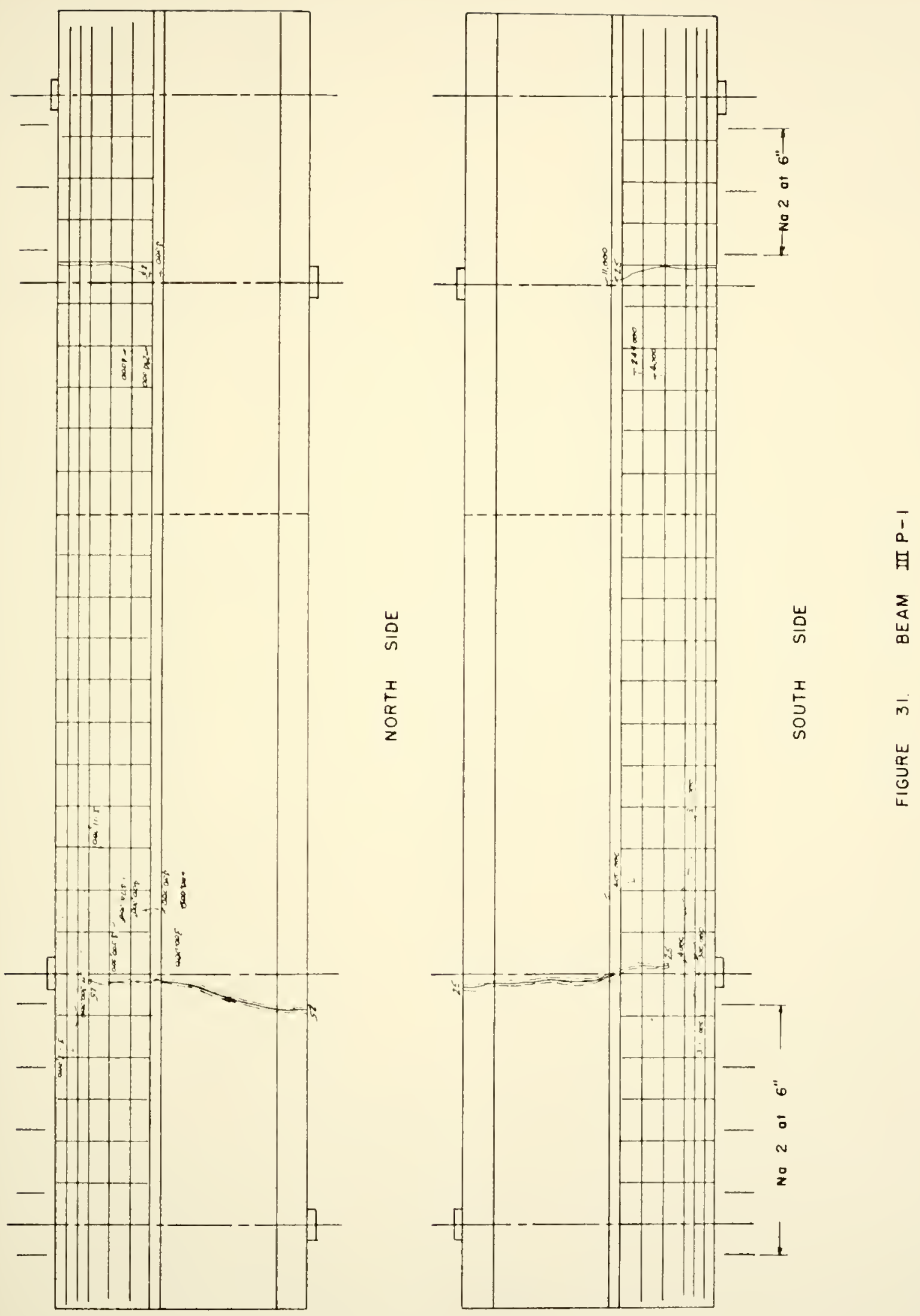

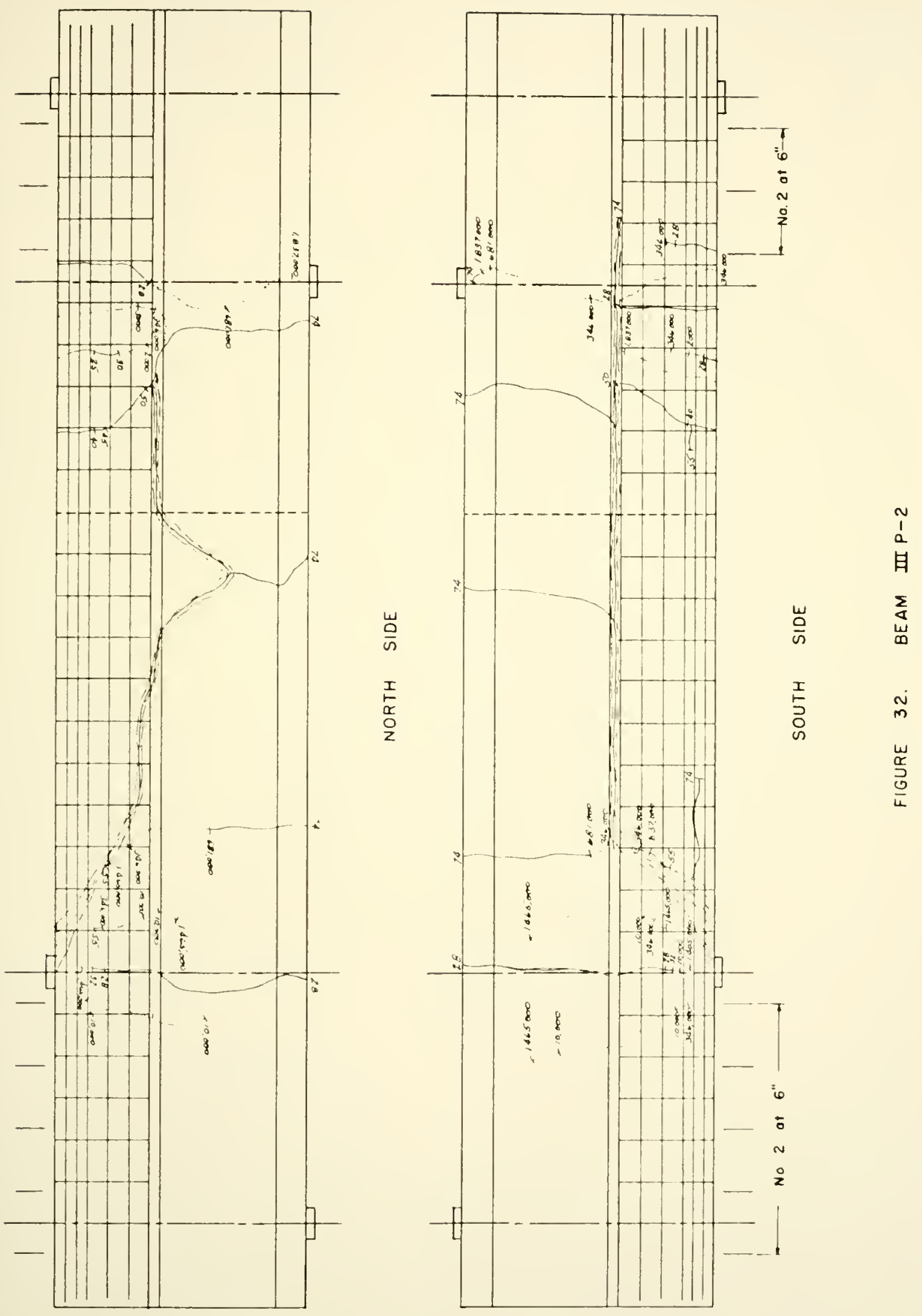

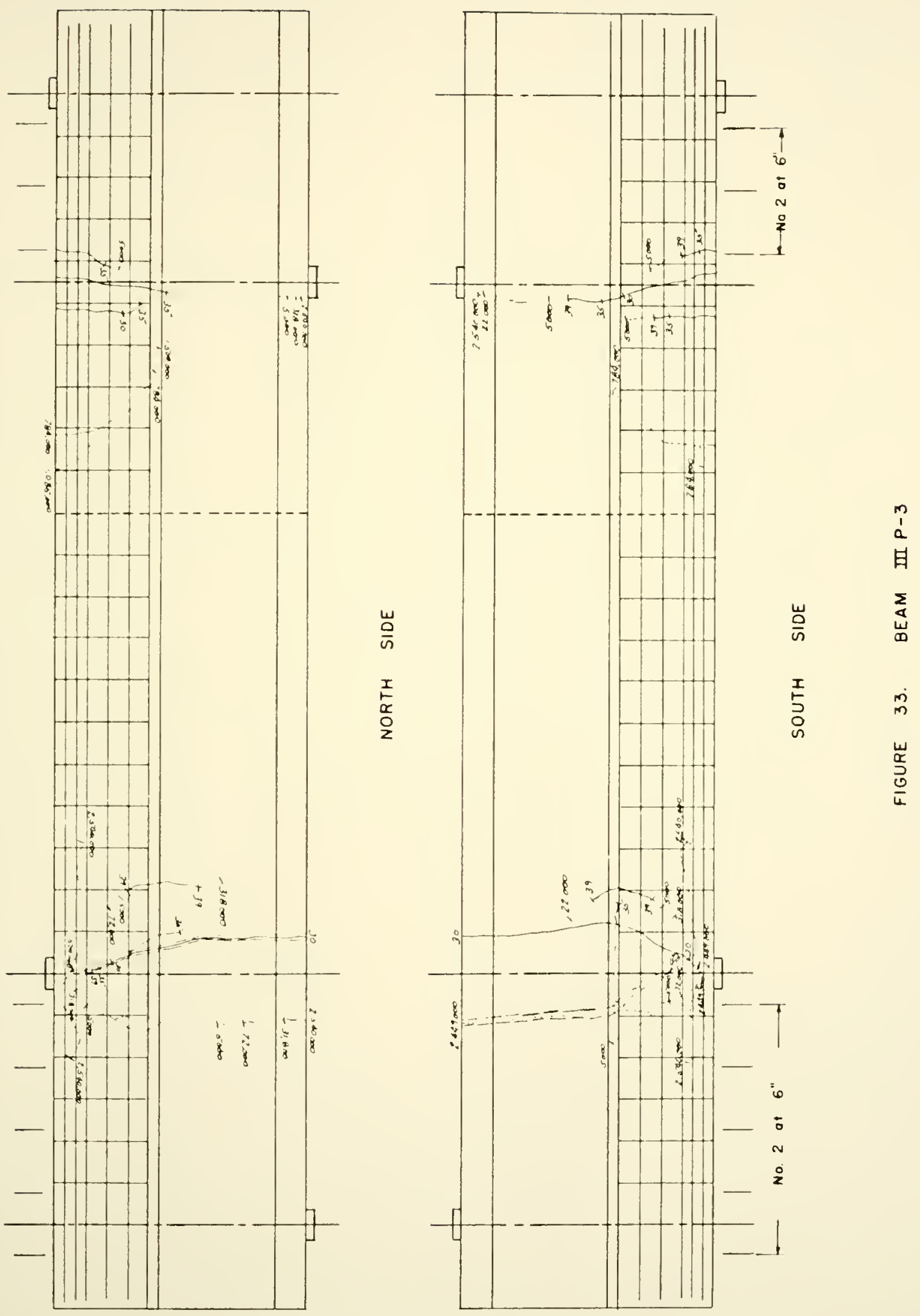

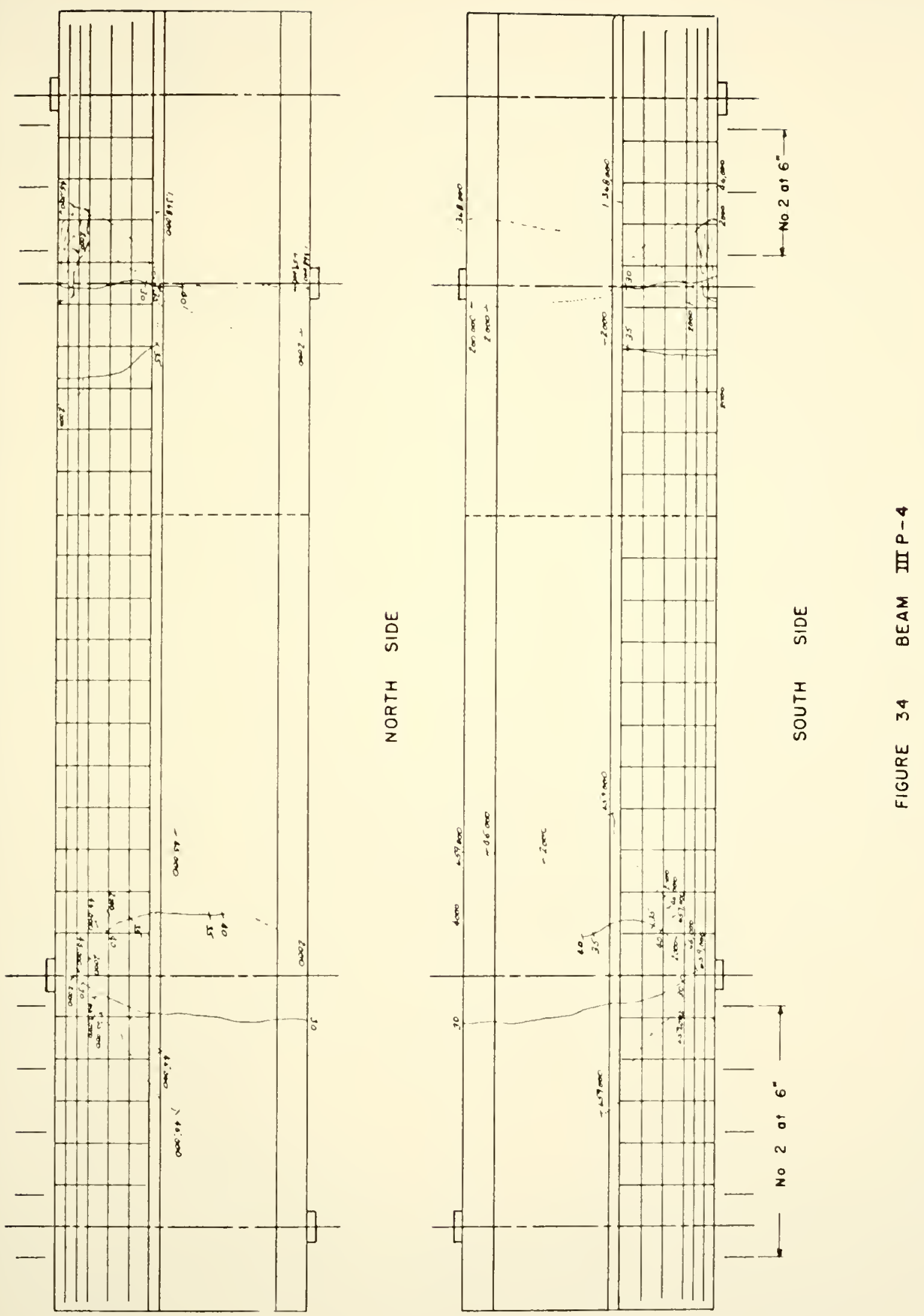

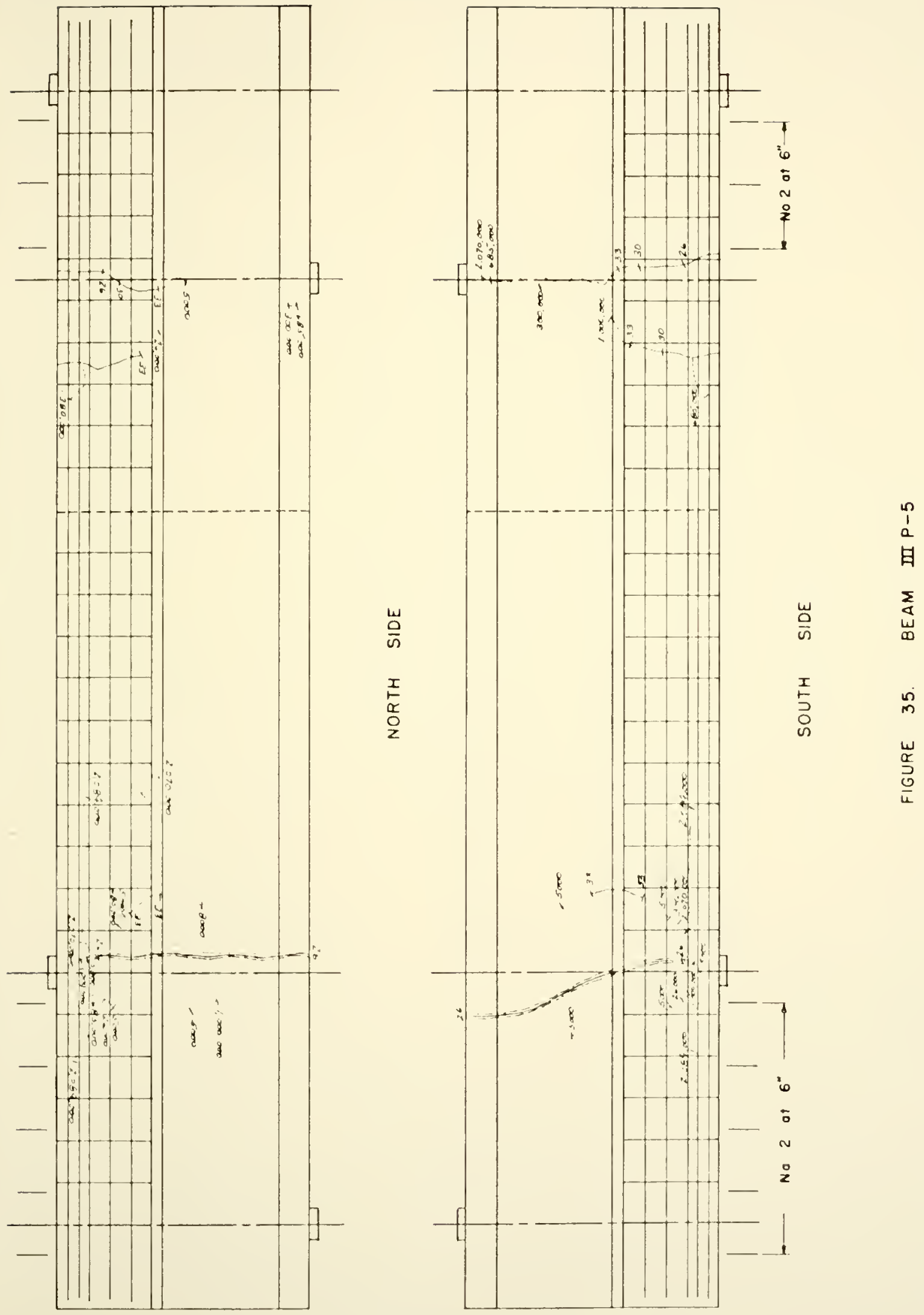

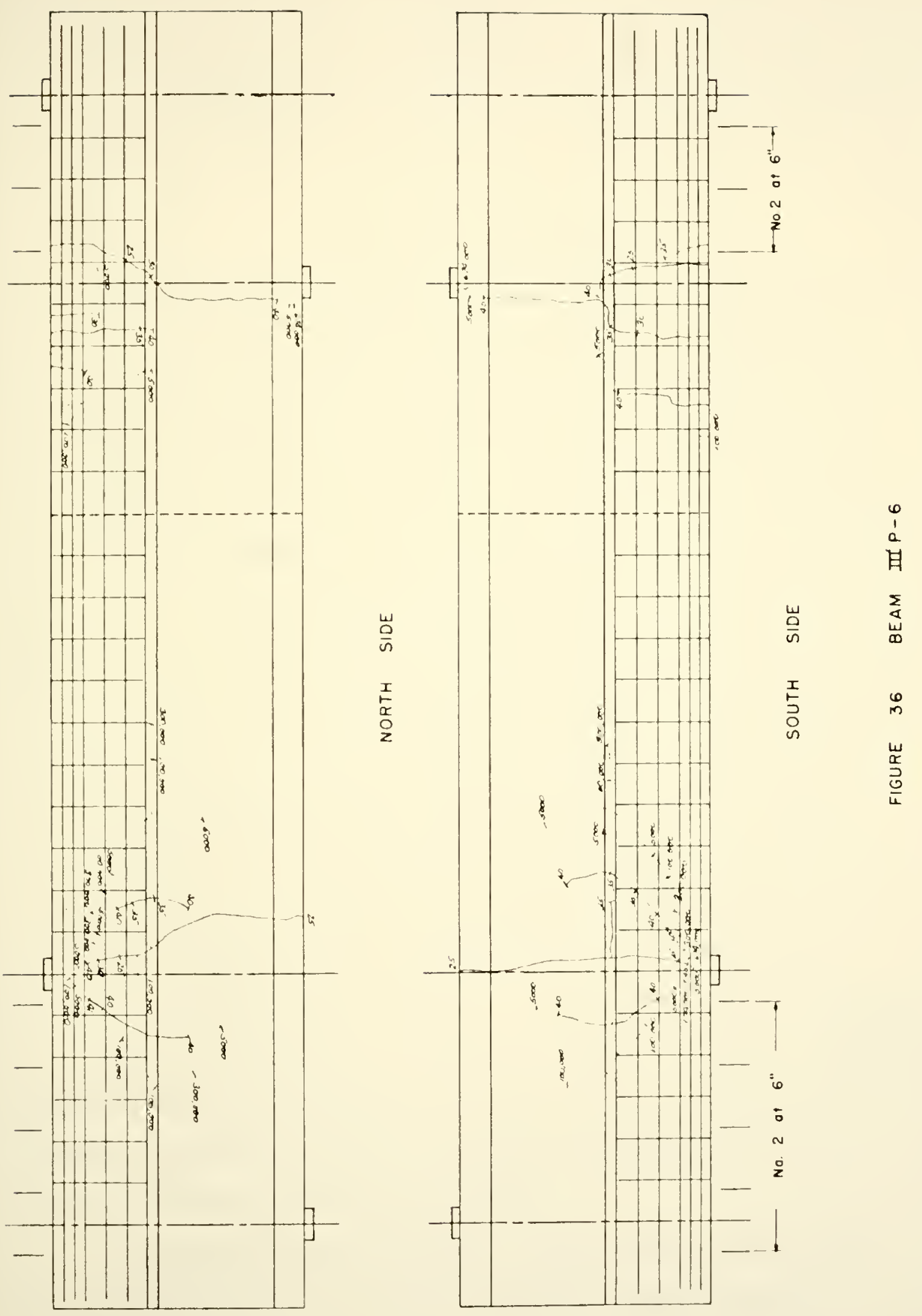


\section{Series IV P}

The specimens of this series had a shear span-to-depth ratio of 5.03. They are companion to the beams of series IV $T$ in Wehr's ${ }^{(26)}$ report.

\section{Beam IV P-I (60\% UItimate)}

The first cycle of loading produced the same crack pattern as in the shorter beams. A flesural crack formed over the support at a load of $25 \mathrm{kips}$, stopping 4 to 5 inches above the compression face. At 30 kips a diagonal crack opened in the shear span 10 inches from the support and lengthened slightly when the first cycle was completed at 31 kips. By 58,000 cycles, two diagonal cracks had opened in the overhang; 4 inches and 8 inches from the support. After 1,839,000 cycles, there was little change in the crack pattern but steel strains had increased greatly. A strain gage attached to the top surface of the north side bar indicated a stress of approximately 90,000 psi \pm 15,000 psi before being lost. The gage attached to the botton surface at the same position remained intact, however, and indicated a stress of only 20,000 psi $\pm 11,250$ psi for almost 3,000,000 additional cycles of loading. Concrete strains also increased steadily during this time, reaching approximately 4200 psi \pm 760 psi after $3,391,000$ cycles. Very short diagonal cracks began to form over almost the entire length of the shear span in the late stages of loading. They were located at approximately 6 inch intervals but extended into the web only tro or three inches from the chamfer.

At 3,490,000 cycles there was a fatigue failure of the south side "t6 reinforcing bar at the point of maximum moment where the 
strain gages had been attached. Failure occurred at the intersection of the deformation lugs and the Iongitudinal rib. Although the top and bottom surfaces of the bar had been smoothed to receive the strain gages, that part of the lug which merged with the rib had not been removed.

\section{Beam IV P-2 (68\% U timate)}

The tension flange cracked directly over the support at a load of 24 kips. At 30 kips the crack had reached a point 3 inches above the compression face, and a diagonal crack began to form 10 inches in the shear span. With the application of 35 kips load, the diagonal. crack lengthened considerably and another crack opened 5 inches from the support in the overhang. The dynamic load was applied but had Iittle effect on the crack pattern. As in the previous specimen, steel strains and related stresses increased rapidly. The static component of stress on the top surface of the north side $\# 6$ bar had reached approxinately 106,000 psi after only 45,000 cycles. The dynamic component of the same stress was 27,000 psi. Again, the stress on the bottom surface remained at approximately 20,000 psi \pm 10,500 psi, only one-fifth of the top surface stress.

At 822,000 cycles, the south side bar failed at a point slightly in the cantilever portion as did the north side bar at 896,000 cycles. The concrete strains were low when compared to those of the previous specimen due to the far smazler muber of cycles required to produce failure of the longitudinal reinforcement. 


\section{Beam IV P-3 (62\% UItimate)}

A flexural crack formed at a load of $26 \mathrm{kips}$ and extended to within 4 inches of the compression face. After the first cycle had been completed, total load $33.5 \mathrm{kips}$, a diagonal tension crack opened 12 inches from the support in the shear span. This crack lengthened with 6,000 cjcles of load and the flexural crack had reached a point 2 inches above the support. A diagonal crack also opened 6 inches out on the overhane and another one 18 inches inside the shear span. No significant additional cracking was noticed until 1,873,000 cycles. As in beam IV F-I, very short cracks had formed throughout the entire length of the shear span. They were spaced 4 to 6 inches apart and all terminated in the chamfer.

Contrary to the results of the two previous specimens, the steel strains remained constant for the duration of the test. The strains on the bottom surfaces of the Iongitudinal reinforcement were not much lower than those on the top surfaces, the ratio being approximately $4 / 5$, indicating much less local bending than in beams IV P-I and IV I-2. At 3,300,000 cycles there was a fatigue failure of both $1 / 5$ reinforcing bars in the positive moment area. 


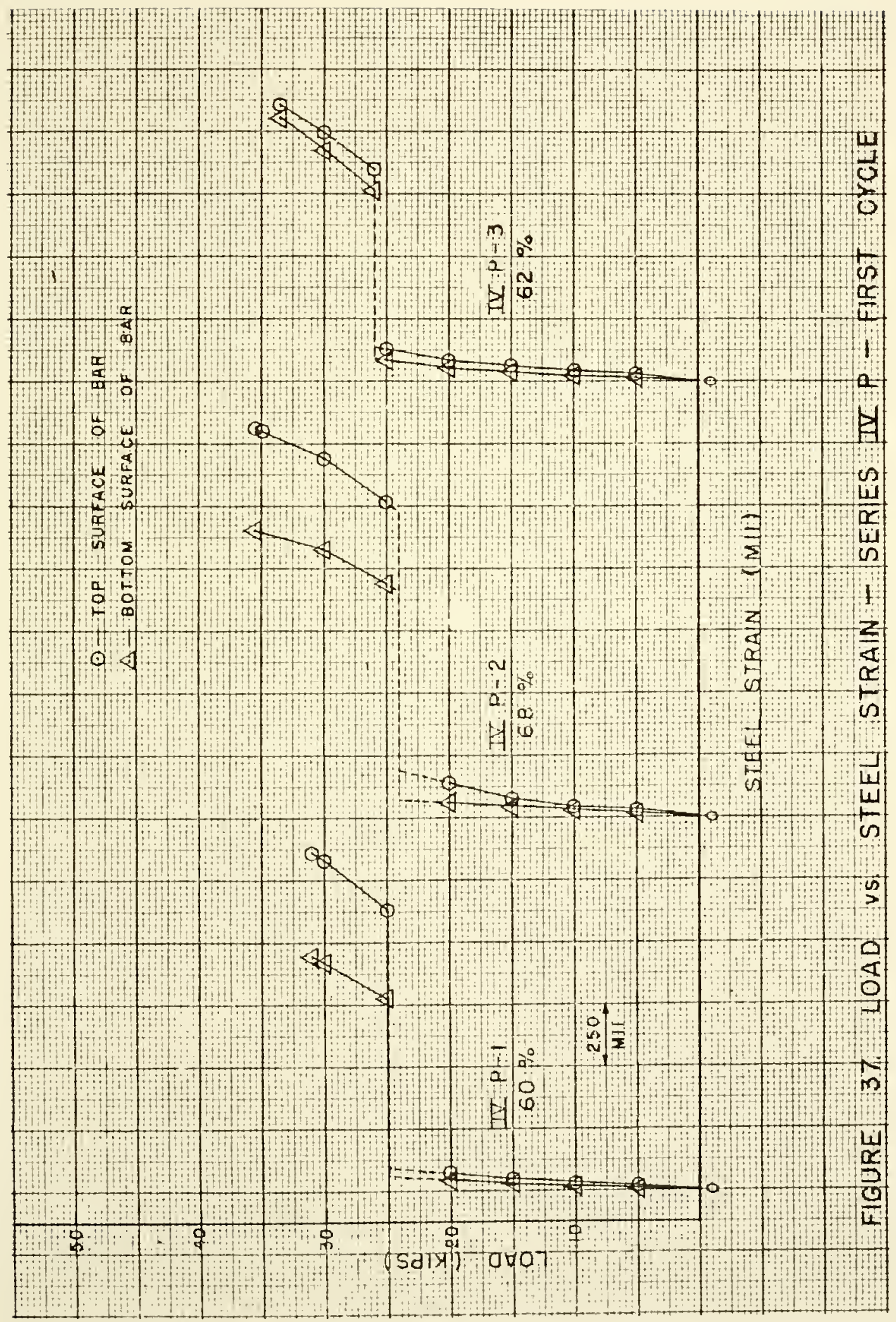




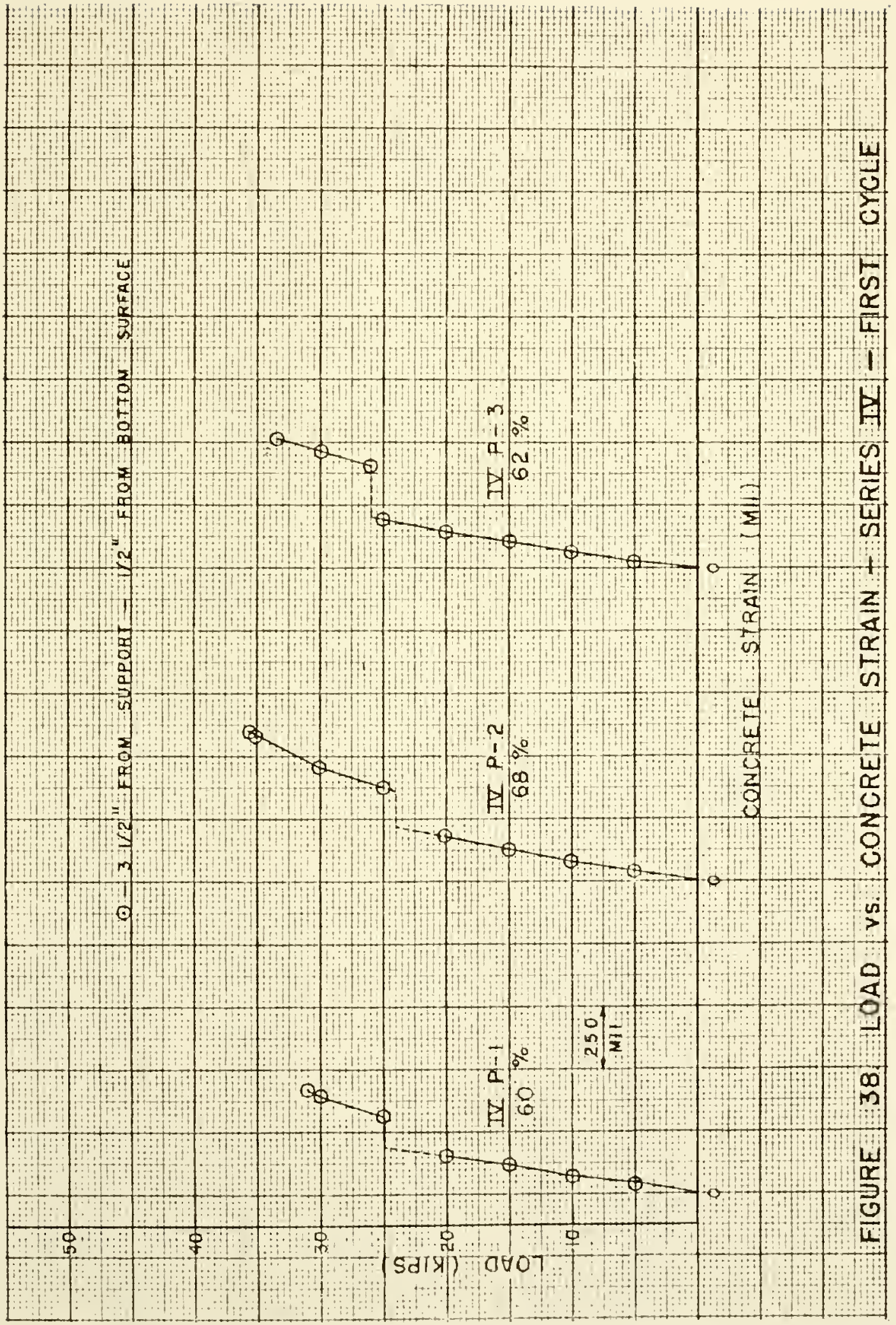



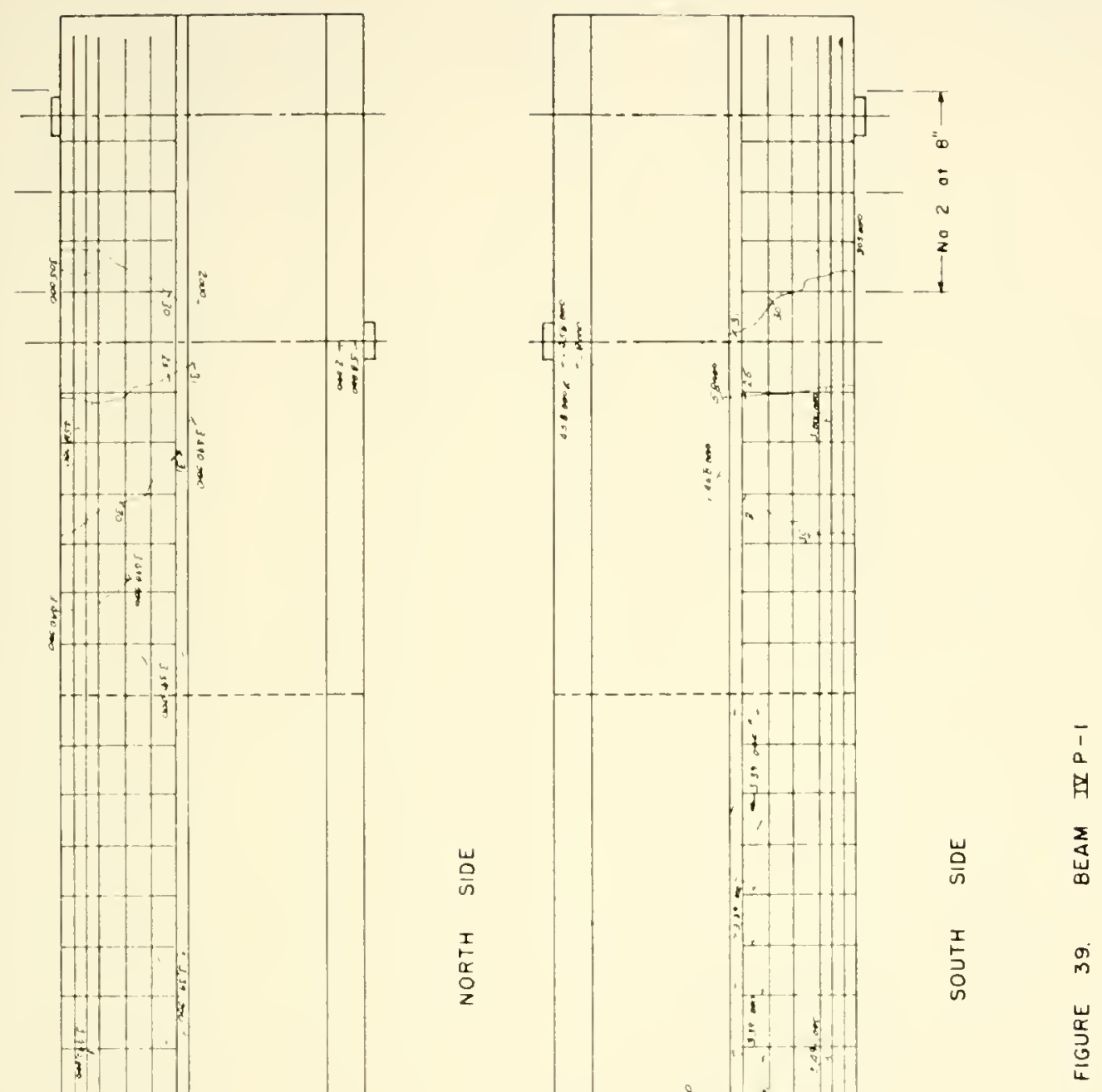

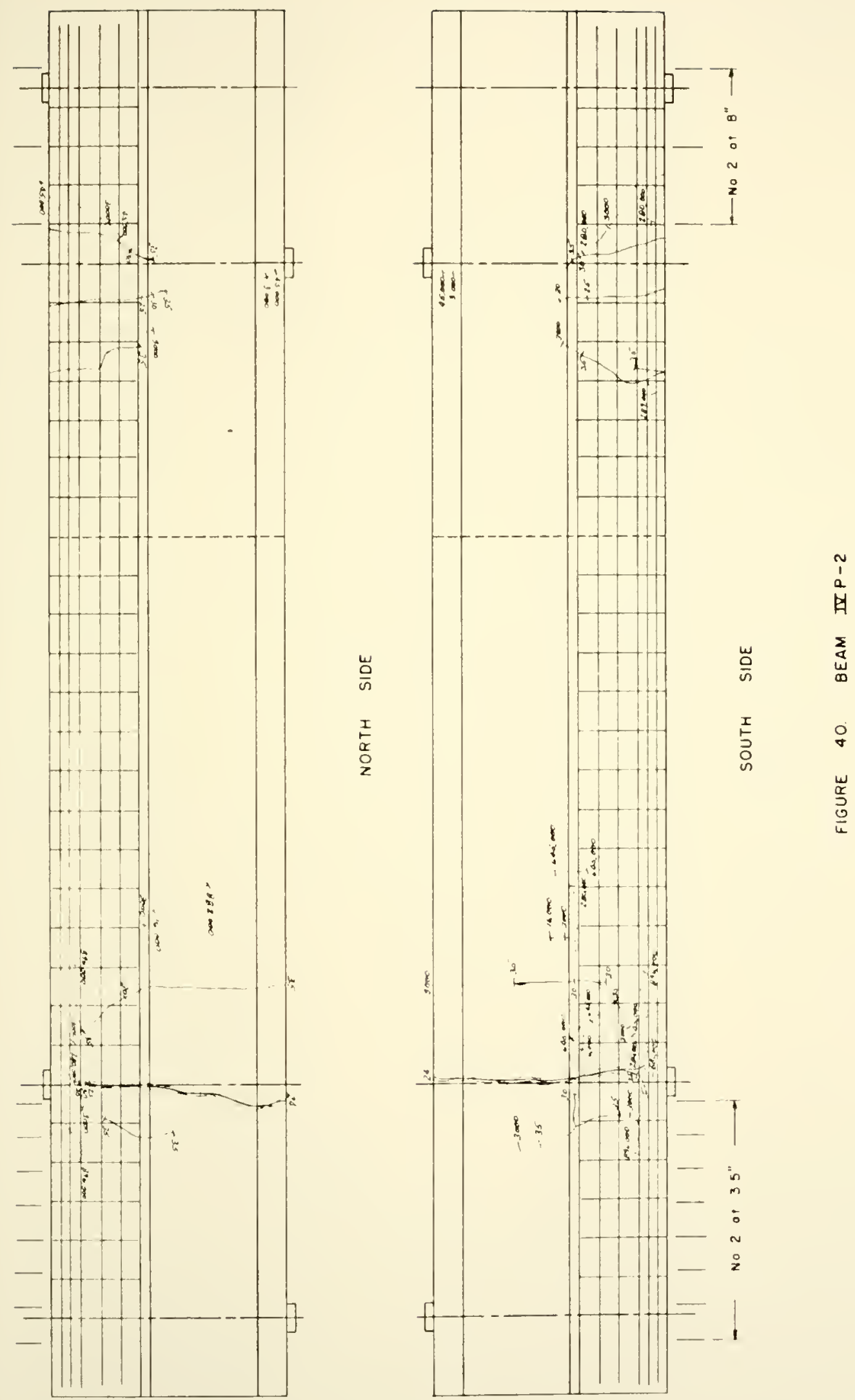

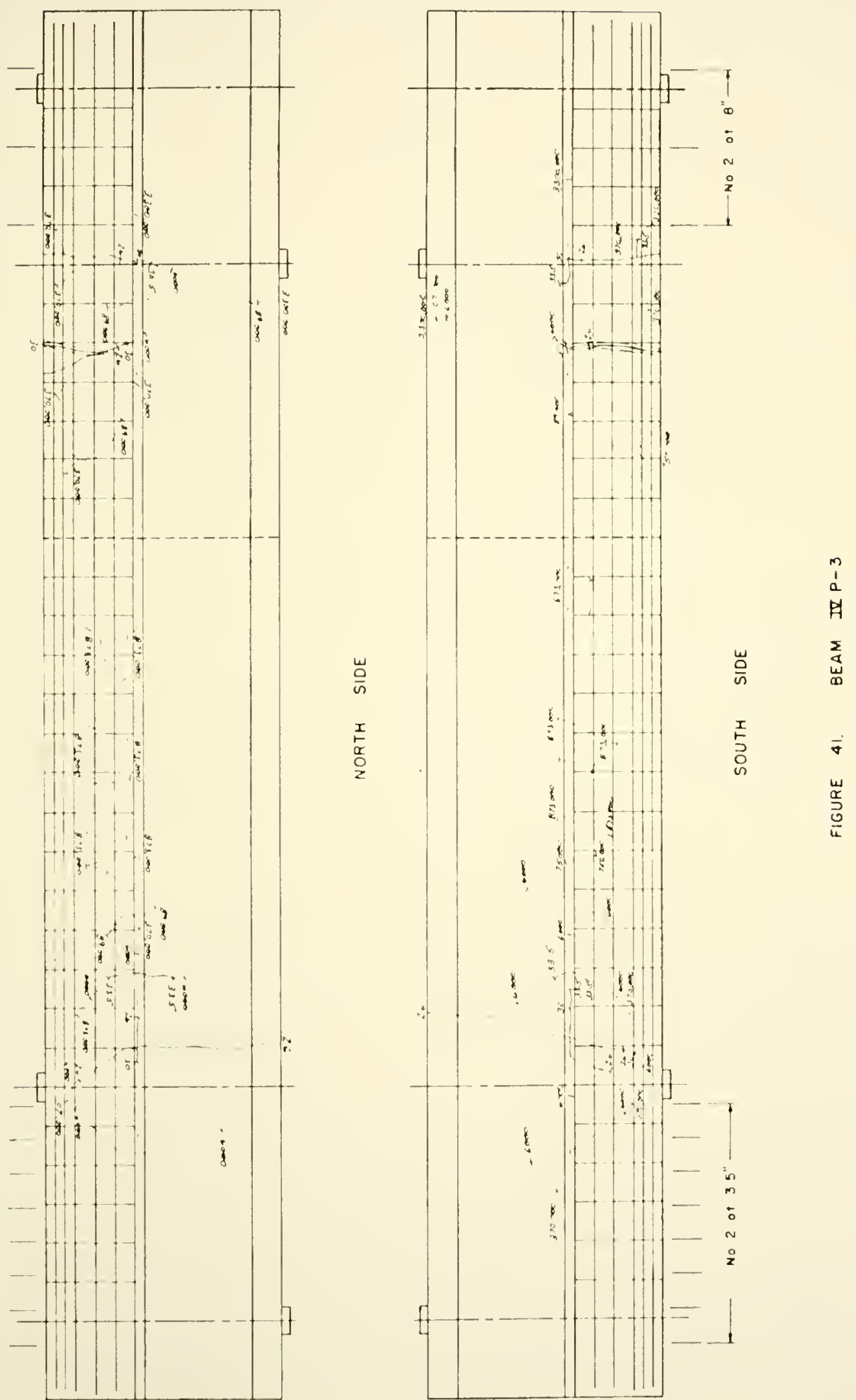


\section{DISCUSSION OF TAST RESULTS}

\section{Temperature}

Iimited time was spent on the investigation of heat generated by repeated stressing of the longitudinal steel reinforcement. Two specinens were equipped with iron-constantan thermocouples attached to the steel bars and in neither case was there a signiflcant temperature increase. A net increase of 5 or 6 degrees Fahrenheit was detected over a period of more than $1,000,000$ cycles of loading and nearly all of this was due to variation in the room temperature. Through frequent monitoring of the thermocouples, it was found that the specimens developed more heat during the curing period (heat of hydration) than during the application of the repeated load.

\section{Nodes of Failure}

Given a sufficient number of loading cycles, the restrained reinforced concrete $T$-beams failed by fatigue of the longitudinal steel reinforcement regardless of the shear span-to-depth ratio or the magnitude of the repeated load.

Beams II P-I, II P-2 and III P-2 were able to withstend at least 3,000,000 repetitions of loading and were therefore tested statically to failure after the repeated load was terminated. These specimens exhibited shear-compression type failures at loads comparable to the predicted ultimate loads based on the expression of Moody and 
using the concrete strength at the time of failure. It can be assumed that, if the repeated load had been contimed, failure would have been caused by fatigue of the Iongitudinal reinforcement since there were too few diagonal cracks in the shear span to indicate imminent diagonal tension failure and the compressive stresses were not high enough at Wint time to cause shar-compression failures. Beams III P- 4 and IV P-3 failed by fatigue of the steel reinforcement in the positive monent area even though the positive moment for all specimens vas only one-half of the negative moment. This may have been caused by the excessive penetration of the flexural crack through the compression flange at the point of maximum positive moment and, again, if this had not occurred, it is presumed that fatigue of the longitudinal reinforcement in the negative momant area would have been the mode of failure.

The nine remaining specimens, with at least two in each series, nad steel fatione failures in the negative moment region after 396,000 to $4,290,000$ cycles of loading. The maximum value of the repeated Ivad at failure ranged from $52 \%$ to 76,0 of the static ultimate Ioad. Identical T-beams subjected to static loading concitions, as found in the report of Wehr, (26) failed by either shear-compression or diagonal tension for all sinear span lentths. Similar reinforced concrete beams of rectangular cross-section subjected to repeated loading by Rogers (19) displayed diagonal tension failures rhen the shear span-to-deptin ratio was small, and steel fatigue failures for larger shear span-to-depth ratios.

Thus, there is a definite change in the mode of failure when a 
reinforced concrete beam without stirrups is exposad to cyclical loading rather than static loading. The presence of the tension flange in the restrained T-beams also has an effect on the failure node under repeated loading. Under the above conditions, the fatigue life of the specimen is limited by the fatigue life of the Iongitudinal reinforcenent.

\section{Factors Affecting Fatigue Iife of Iongitudinal Reinforcement}

The fact that there were relatively few flexural and diagonal tension cracks contributed greatly to reducing the fatigue limit of the steel reinforcing bars. A typical T-beam during testing, even after numerous loading cycles, contained only one major flexural crack close to the point of maximum negative noment, and, at most, only two diagonal tension cracks within the shear span. These diagonal cracks appeared no more than sixteen inches from the support location and were usually extensions of maller flexural cracks. Some diagonal cracks formed independently in the shear span but were prevented from penetrating as far as the level of the tensile steel reinforcement by the large concrete tension flange and lon magnitude of load. Under static loading conditions, additional diagonal cracks would have formed further out in the shear span as the load approached its ultimate value. Inder repeated loading, however, the maximum value of load was not high enough to produce these cracks nor did a large number of repetitions have that effect. Thus, very high steel strains were localized at the section of the flexural crack. Steel strains were noticed to jump suddenly upon the formation of the flexural crack and to reach higher values than in beams of rectangular cross-section subjected to 
comparable loads but having many more cracks. This was especially evident in series III $P$ which is similar to series III BF in Rogers (19) report. It was also observed during testing that the width of the flexural crack at the top of the flange was approximately one-tenth of an inch while the diagonal cracks hardly opened.

The cracking of the flange at only one location also caused bending to be concentrated at that point. In contrast to the curvature of beams cracked at many places, the specimens and, likewise, the ste日l reinforcenent were composed of two linear sections rotated about the support and resembled broken pencils. Strain gages attached to both top and bottom surfaces of the longitudinal reinforcernent indicated a higher ratio of top-to-bottom stress than can be explained by the difference in distance from the compression face. This was particularIy evident in series IV $P$. Beams IVF -1 and $I V P-2$ developed ratios of approximately $4: 3$ under static loading, and as much as $4: 1$ and 5:1 under repeated loading while the ratio of the distances from the compression face to the respective surfaces is only approxinately $12: 11$. (This was also reported in an Investigation by Pfister and Fognestad $(18)$ in which the strain on the top surface was consistently 10 to 20 percent higher than that on the bottom surface.) Bean IV F-3 was stressed at a much higher level than IV $P-i$ but was able to withstand nearly as many repetitions of loading (probably more since the test was teminated by fracture of the $\$ 5$ bars) due to the fact that the ratio of the stresses on the top surface of the bars to those on the bottom was only 20:19 under static loading, and 5:4 after more than three million load cycles. Thus, bending stresses were superposed on the 
already high tensile stresses.

As expected, the longitudinal reinforcement fractured at either of two places; one passing through the intersection of two diagonal Iugs at the top surface of the bar, and the other passing through the point where two lugs merge with the longitudinal rib. These have previously been noted as points of high stress concentration ( $B$ and $C$ in Pigure 3b). All specimens were cast with bars positioned as shown in Figure 3b. Inspection of bars whose failure planes passed through the intersection of two lugs with the longitudinal rib revealed that the cracks had originated at point $C$ rather than at the top surface which is further from the compression face. This is a strong indication that a poor deformation pattern, perhaps caused by the rolling process itself, could decrease the fatigue limit of Iongitudinal steel reinforcenent. That is, the stress range required to produce failure at two million cycles of loading could be less than for a bar whose deformations merged more smoothly.

The stress range was found to have the most influence on the fatigue life of the steel reinforcment and the shear span-to-depth ratio to have little effect, if any. Figure 42 is a plot of the stress range versus the nubber of cycles to failure (plotted on logarithm paper) for each series. The stress range is defined as the maximum stress minus the minimum stress as calculated from $f_{s}=N / A_{S} j d$, assuming $j=7 / 8$. The number of cycles to failure is scen to decrease with increasing stress range and the fatigue limit for all shear span lengths is $40 \mathrm{ksi}$. In Figure 43, the number of cycles for all specimens are plotted together on the same set of axes 


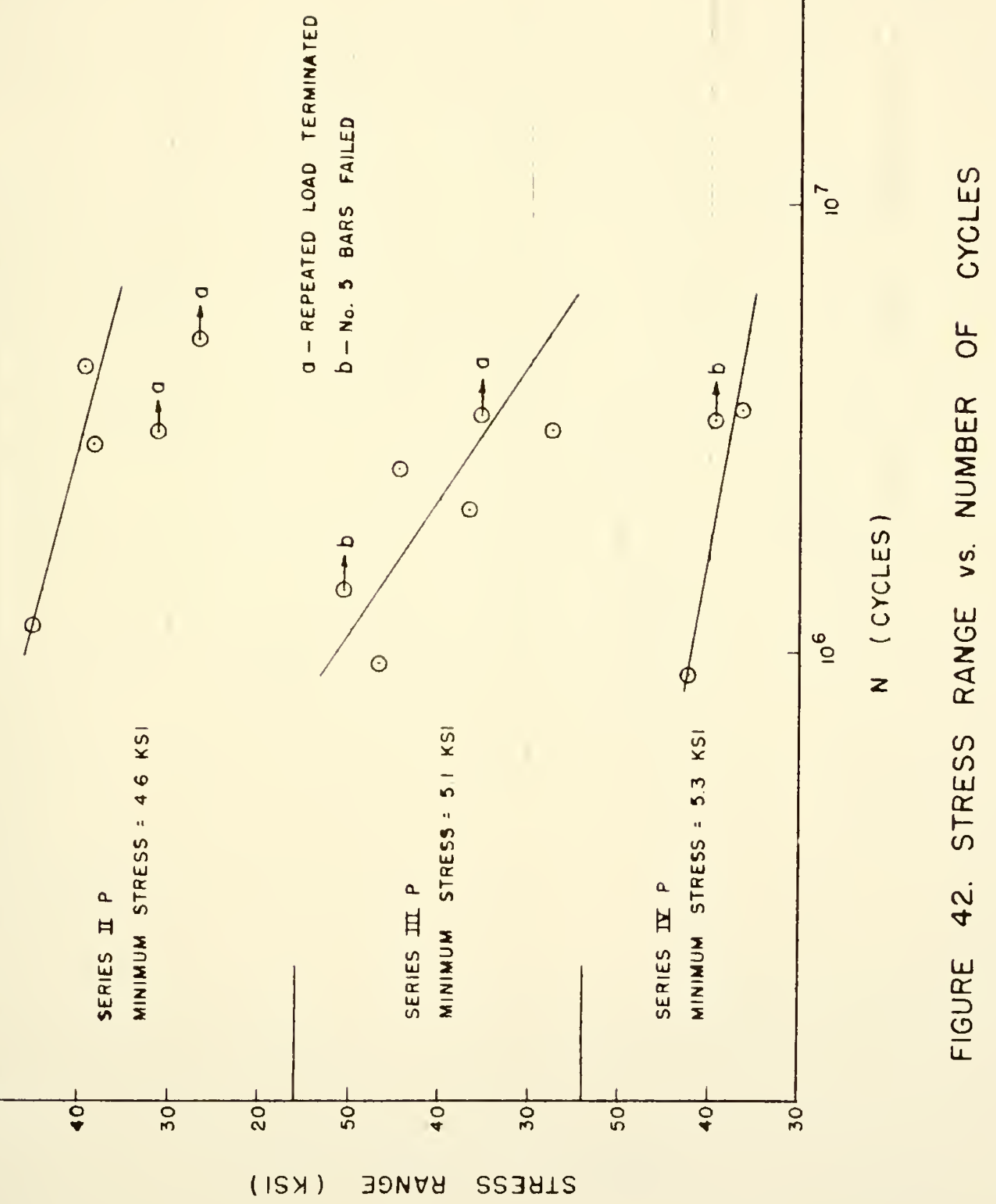




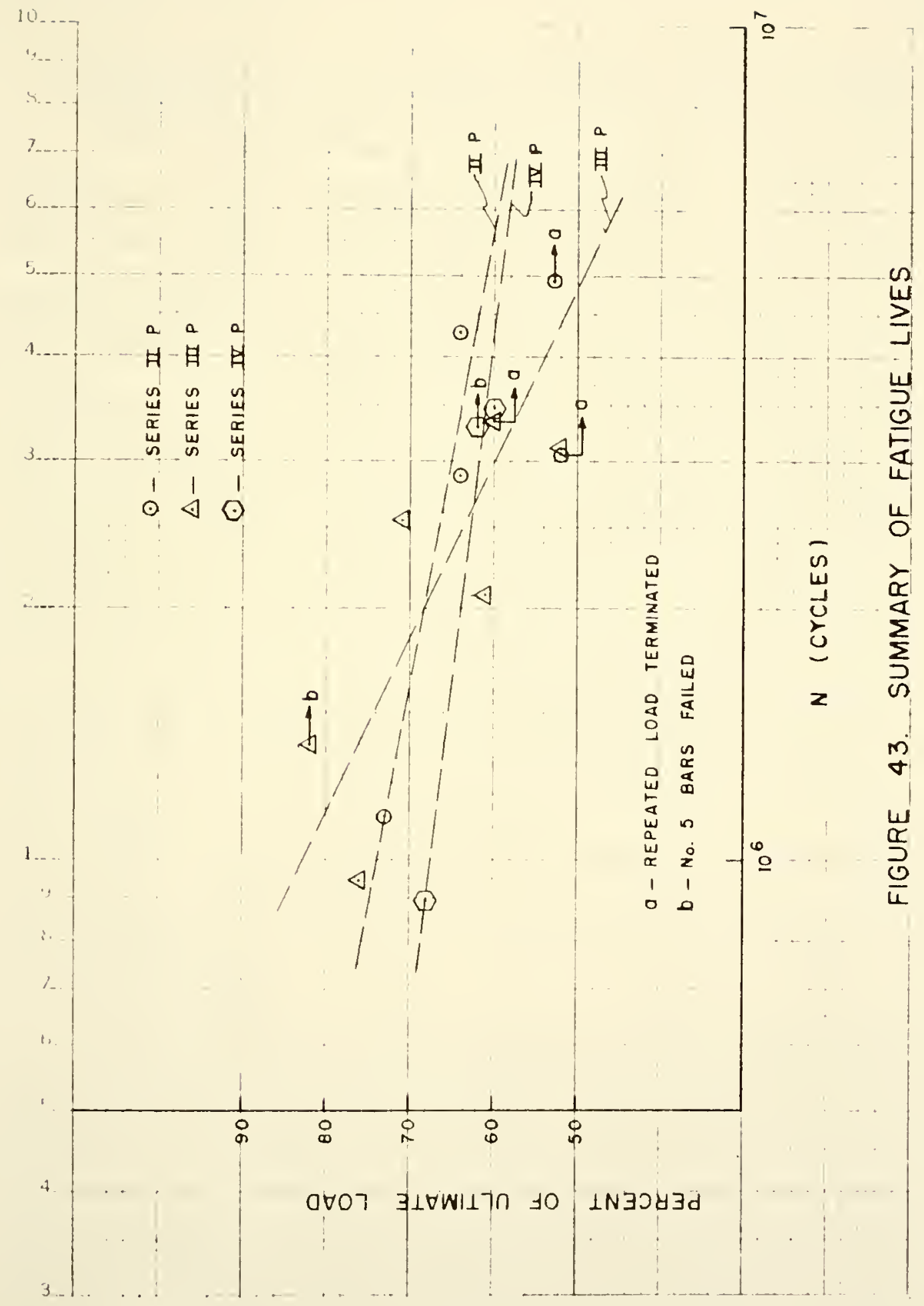


versus percent of static ultimate load. The overlapping of points from each series indicates that neither the fatigue Iimit nor the fatigue Iife is influenced by the length of the shear span.

\section{Resistance to Diagonal Tension and Shear-Compression Failures}

Each of the preceding factors, i.e.; localized steel stress and excessive bar bending caused by the small number of flexural and diagonal cracks, points of high stress concentration, and stress range, Iimit the fatigue Iife of the Iongitudinal steel reinforcement to some degree. They do not explain, horever, the lack of diagonal tension and shear-compression failures. Chang and Kesler ${ }^{(8)}$ reported on the fatigue behavior of 6 inch deep reinforced concrete beams and related the mode of failure to the magnitude of the repeated load. They concluded, for their particular specimens, that the beam would generally fail by fatigue of the reinforcement under two conditions:

1. If the maxioum repeated load would not cause diagonal cracking during loading, i.e.; $\mathrm{V} / \mathrm{v}_{\mathrm{c}}$ is approximately equal to or less than 0.60 .

2. If the maximum repeated load does not cause shear-compression failure before the reinforcement breaks, i.e.; $M / M_{s}$ mast be equal to or less than 0.70 .

It can be seen from Table 4 that the repeated Ioad was well above that required to produce diagonal tension failure for all specimens and, in some cases, was sufficient to cause shear-compression type failures. The absence of a major diagonal crack, obviously, prevented either type failure from occuring. It is here that the presence of a large tension flange influences the mode of failure. As 


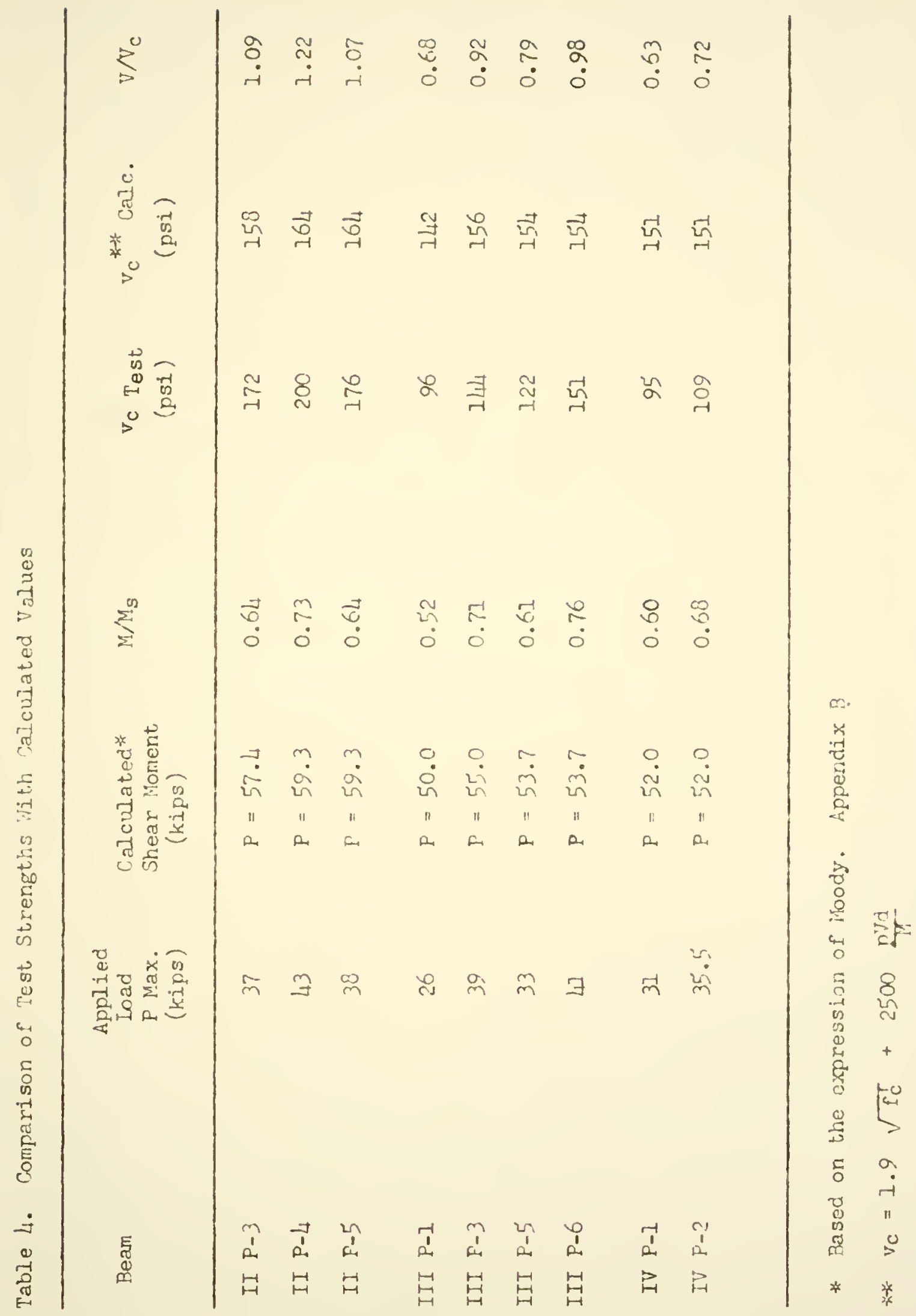


discussed previously in the Introduction, inverted T-beams have been found to resist higher shearing stresses than regular T-ieams and to resist the horizontal splitting of the concrete along the tensile reinforcement associated with diagonal cracking. Since the reinforcing bars are embedded in the concrete flange, there is an additional area of concrete surrounding the bars which seems to act in much the same way as stirmps in resisting dowel forces. The masses of concrete above and below the steel are prevented from separating as they would in a beam of rectangular cross-section, delaying the formation of diagonal failure cracks and allowing the longitudinal reinforcement to fail by fatigue. 


\section{STRMARY AIND CONCLUSIONS}

1. The restrained reinforced concrete T-beams without web reinforcement subjected to repeated loading in this investigation were weak with respect to shear but failed by fatigue of the longitudinal steel reinforcement.

2. The stress range had the most significant effect on the fatigue life of the longitudinal reinforcament. Increasing the stress range decreased the fatigue life. The fatigue limit, or stress range at two million cycles of loading, was found to be $40 \mathrm{ksi}$.

3. The concrete tension flange seemed to produce the same effect as would be expected from web reinforcement by preventing horizontal concrete splitting along the tensile reinforcement the reby delaying diagonal cracking:

4. High steol stresses and excessive bar bending were localized at the section of maximm moment due to the small number of cracks.

5. The stee]. reinforcing bars failed on planes passing through points of high stress concentration. The cracks were found to have initiated at these points.

6. The shear span-to-depth ratio did not influence the mode of failure or the fatigue limit of the longitudinal steel reinforcement. 
BIBIIOGRAPHY 


\section{BIBLIOGRAPIYY}

1. ACI-ASCE Committee 426, "Shear and Diagonal Tension", ACI Journal, January, February, March, 1962, Proceedings, Vol. 59.

2. ACI Committee 318, "Building Code Requirements for Reinforced Concrete (ACI 318-63)", ACI Standard, June 1963.

3. Acharya, D. N. and Kemp, K. O., "Signiflcance of Dowel Forces on the Shear Failure of Rectangular Reinforced Concrete Beams Without Web Reinforcement", ACI Jourmal, October 1965, Proceedings, Vol. $62^{2}$, P. 1265.

4. Acharya, D. N. and Kemp, K. O. - Authors closure to discussion of reference 3. ACI Journal, June 1966, Proceedings, Vol. 622, P. 1771 .

5. Al-Alusi, A. F., "Diagonal Tension Strength of Reinforced Concrete T-Beams with Varying Shear Span", ACI Journal, May 1957, Proceedings Vol. 53, P. 1067.

6. Burton, K. T., "Fatigue Tests of Reinforcing Bars", Journal of the PCA Research and Development Laboratories, Vol. 7 No. 3, September 1965; PCA Development Department, Bulletin D. 93.

7. Chang, T. S. and Kesler, C. E., "Static and Fatigue Strength in Shear of Beams with Tensile Reinforcement", ACI Journal, June 1958, Proceedings, Vol. 54, P. 1033.

8. Chang, T. S. and Kesler, C. E., "Fatigue Behavior of Reinforced Concrete Beams", ACI Journal, August 1958, Proceedings, Vol. 55. P. 245 .

9. Fisher, J. W. and Viest, I. M., "Fatigue Tests of Bridge Materlals of the AASHO Road Test", AASHO Road Test Technical Staff Papers, Special Report 66, 132-147, Highway Research Board (1961).

10. Hanson, J. M., Burton, K. T. and Hognestad, E., "Fatigue Tests of Reinforcing Bars - Effect of Deformation Pattern", Jourmal of the PCA Research and Development Laboratories, Vol. 10, No. 3, September 1968.

11. Harvey, $W_{0}$ N., "A Study of Diagonal Tension Failure in Reinforced Concrete Beams", M.S. Thesis, Purdue University, 1964. 
12. Jones, R., "The UItimate Strength of Reinforced Concrete Beams in Shear", Magazine of Concrete Research, August 1956, Vol. 8, No. 23, P. 69.

13. Kokubu, M. and Okamura, H., "Fundamental Study on Fatigue Behavior of Reinforced Concrete Beams Using High Strength Deformed Bars", Transactions of the Japan Soclety of Civil Angineers, No. 122, October 1965.

14. Krefeld, W. J. and Thurston, C. W., "Contribution of Iongitudinal Steel to Shear Resistance of Reinforced Concrete Beams", ACI Journal, March, April 1966, Proceedings, Vol. 63, P. 325, 451.

15. Krefeld, W. J. and Thurston, C. W. - Authors closure to discussion of reference 14. ACI Journal, December 1966, Proceedings, Vol. $63^{2}$, P. 1474 .

16. Murdock, J. W. and Kesler, C. E., "Iffect of Range of Stress on Fatigue Strengths of Plain Concrete Beams", ACI Journal, August 1958, Proceedings, Vol. 55, P. 221.

17. Nordby, G. M., "Fatigue of Concrete - A Review of Research", ACI Journal, August 1958, proceedings, Vol. 55, P. 191.

18. Pfister, J. F. and Hognestad, E., MHigh Strength Bars as Concrete Reinforcement - Part 6. Fatigue Tests", Joumal of the PCA Research and Development Iaboratories, Vol. 6, No. 1, January 1964; PCA Development Department, Bulletin D 74.

19. Rogers, W. A., "A Study of the Behavior of Reinforced Concrete Beams Subjected to Repeated Ioads", M.S. Thesis, Purdue University, 1968.

20. Stelson, T. E. and Cernica, J. N., "Fatigue Properties of Concrete Beams", ACI Joumal, August 1958, Proceedings, Vol. 55, P. 255.

21. Taub, J. and Neville, A. M., "Resistance to Shear of Reinforced Concrete Beams", ACI Journal, August 1960, Proceedings, Vol. 57 , P. 193.

22. The AASIIO Road Test, Report 4, Bridge Research, Special heport 61 D, Highway Research Board (1962).

23. Verna, J. R. and Stelson, T. I., Mailure of Small Reinforced Concrete Beams Under Repeated Ioads", ACI Joumal, October 1962, Proceedings, Vol. 59, P. 1489.

24. Verna, J.R. and Stelson, T. E., "Repeated Loading Effect on Utimate Static Strength of Concrete Beams", ACI Journal, June 1963, Proceedings, Vol. 60, P. 743. 
25. Watstein, D. and Mathey, R. G., "Strains in Beams Having Diagonal Cracks", ACI Journal, December 1958, Proceedings, Vol. 55, P. 717.

26. Wehr, K. E., "Shear Strength of Reinforced Concrete T-Beams", M. S. Thesis, Purdue University, 1967. 
APPENDIX A 
APPENDIX A

Stress-Strain Properties of the Reinforcement

Several coupons of the stael reinforcement were selected and tested to determine the properties. The resultant stress-strain properties of an average test for both size longitudinal steel are shown in Figures $\psi_{4}$ and 45. 


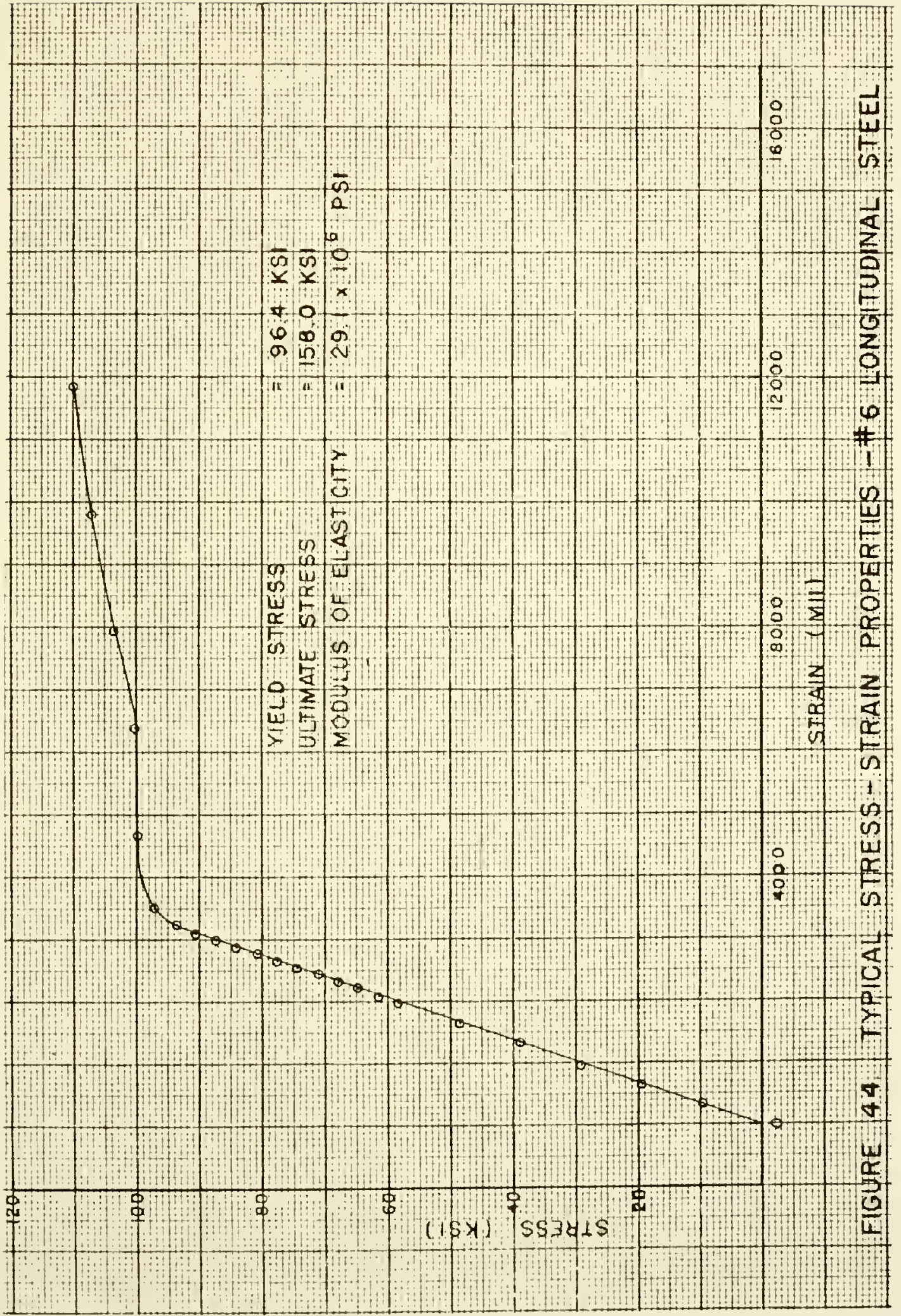




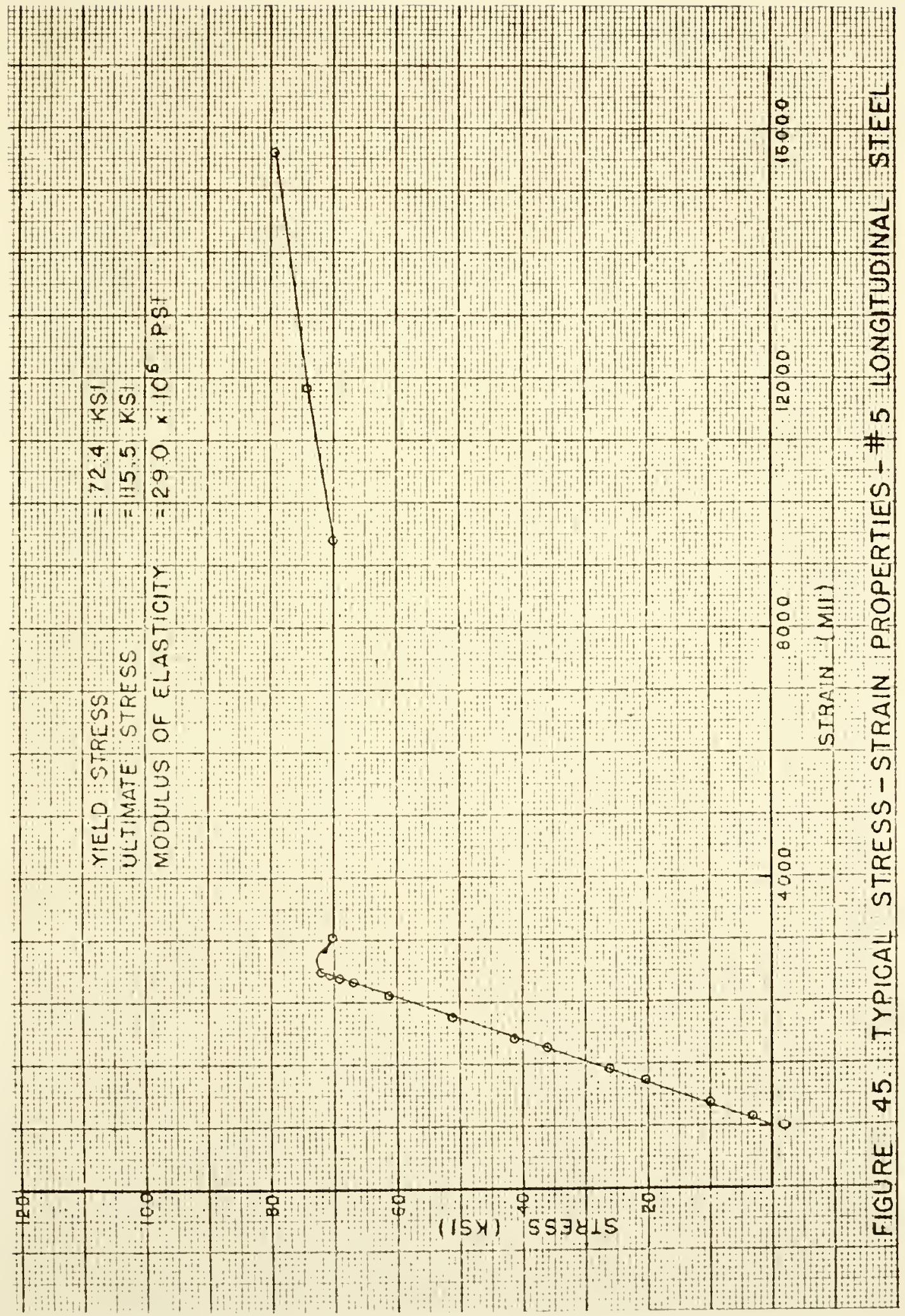


APPENDIX B 
APPENDIX B

\section{Sample Calculations for Ultimate Ioad Prediction}

The static ultimate load of a specimen of rectangular crosssection was estimate as the average of the values predicted by the shear-moment expressions of Moody and Morrow. For T-beams, the static ultimate load was taken as that predicted by the expression of Moody only. The statically loaded T-beams in Wehr's ${ }^{(26)}$ investigation showed this value to be a good indication of the fallure load and the expression of Morrow to be very conservative. The effect of compression steel has been neglected.

Moody developed the following expression.

$$
M_{s}=p f_{s}\left(1-\frac{k_{2}}{k_{1} k_{3}} \frac{p f_{s}}{f_{c}^{\prime}}\right) b d^{2}
$$

where

$$
k_{2}=.42, \quad k_{1} k_{3}=1.121-.0485 \frac{f^{\prime} c}{1000}
$$

and

$$
f_{s}=\frac{\frac{3 M}{V d}-0.45}{\frac{3 M}{V d}+0.55}\left[6.9 \times 1.0^{-4} E_{s}\left(-1+\sqrt{\left.1+\frac{1450}{p E_{s / k_{1} k_{3} f^{\prime}}}\right)}\right]\right.
$$

Morrow developed similar expressions for beams without stirrups.

$$
M_{s}=p f_{s}\left(1-\frac{k_{2}}{k_{1} k_{3}} \frac{p f_{s}}{f_{c}^{\prime}}\right) b d^{2}
$$

where

$$
\frac{k_{2}}{k_{1} k_{3}}=.44, \quad k_{1} k_{3}=\frac{800+f^{\prime} c}{70+f^{\prime} c}
$$


and

$$
\begin{aligned}
& f_{s}=\frac{1}{2} E_{s} k \varepsilon_{u}\left(-I+\sqrt{1+\frac{4 k_{I} k_{3} f_{c}}{p E_{s} k \varepsilon_{u}}}\right) \\
& 10^{4} k_{u}=\frac{1.176 \mathrm{a} / \mathrm{d}+.174}{2 / d-.872}
\end{aligned}
$$

For all cases the calculated load was based on the moment, $M_{\mathcal{S}}$, developed at the edge of the support block.

$$
\begin{array}{lll}
\text { Series I: } & P_{f}=\frac{\text { Average } M_{s}}{10.18} \\
\text { Series II: } & P_{f}=\frac{M_{s}}{9.32} \\
\text { Series III: } & P_{f}=\frac{M_{s}}{10.18} \\
\text { Series IV: } & P_{f}=\frac{M_{s}}{10.75}
\end{array}
$$

\section{Sample Calculations}

For Beam I P-I

$$
\begin{aligned}
& \rho_{c}=5270 \mathrm{psi} \\
& a / d=3.95 \\
& E_{s}=30 \times 10^{6} \mathrm{psi} \\
& p=.01318
\end{aligned}
$$

Moody:

$$
\begin{aligned}
\frac{M}{V d} & =\frac{10.18 P}{.247 P(1.13)} \Rightarrow 3.7 \\
k_{I} k_{3} & =1.121-.0485\left(\frac{5270}{1000}\right)=.866 \\
f_{S} & =\frac{3(3.7)-.45}{3(3.7)+.55}\left[6.9 \times 10^{-4}\left(30 \times 10^{6}\right)(-1+\right. \\
& \sqrt{\left.\left.1+\frac{1450(.866)(5270)}{.01318\left(30 \times 10^{6}\right)}\right)\right]}
\end{aligned}
$$




$$
\begin{aligned}
& f_{s}=61,000 \text { psi } \\
& M_{s}=.01318(61,000)\left(1-\frac{.42(.01318) 61,000}{.066}\right) 6(11.13)^{2} \\
& M_{s}=554,000 \text { in.-1b. }
\end{aligned}
$$

\section{Morrow:}

$$
\begin{aligned}
& k_{1} k_{3}=\frac{800+5270}{70+5270}=1.136 \\
& 10^{4} \mathrm{k} \varepsilon_{u}=\frac{1.116(3.95)+.174}{3.95-.872}=1.486 \\
& f_{s}=\frac{\left.3+13010^{6}\right)\left(1.486 \times 10^{-4}\right)(-1+}{\left.\sqrt{1+\frac{4(1.136) 5270}{(.01318)\left(30 \times 10^{6}\right)\left(1.486 \times 10^{-4}\right)}}\right)} \\
& f_{s}=42,8000 \mathrm{psi} \\
& M_{S}=.01318(42,800)\left(1-\frac{.44(.01318) 42,800}{5270}\right) 6(11.13)^{2} \\
& M_{S}=399,000 \text { in. }-1 \mathrm{~b} \text {. } \\
& \text { Ave. } M_{S}=\frac{554,000+399,000}{2}=476,500 \text { in. }-1 \mathrm{~b} \text {. } \\
& P_{f}=\frac{476,500}{10.18}=46.9^{k} \\
& P_{\text {test }}=28.5^{\mathrm{k}} \\
& \% \text { of } \mathrm{P}_{\mathrm{f}}=\frac{28.5}{46.9}=61 \%
\end{aligned}
$$


APPENDIX C 


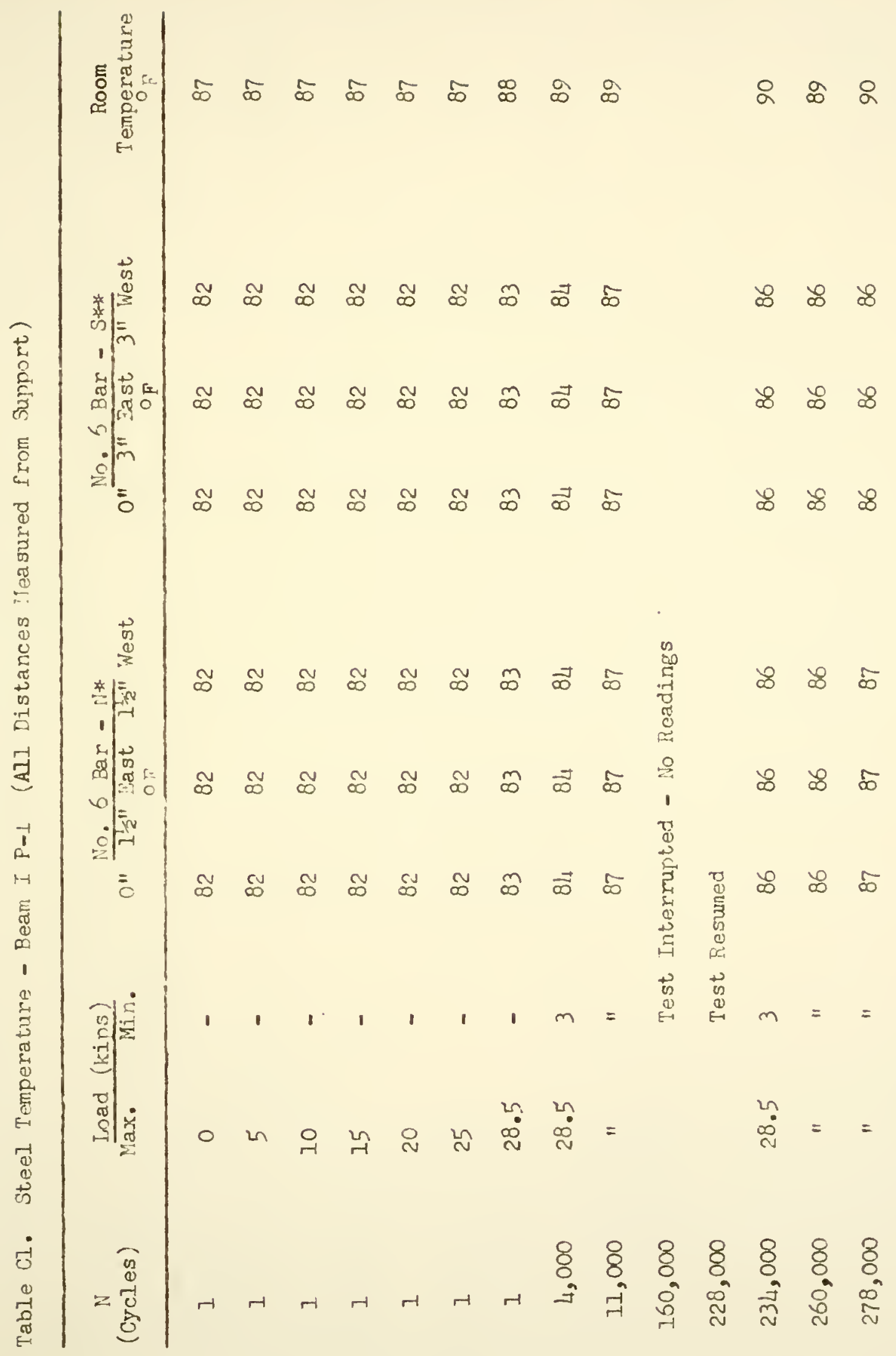




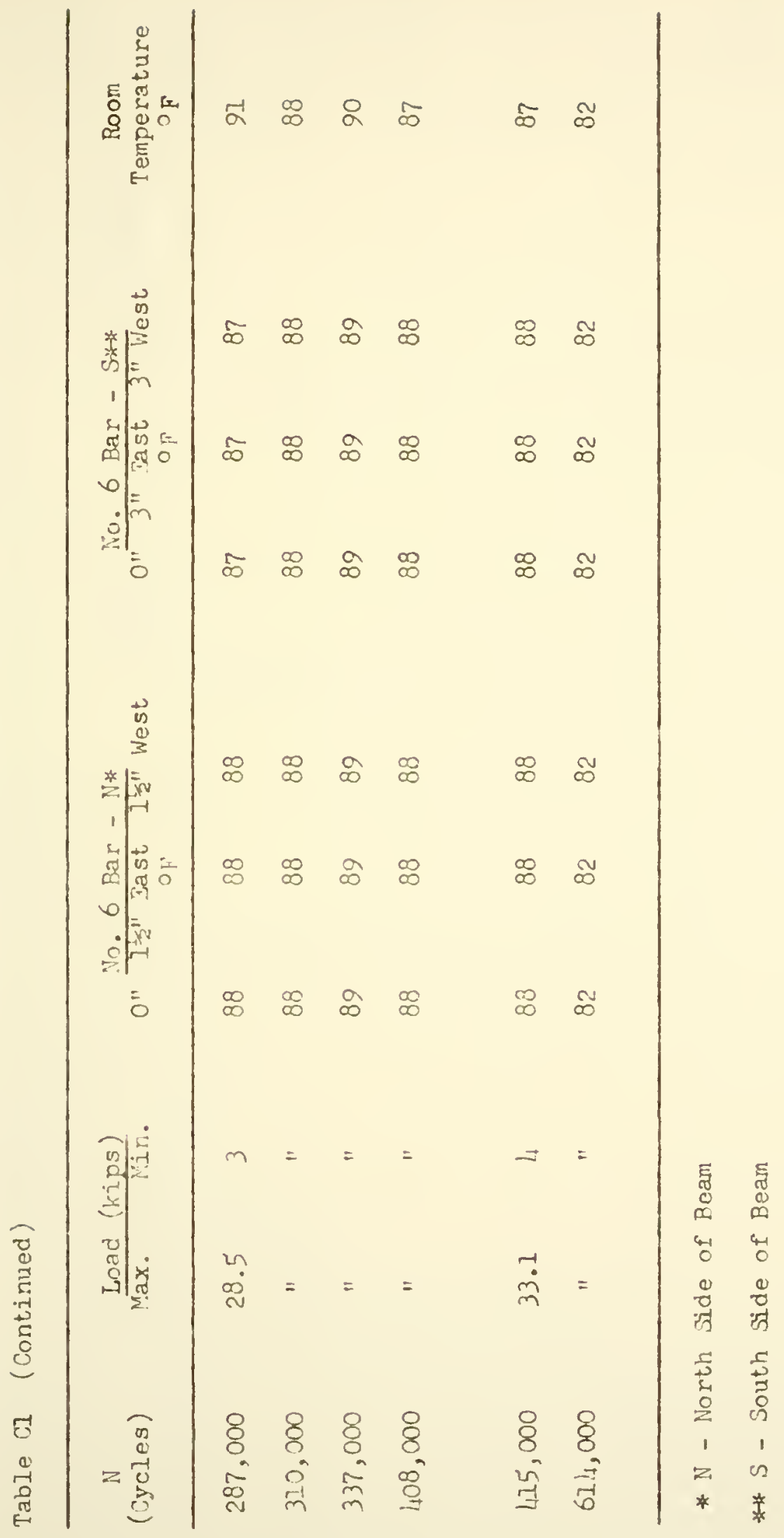




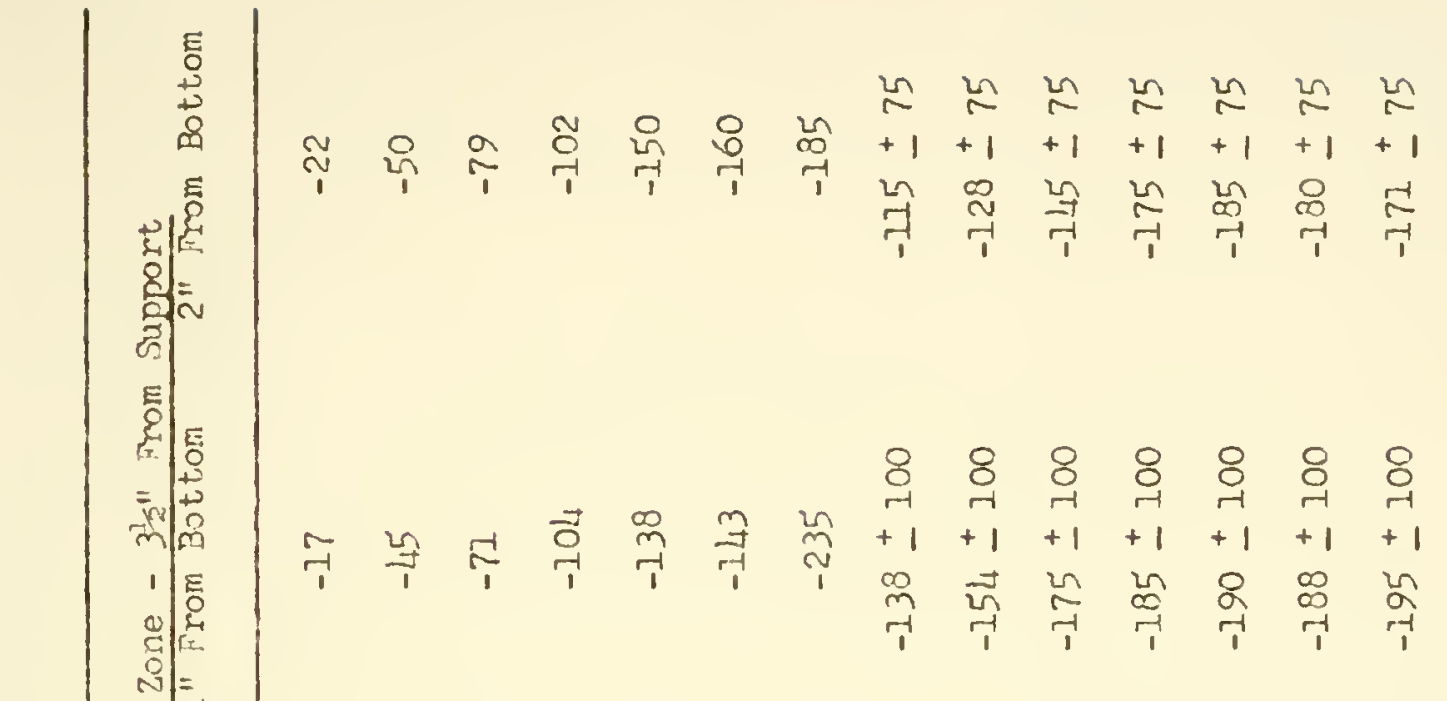

$$
\begin{aligned}
& 1 \\
& \text { H } \\
& \text { ज़ } \\
& \begin{array}{l}
1 \\
0 \\
5 \\
4 \\
4 \\
4 \\
0 \\
0 \\
0 \\
0 \\
0 \\
0 \\
0 \\
0
\end{array} \\
& \text { E }
\end{aligned}
$$

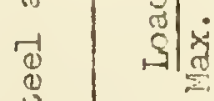

$$
\begin{aligned}
& \text { c) E } \\
& \text { है। } \\
& \text { हू }
\end{aligned}
$$

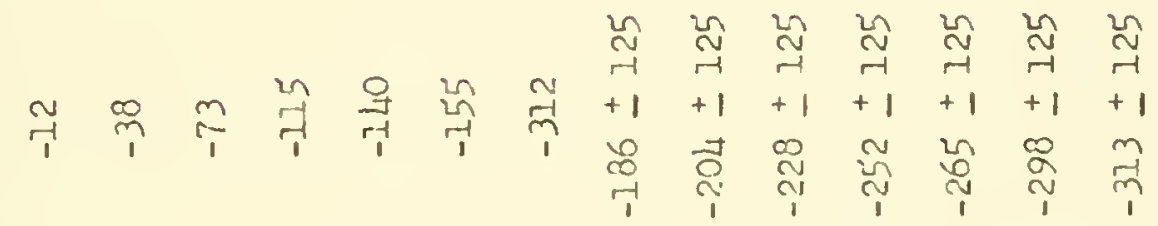

$$
\begin{aligned}
& \text { iviv } \\
& \text { H }
\end{aligned}
$$




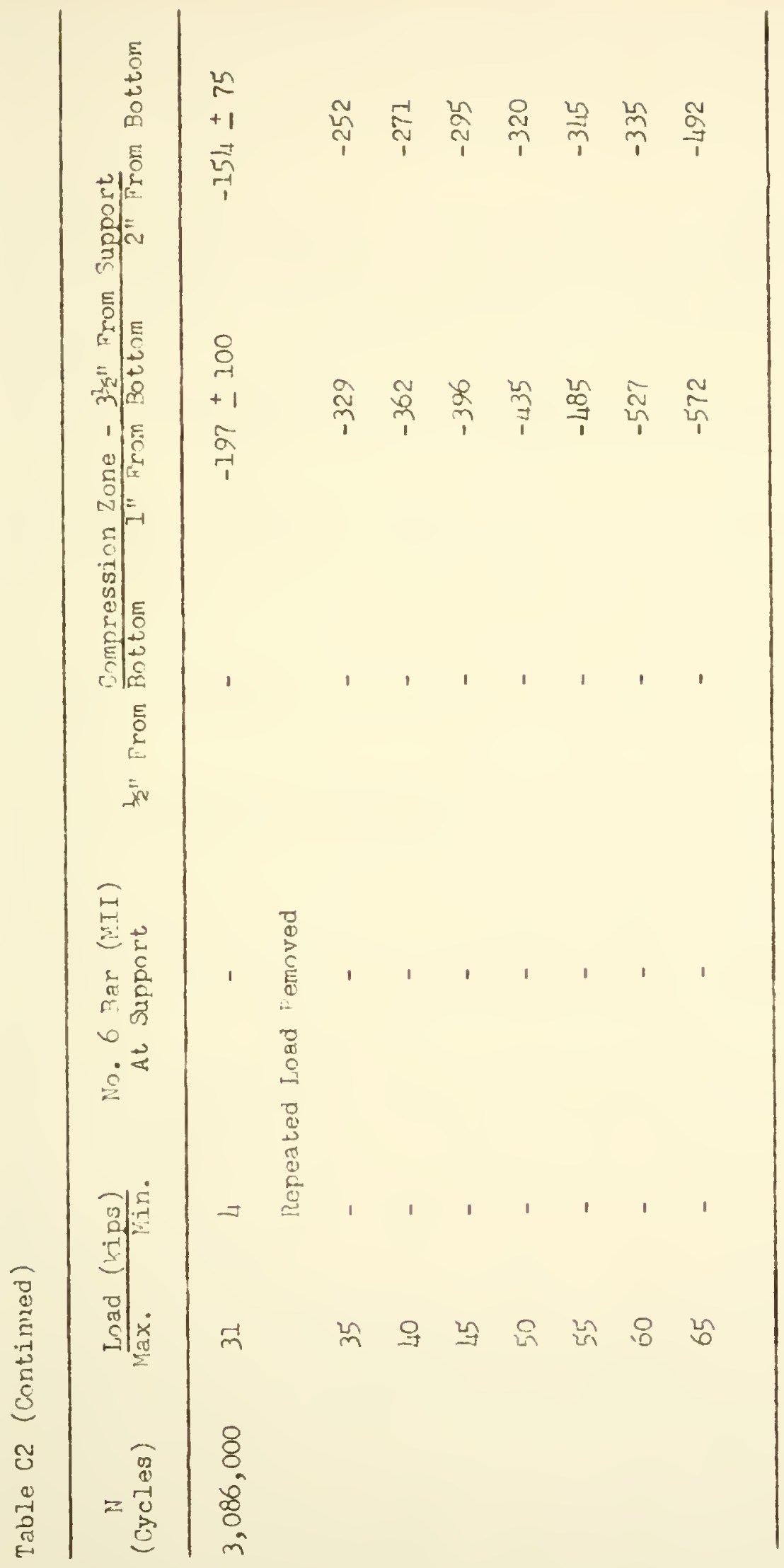




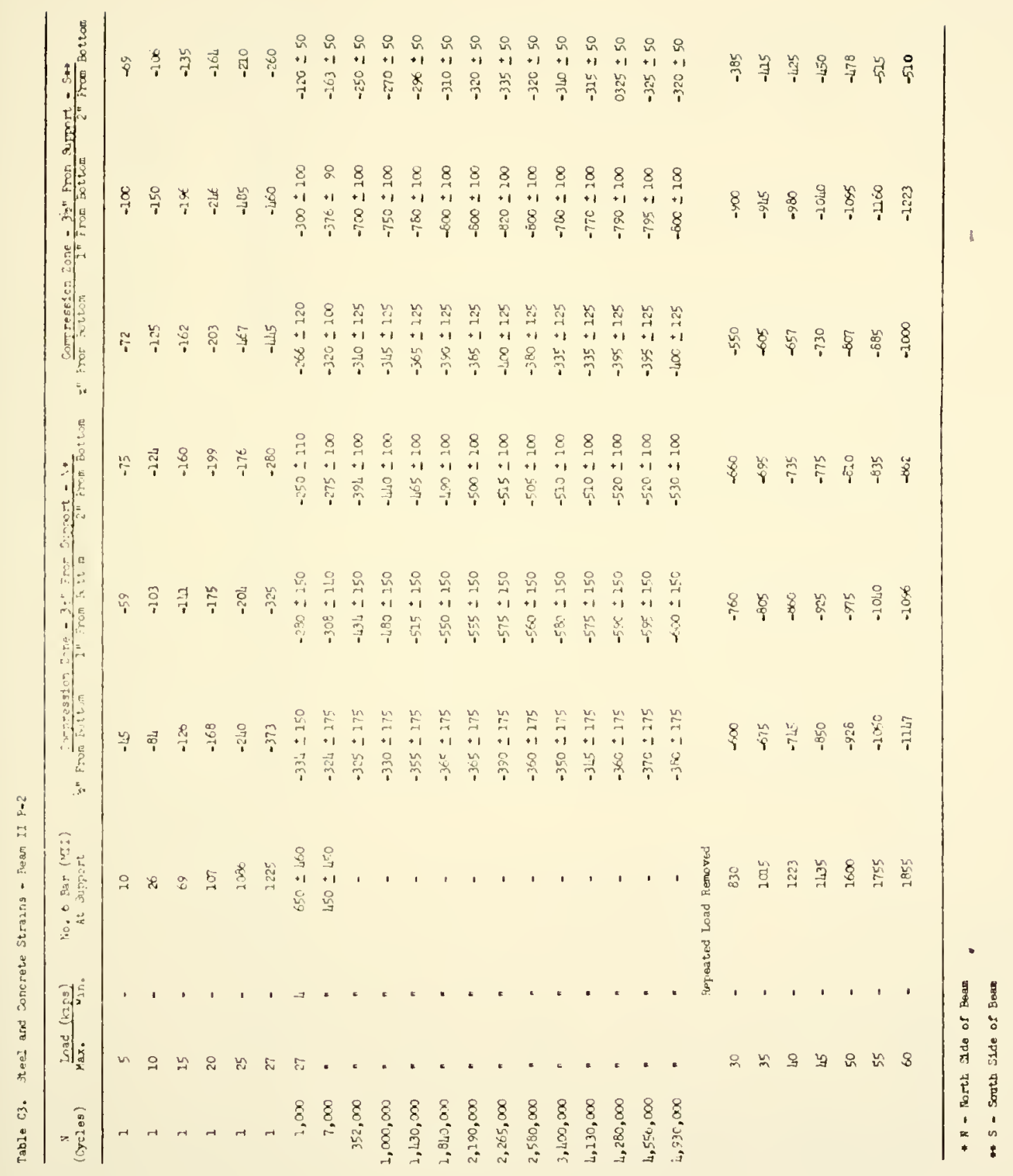




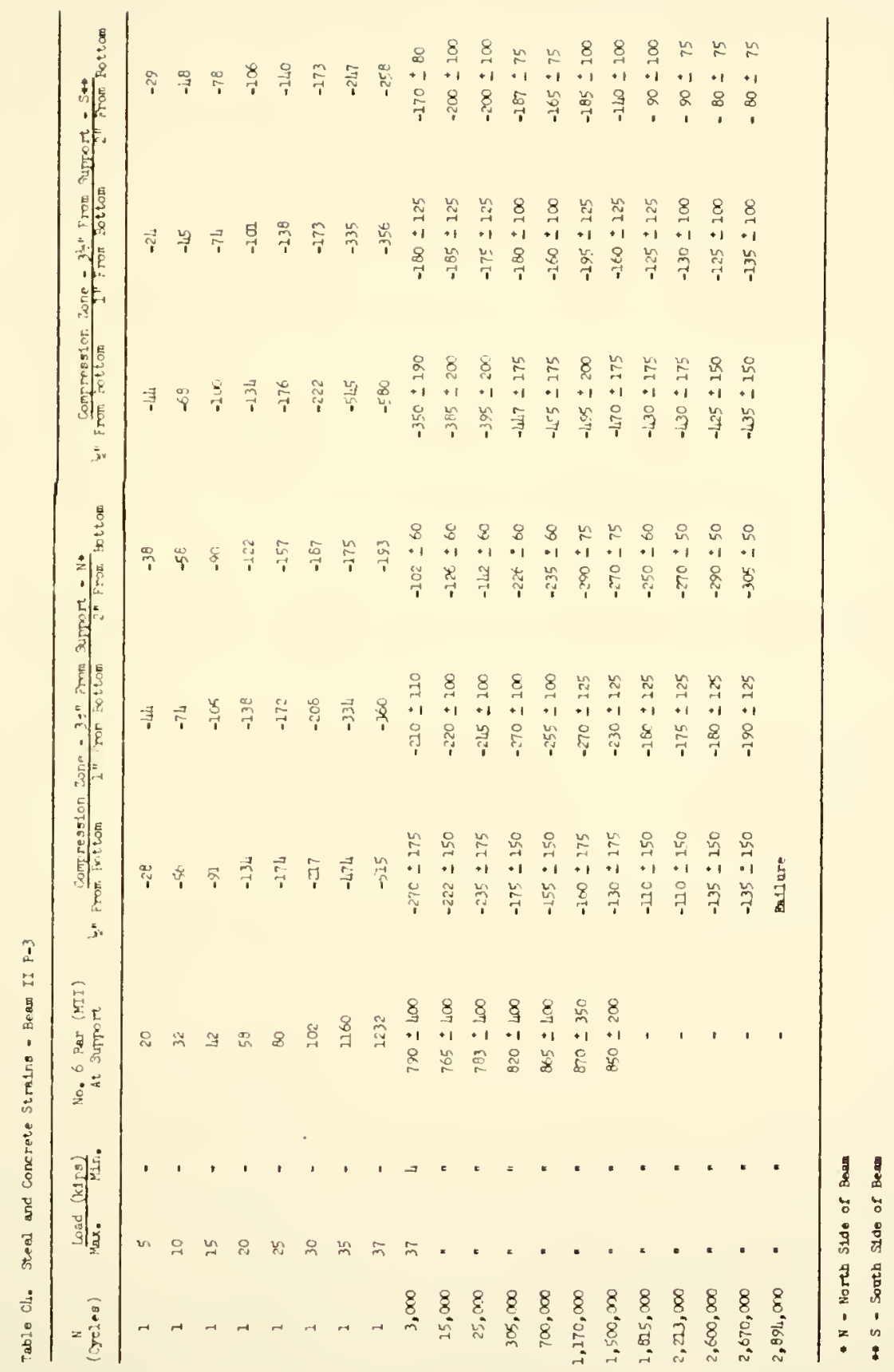




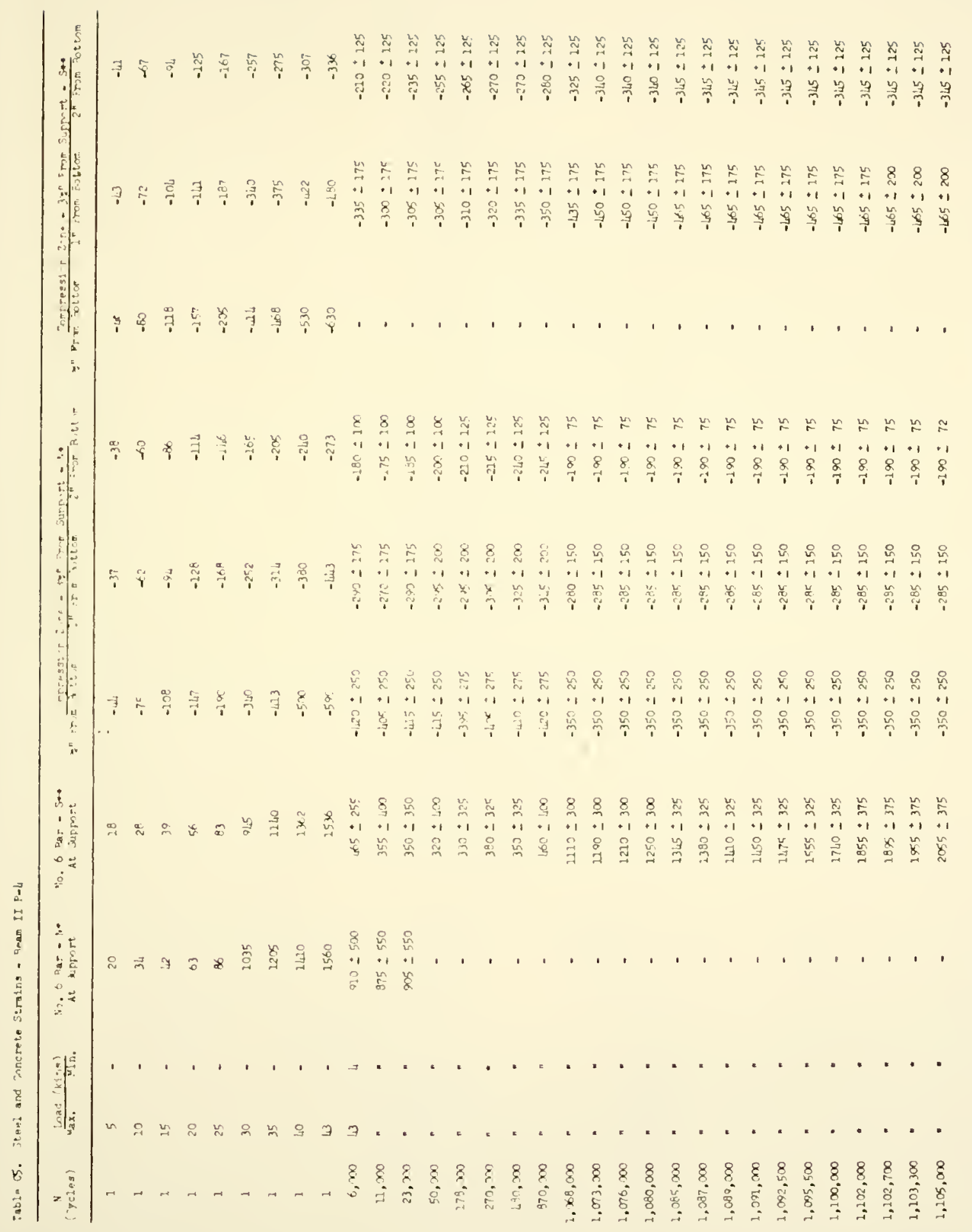




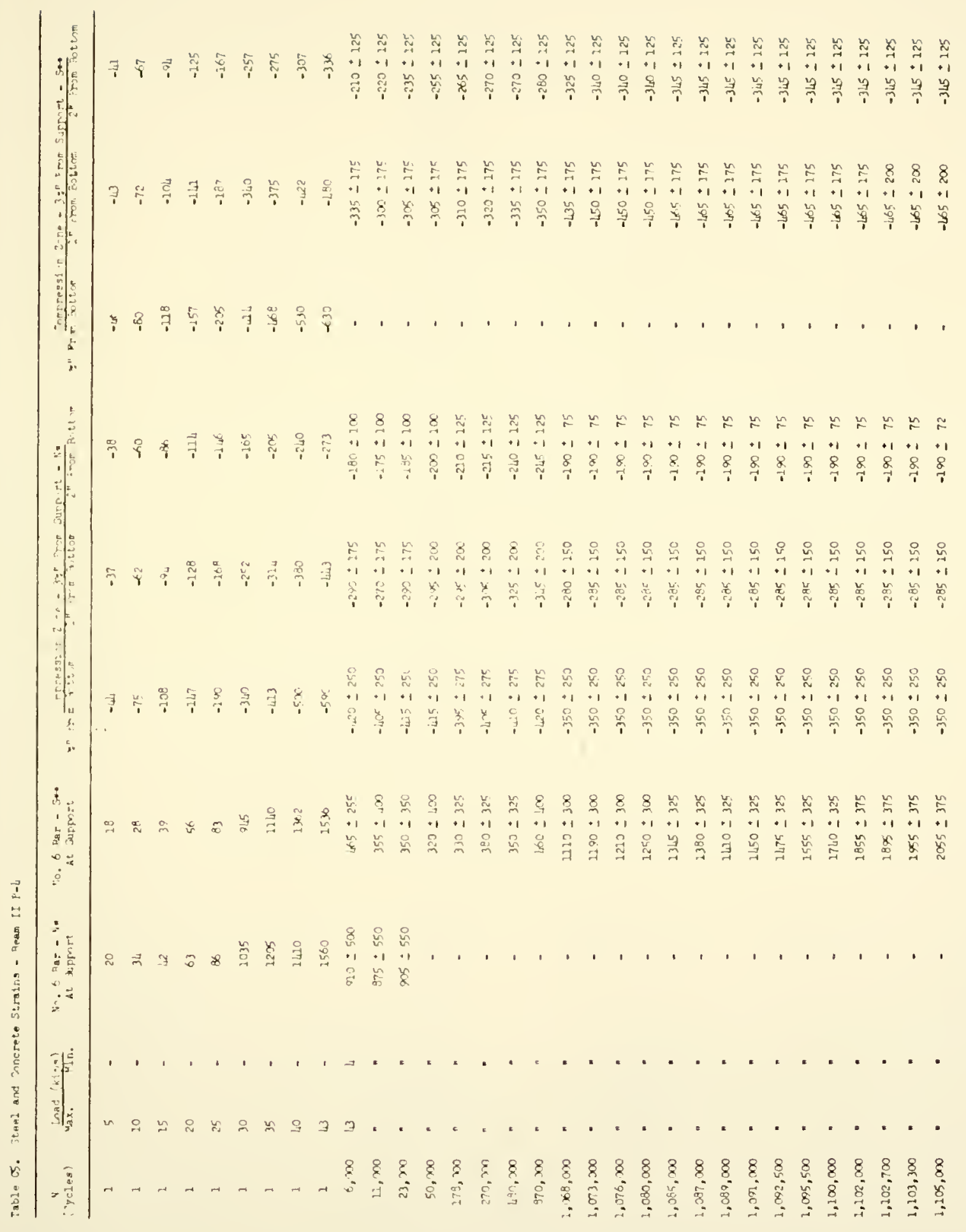




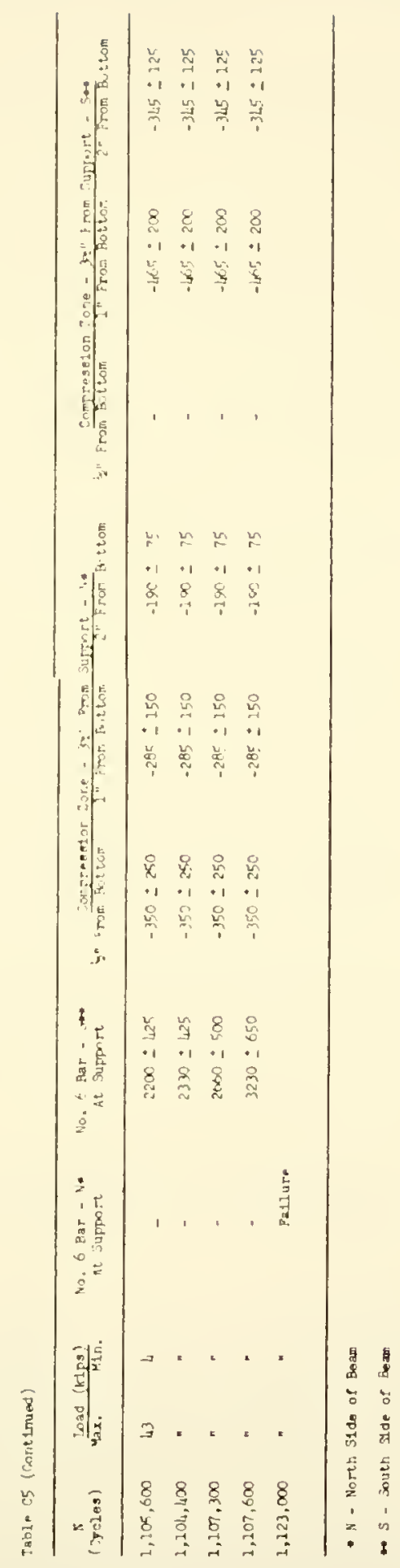




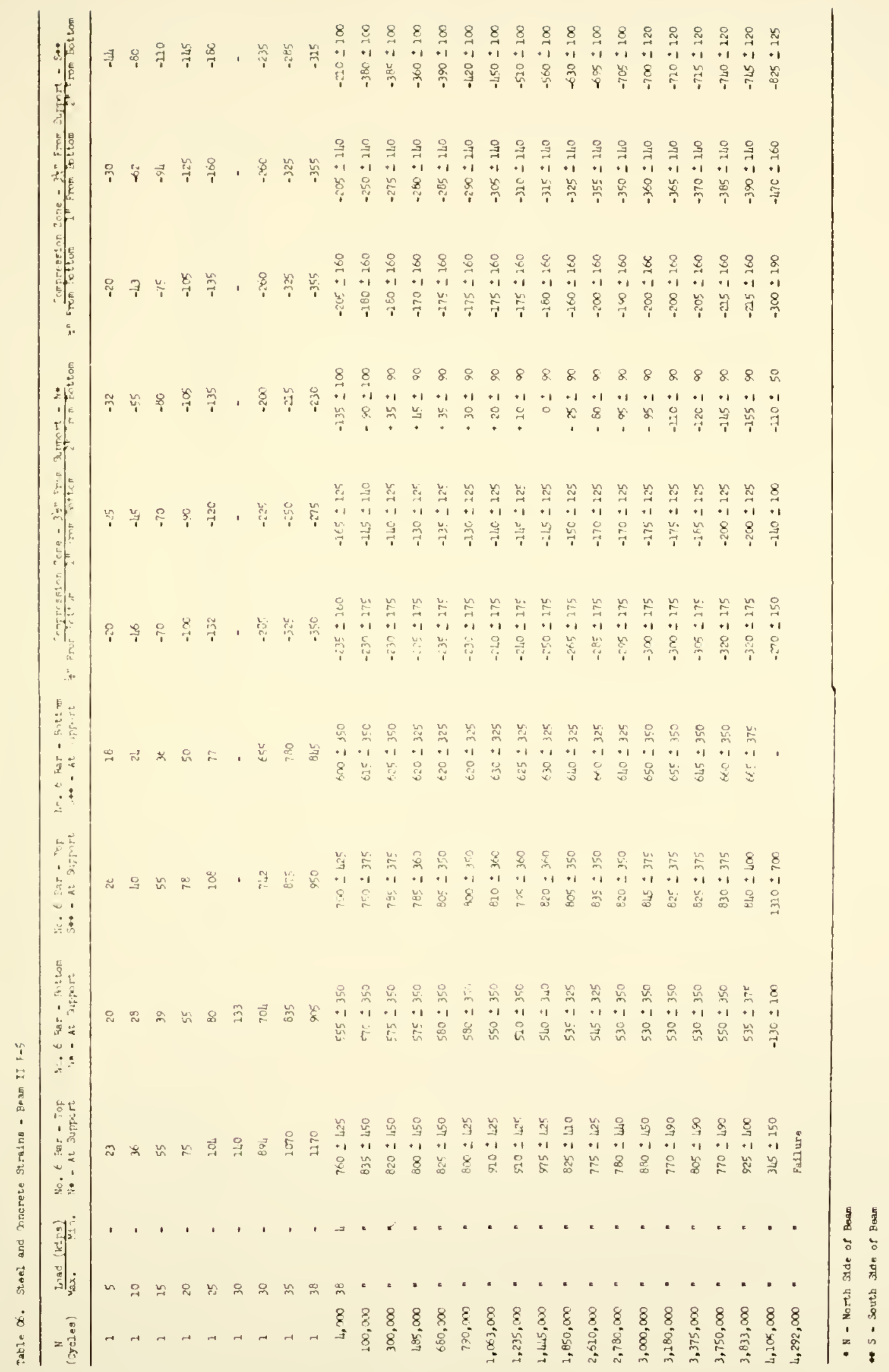




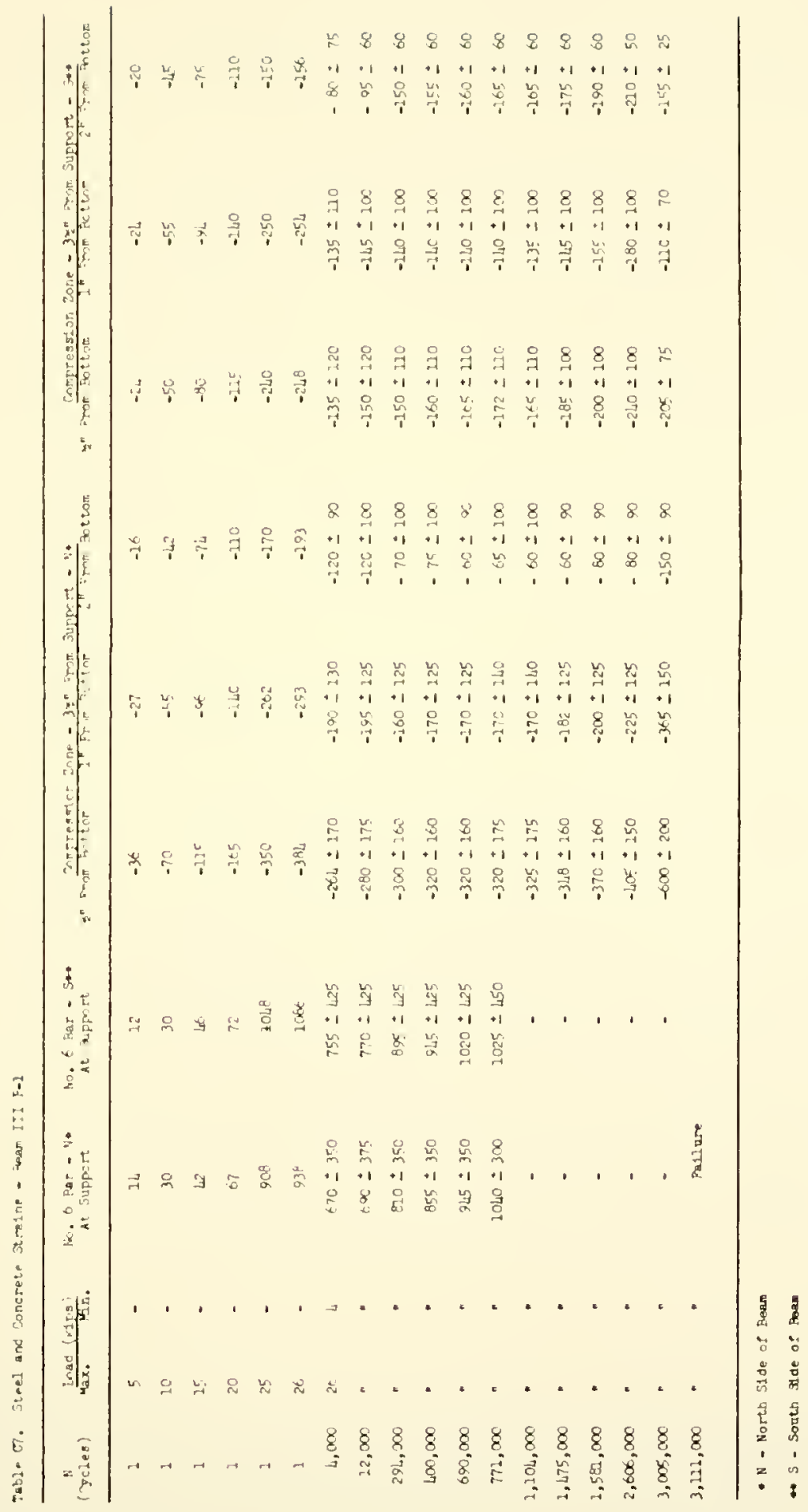




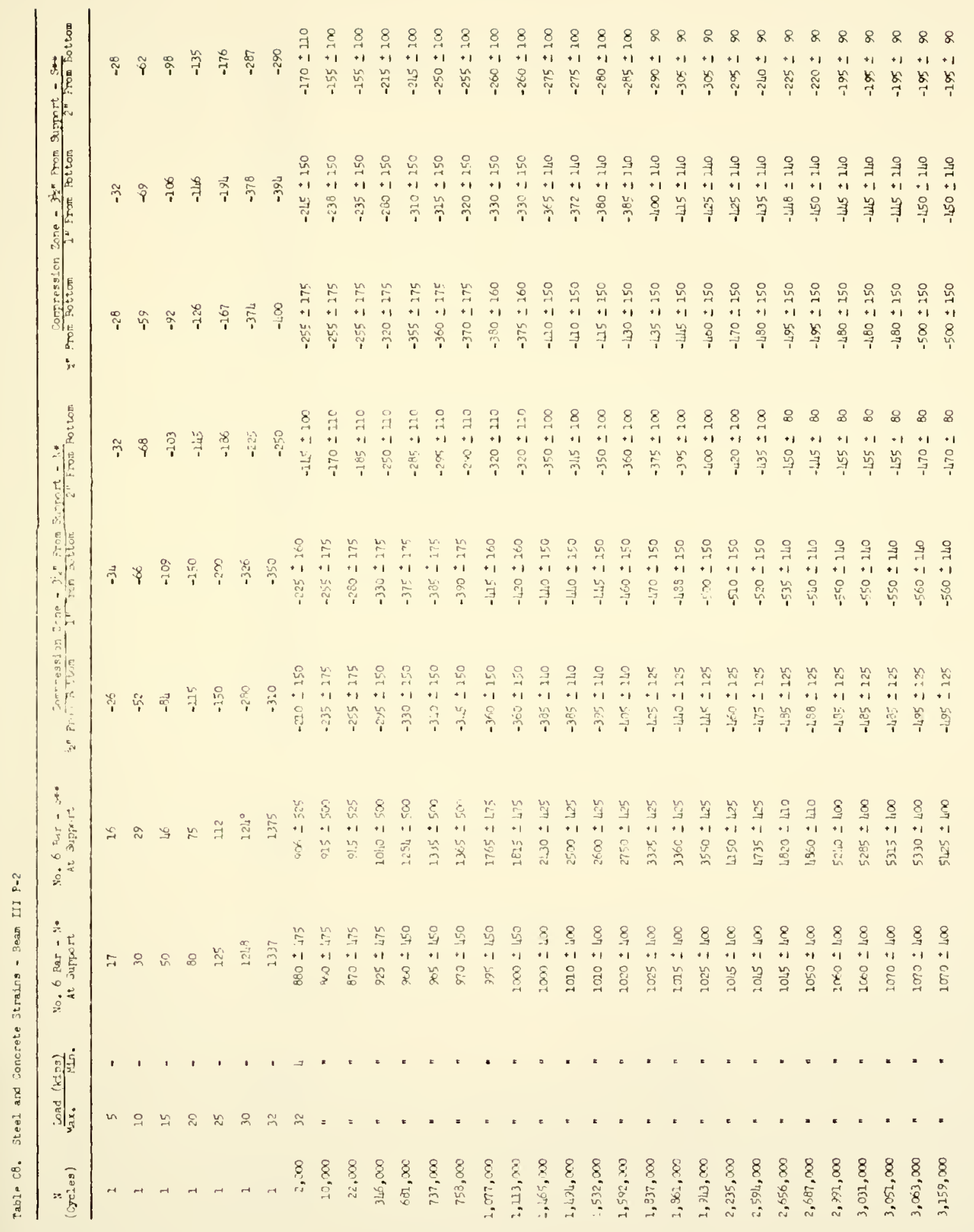




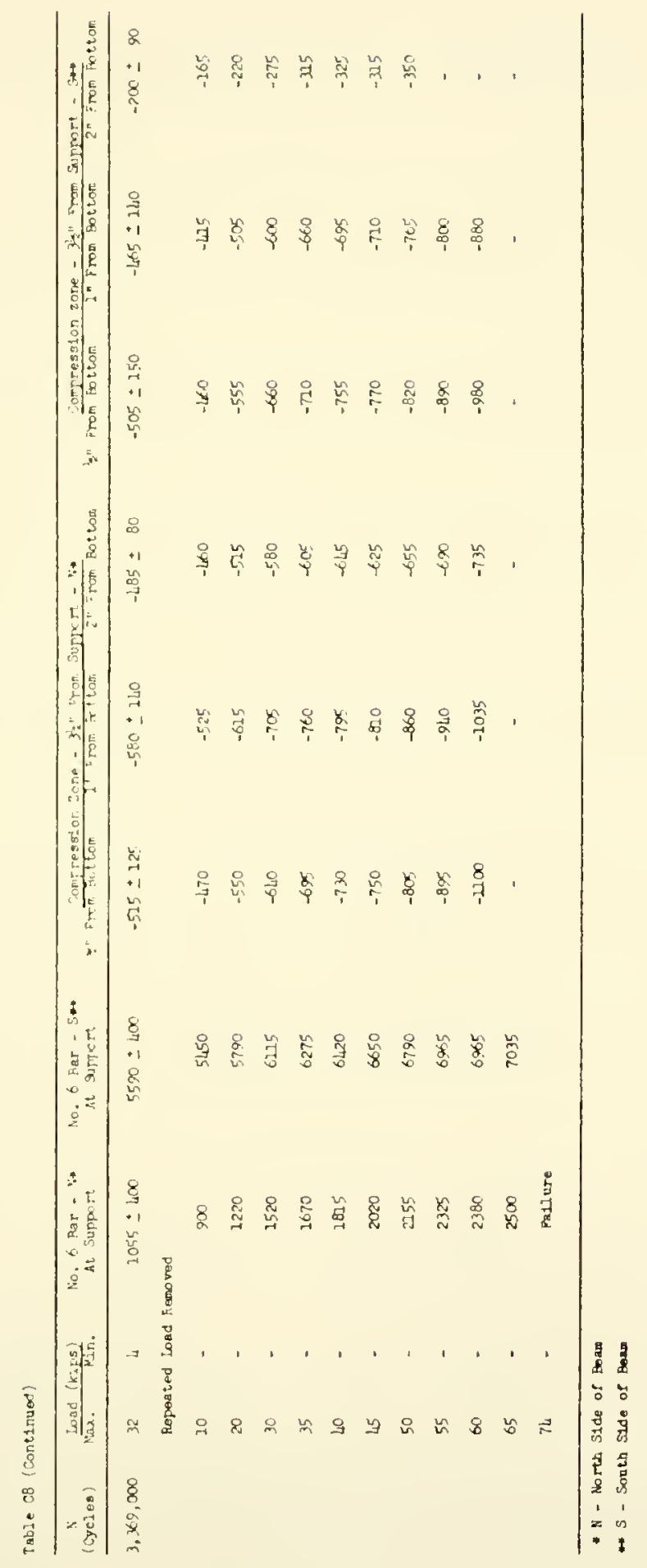




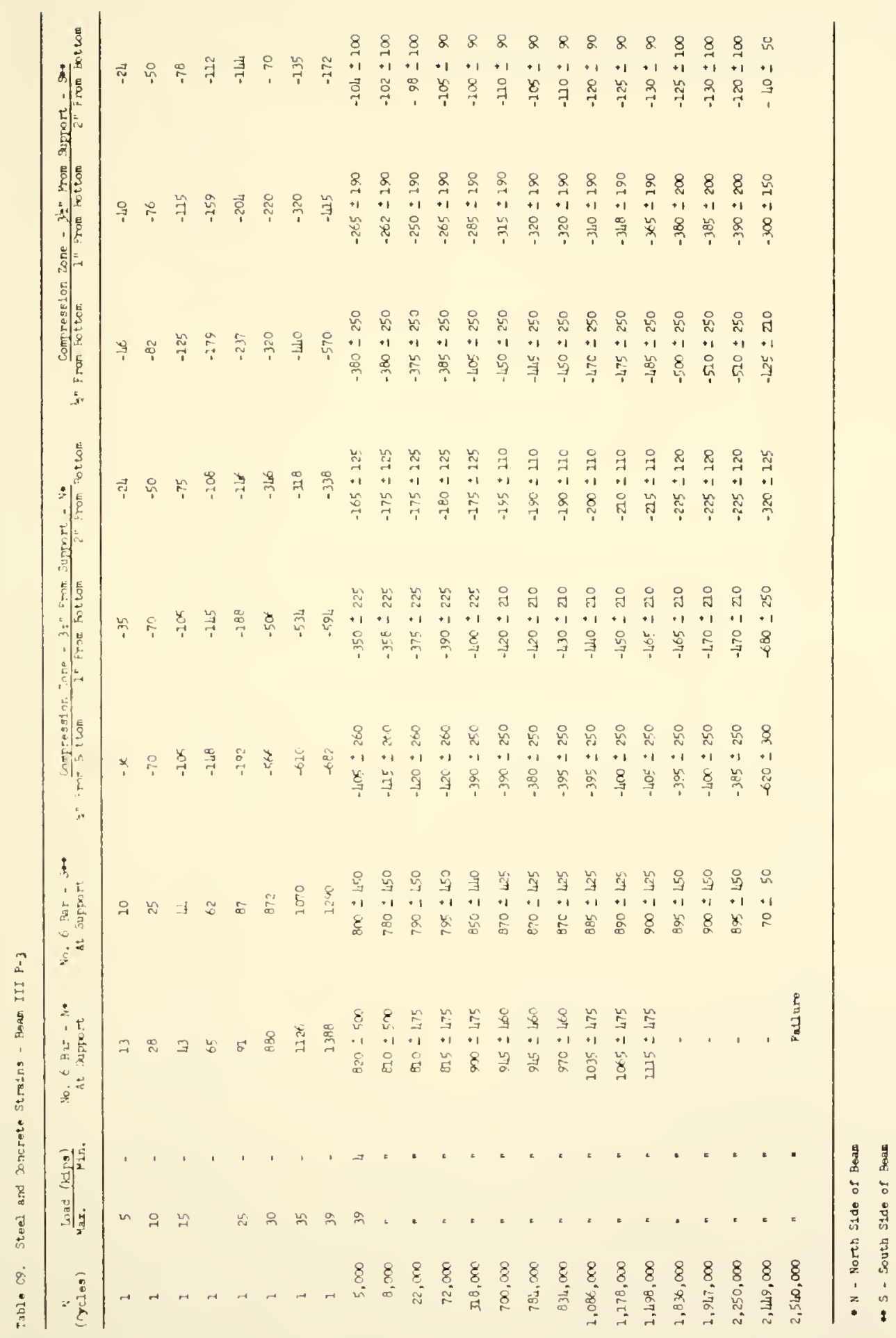




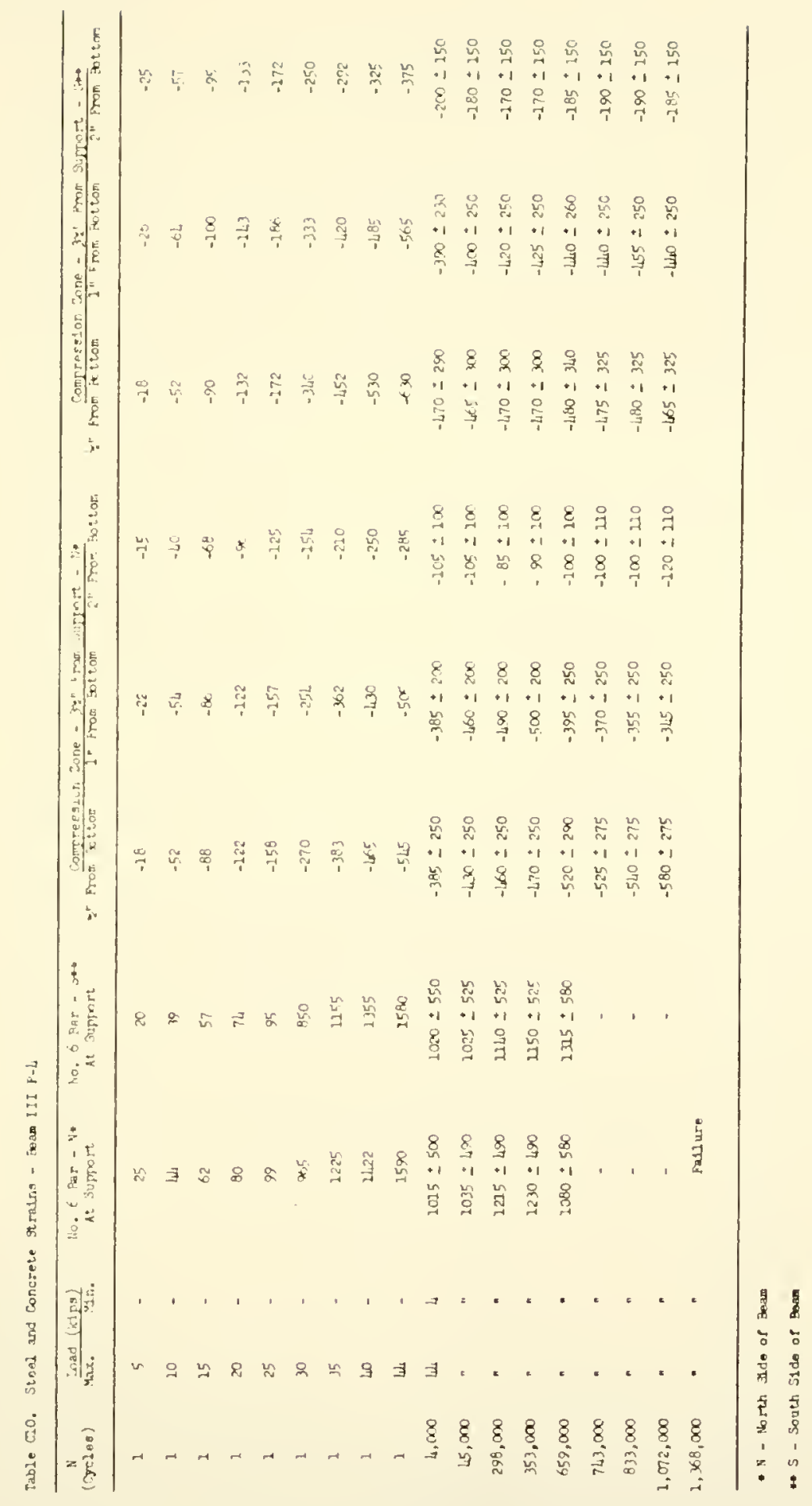




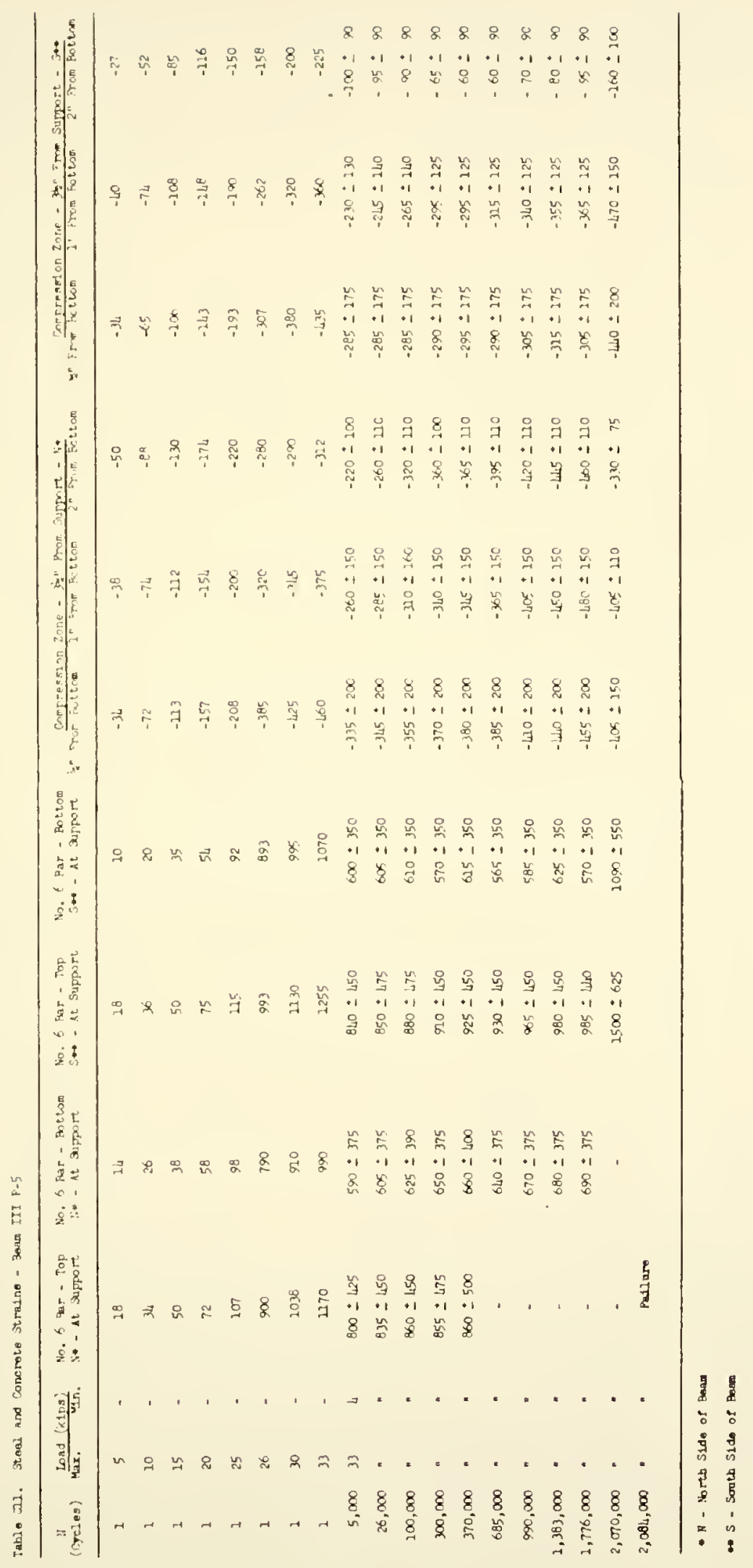




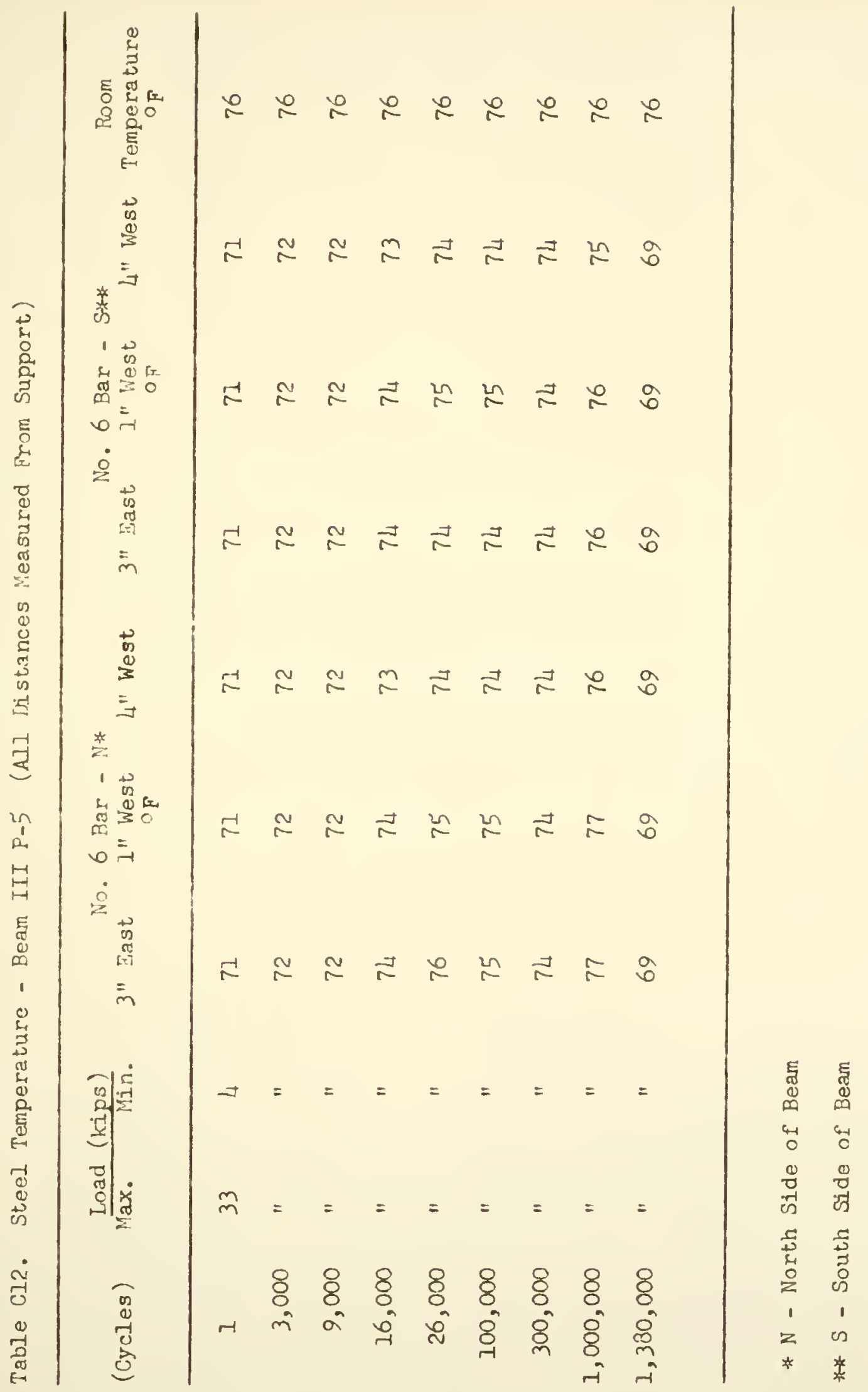




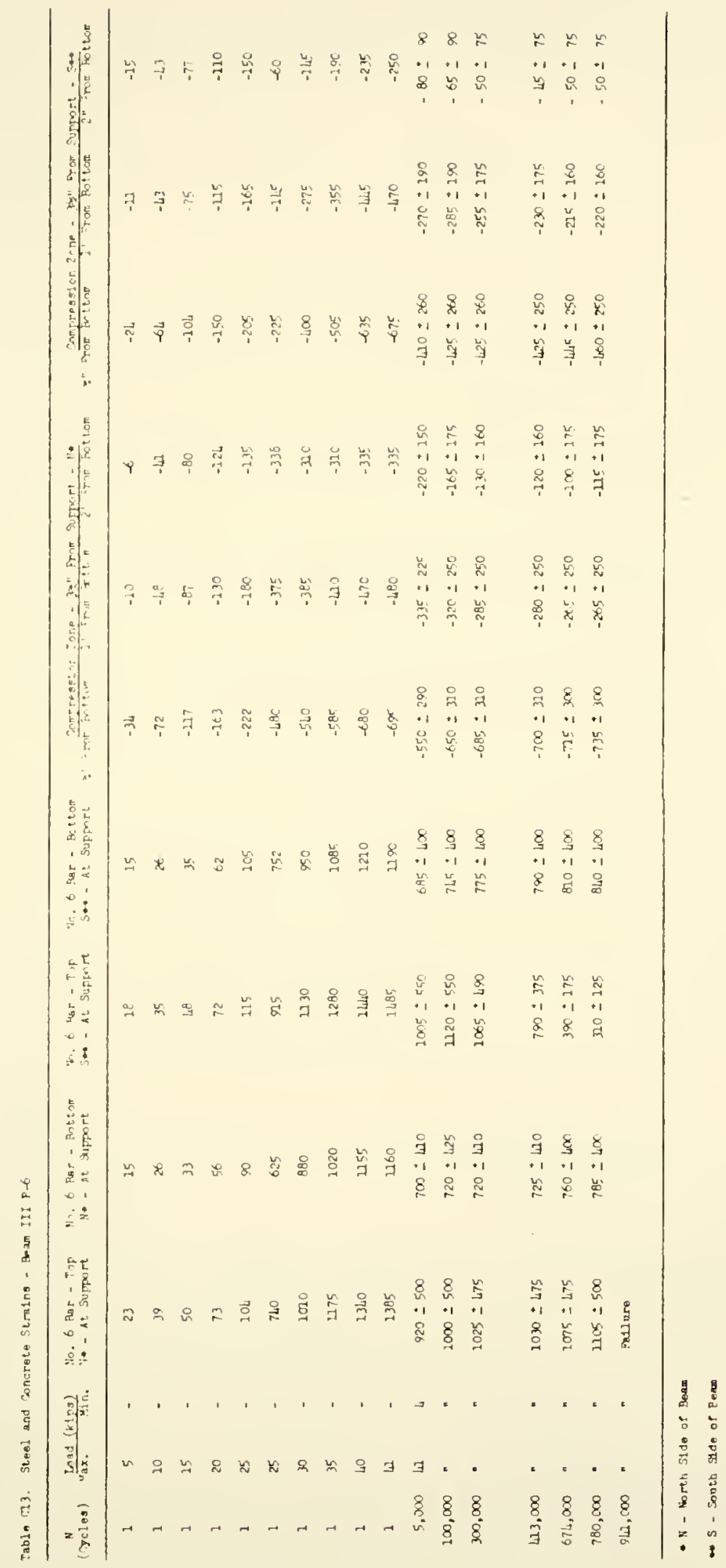




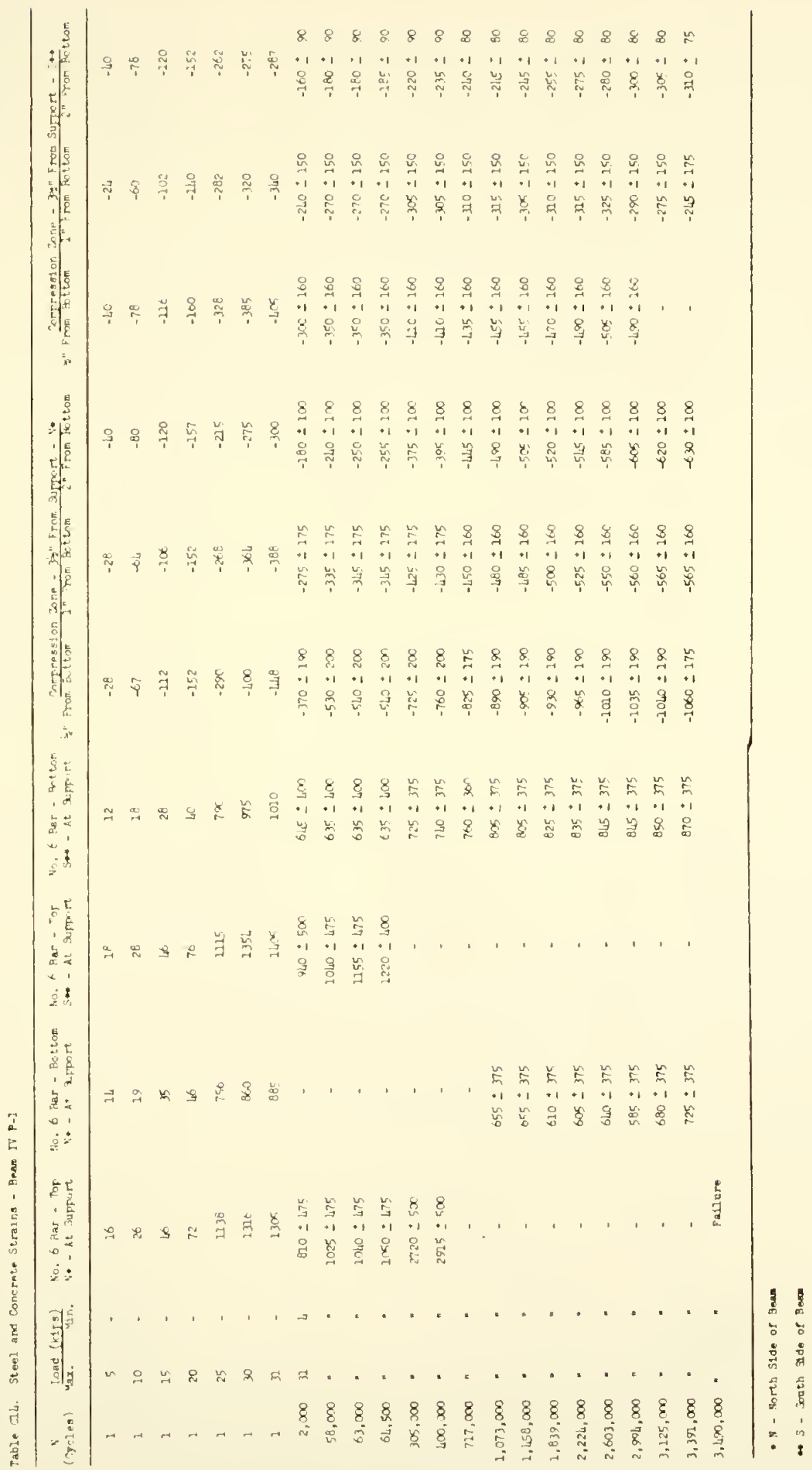




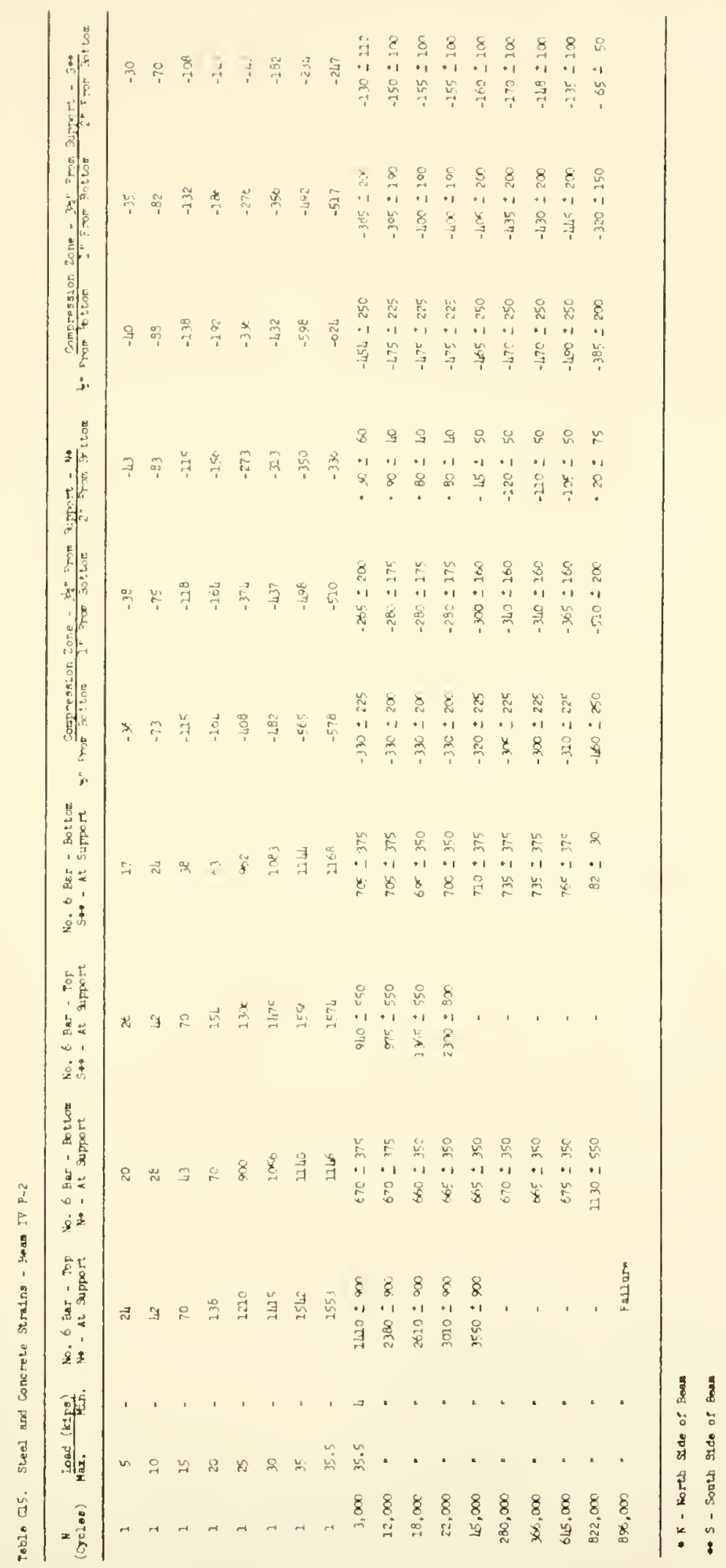




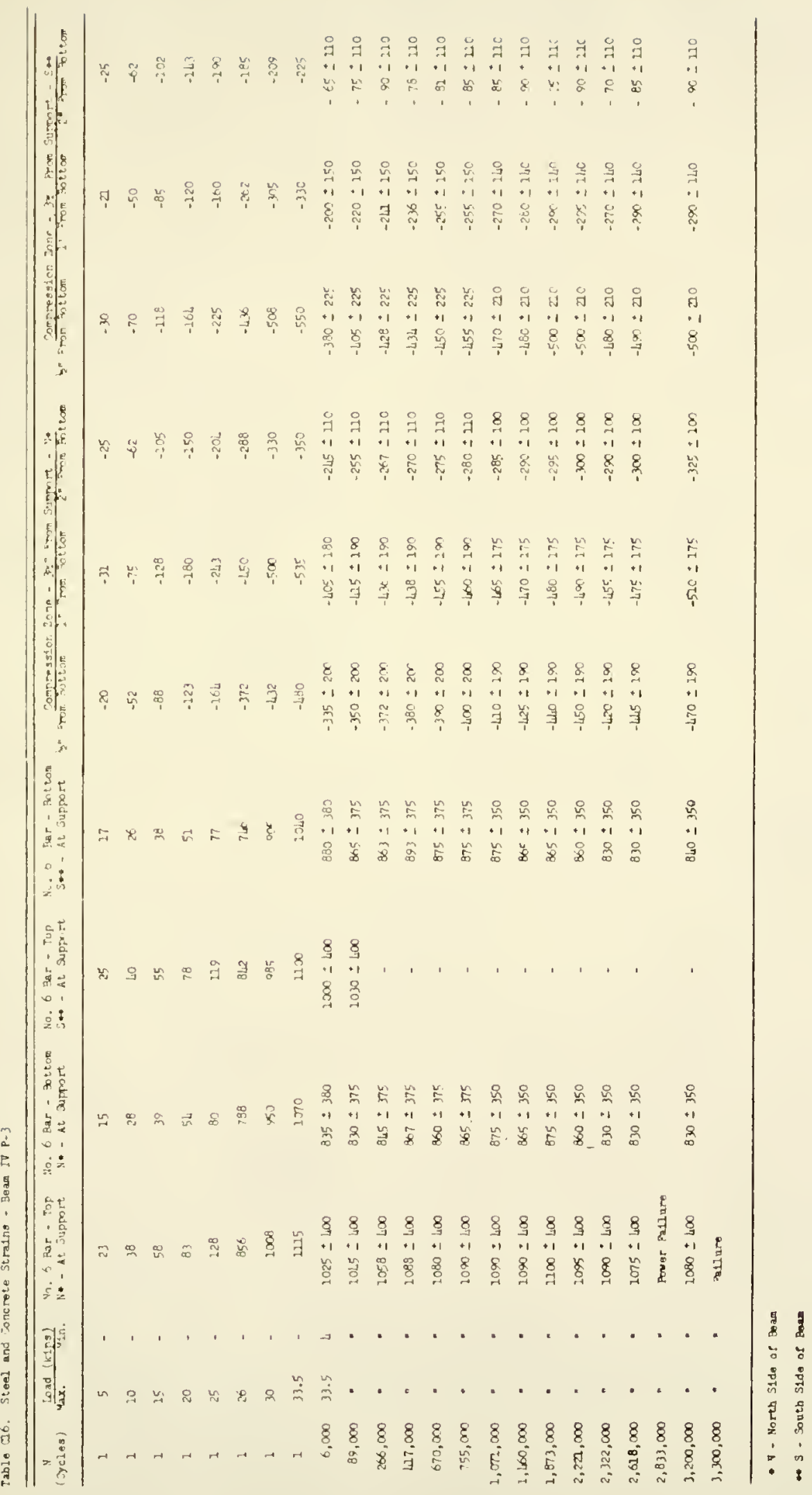



